\title{
Functional significance of fatty acid translocase (FAT/CD36) in rodent cardiac muscle
}

\author{
Citation for published version (APA):
}

Brinkmann, J. F. F. (2003). Functional significance of fatty acid translocase (FAT/CD36) in rodent cardiac muscle. [Doctoral Thesis, Maastricht University]. Universiteit Maastricht. https://doi.org/10.26481/dis.20030101jb

Document status and date:

Published: 01/01/2003

DOI:

10.26481/dis.20030101jb

Document Version:

Publisher's PDF, also known as Version of record

\section{Please check the document version of this publication:}

- A submitted manuscript is the version of the article upon submission and before peer-review. There can be important differences between the submitted version and the official published version of record.

People interested in the research are advised to contact the author for the final version of the publication, or visit the DOI to the publisher's website.

- The final author version and the galley proof are versions of the publication after peer review.

- The final published version features the final layout of the paper including the volume, issue and page numbers.

Link to publication

\footnotetext{
General rights rights.

- You may freely distribute the URL identifying the publication in the public portal. please follow below link for the End User Agreement:

www.umlib.nl/taverne-license

Take down policy

If you believe that this document breaches copyright please contact us at:

repository@maastrichtuniversity.nl

providing details and we will investigate your claim.
}

Copyright and moral rights for the publications made accessible in the public portal are retained by the authors and/or other copyright owners and it is a condition of accessing publications that users recognise and abide by the legal requirements associated with these

- Users may download and print one copy of any publication from the public portal for the purpose of private study or research.

- You may not further distribute the material or use it for any profit-making activity or commercial gain

If the publication is distributed under the terms of Article $25 \mathrm{fa}$ of the Dutch Copyright Act, indicated by the "Taverne" license above, 


\section{Promotor:}

Prof dr. G.J van der Vusse

\section{Co-promotor:}

Dr. J.F.C. Glatz

\section{Beoordelingscommissie:}

Prof. dr. H.A.J. Struijker Boudier (voorzitter)

Prof. dr. A. Bonen (Universiteit van Waterloo, Canada)

Prof. dr. M.H. Hofker

Prof. dr. F.C. Visser (VU medisch centrum, Amsterdam)

Prof. dr. R.F.A. Zwaal

Financial support by the Netherlands Heart Foundation for the publication of this thesis is gratefully acknowledged

The study described in this thesis was supported by a grant of the Netherlands Heart Foundation (NHS-97.149)

ISBN 90-6464649-X

(C) J.F.F. Brinkmann, Maastricht 2003 
Voor Beatrijs en Franz. 


\section{Contents}

\section{Chapter 1}

Introduction

\section{Chapter 2}

New insights into long-chain fatty acid uptake by heart muscle:

a crucial role for FAT/CD36

\section{Chapter 3}

Purification, immunochemical quantification and localization of fatty acid translocase (FAT)/CD36 from rat heart

\section{Chapter 4}

Metabolic abnormalities of FAT/CD36 null mice are normalized by restoring FAT/CD36 expression in heart and skeletal muscle

\section{Chapter 5}

The FAT/CD36 protein is a modulator of ischemic tolerance in the murine heart

\section{Chapter 6}

Targeted disruption of heart-type fatty acid binding protein does not influence ischemic tolerance of the murine heart

\section{Chapter 7}

General discussion

Summary

Samenvatting 


\section{FUNCTIONAL SIGNIFICANCE OF FATTY ACID \\ TRANSLOCASE (FAT/CD36) IN RODENT CARDIAC MUSCLE}

FUNCTIONELE BETEKENIS VAN FATTY ACID TRANSLOCASE

(FAT/CD36) IN DE HARTSPIER VAN KNAAGDIEREN

\section{PROEFSCHRIFT}

ter verkrijging van de graad van doctor aan de Universiteit Maastricht, op gezag van de Rector Magnificus, Prof. dr. A.C. Nieuwenhuijzen Kruseman, volgens het besluit van het College van Decanen, in het openbaar te verdedigen op donderdag 22 mei 2003 om 16.00 uur

door

Joseph Franz Fidelis Brinkmann

geboren op 17 april 1970 te Haarlem 
Chapter 1

\section{Introduction}


Normal cellular and organ function requires that oxygen and metabolic substrates are supplied to organs, and metabolic waste products and heat are removed from tissues by the flow of blood through the vasculature. The driving force for this blood flow is generated by the pumping activity of the heart, and the mechanical force for cardiac contraction is provided by the cardiac myocyte. Cardiac myocytes are the structural cell types of the heart, and account for more than half of the heart's weight ". The energy required for contraction is generated by the oxidation of substrates in the mitochondria of these cells. Though cardiac myocytes are essentially omnivorous, under normal circumstances long-chain fatty acids (FA) are the major source of energy, their part amounting to $60-90 \%$ of the ATP generated $^{2,3}$. Ketone bodies, lactate, glucose, and amino acids fill in the rest of the cardiac energy need ${ }^{2}$.

Because of their long hydrophobic tail, FA are poorly soluble in aqueous environments. To reach physiological concentrations, FA are therefore bound by proteins. In the blood, FA travel bound to plasma albumin, or they are complexed into the lipid core of lipoproteins ${ }^{4}$. On their way to the cardiomyocyte, FA first reach the vascular endothelium. Here, they are released from albumin or liberated from lipoproteins and pass the endothelium layer through a yet unidentified mechanism, after which they reach the interstitial space. In this space, FA re-associate with albumin, and these complexes reach the sarcolemma (plasma membrane) of cardiac myocytes ${ }^{2.5}$. At the sarcolemma, the FA-albumin complexes dissociate, and the liberated FA molecules cross the lipid bilayer. Intracellularly, FA bind to cytoplasmic $\mathrm{FA}$ binding proteins $\left(\mathrm{FABP}_{\mathrm{c}} \mathrm{s}\right)$, which enables transport to their site of action ${ }^{6,7}$. H-FABP is the major FABP in heart and skeletal muscle, $_{\text {, }}$ and expression of this protein was recently shown to be essential for efficient FA uptake and utilization by the cardiomyocyte ${ }^{8,9}$.

For a long period of time, it was generally believed that FA pass plasma membranes by a spontaneous diffusional process. Elegant measurements using a sensitive $\mathrm{pH}$ indicator showed that uncharged FA can indeed move quickly across the phospholipid bilayers of both unilamellar vesicles and isolated adipocytes by a 
flip-flop process ${ }^{10,11}$. Uncharged FA moving across phospholipid bilayers by flipflop were hypothesized to ionize after reaching the inner-site of the membranes, and the presence of the resulking intravesicular or intracellular $\mathrm{pH}$ change could be demonstrated. In the $80^{\circ} \mathrm{s}$, however, the presence of an additional proteinfacilitated component became appreciated in the transport of FA across adipocyte, hepatocyte and cardiac and skeletal muscle myocyte membranes ${ }^{12 \cdot 16}$. This high affinity component has the characteristics of facilitated diffusion and led to the identification of three major candidate FA transport proteins named plasma membrane fatty acid binding protein $\left(\mathrm{FABP}_{\mathrm{PM}}\right)^{17}$, fatty acid translocase (FAT) ${ }^{18.19}$, a protein more widely known as $\mathrm{CD} 36^{20}$, and fatty acid transport protein (FATP) ${ }^{21}$. All three proteins are expressed by the cardiomyocyte ${ }^{22.23}$, and expression of each of the proteins was shown to enhance FA uptake rates in cell models $^{21,24-27}$.

\section{Aim of the study}

Initial studies showed that the majority of the FA utilized by the cardiac myocyte is transported through a protein-mediated mechanism ${ }^{16}$. Though the expression of each of the three candidate FA transporters is linked to FA uptake, the significance of these proteins for myocardial FA transport remains unclear. However, two major lines of evidence led to a focus on FAT/CD36. First, this protein is abundantly expressed in tissues active in FA metabolism such as heart, skeletal muscle, adipose tissue and intestine, its expression profile coincides with a role in FA uptake, and its expression is modulated by conditions that alter lipid metabolism 20,22.28-30. Second, in isolated cardiomyocytes and adipocytes, as well as in skeletal muscle, FA uptake is drastically inhibited by a non-metabolized FA derivative specific for FAT/CD36 16,19.31. The experiments described in this thesis were therefore primarily aimed at determining the significance of FAT/CD36 in myocardial FA transport under both normal and pathophysiological circumstances. 


\section{Outline of the thesis}

Following an outline of FA utilization by the cardiac myocyte, Chapter 2 describes the current knowledge of the proteins potentially involved in membrane FA transport, i.e. FABP, FAT/CD36, and FATP. Evidence for the involvement of FAT/CD36 as a membrane FA transporter in several tissues is quickly evolving due to the availability of several genetic models. These models, the consequences of FAT/CD36 deficiency to cardiac and whole body lipid metabolism, and the different mechanisms for regulating FAT/CD36 expression known to date are discussed in detail.

Several studies suggest that FAT/CD36 is expressed by the cardiomyocyte $22,29,32$. Of these, the most direct approach was to measure FAT/CD36 at the protein level by using a sensitive immunoassay, which indicated that the protein is abundantly expressed by the cardiomyocyte ${ }^{29}$. In contrast, published immunohistochemical studies showed expression of FAT/CD36 by capillary endothelial cells in the heart and other tissue types only ${ }^{28.33}$. Because FAT/CD36 was not detected on the sarcolemma of cardiomyocytes in these studies, expression of FAT/CD36 by these cells has been doubted ${ }^{28}$. To clearly establish whether FAT/CD36 is expressed by the cardiomyocyte at significant levels, Chapter 3 describes the purification of the native protein from hearts, and the subsequent quantification of FAT/CD36 in total rat hearts and isolated cardiomyocytes.

Recently, a mouse null in FAT/CD36 was generated by targeted genedisruption ${ }^{34}$. This mouse indeed showed abnormalities associated with a defect in FA transport and utilization ${ }^{34,35}$. Chapter 4 describes the generation and characterization of a new transgenic FAT/CD36 gene-rescued mouse. In this murine model, raised on the FAT/CD36 null background, FAT/CD36 is reexpressed in heart and skeletal muscle so as to further analyze and specify the function of the protein in muscle FA transport.

Myocardial ischemia is the result of insufficient blood-flow to the heart leading to an inadequate supply of oxygen and substrates. Because the energy derived from FA metabolism is thought to be essential for cardiac function and to play a role in 
cardiac ischemic tolerance ${ }^{36}$, the tolerance to ischemia and reperfusion of FAT/CD36 null and gene-rescued hearts was analyzed in an isolated working heart model. The results of this study are described in Chaprer 5.

In the cytoplasm of the cardiomyocyte, FA are bound by H-FABP, which is essential for efficient intracellular transport. H-FABP has also been hypothesized to have a direct protective role during pathophysiological conditions as ischemia ${ }^{37}$. This provided the rationale to carry out the experiments outlined in Chapter 6 , which describes the tolerance of H-FABP null hearts to ischemia and reperfusion.

A general discussion about the new findings obtained with the present studies is provided in Chapter 7 , and a brief summary concludes this thesis.

\section{References}

1. Opie LH. The heart: physiology, metabolism, pharmacology, and therapy: Grune \& Stratton Inc, London, 1984.

2. Van der Vusse GJ, Glatz JFC, Stam HCG and Reneman RS. Fatty acid homeostasis in the normoxic and ischemic heart. Physiol Rev 72: 881-940, 1992.

3. Neely JR, Rovetto MJ and Oram JF. Myocardial utilization of carbohydrate and lipids. Prog Cardiovasc Dis 15: 289-329, 1972.

4. Spector AA. Plasma lipid transport. Clin Physiol Biochem 2: 123-134, 1984.

5. Van der Vusse GJ, Glatz JF, van Nieuwenhoven FA, Reneman RS and Bassingthwaighte JB. Transport of long-chain fatty acids across the muscular endothelium. Adv Exp Med Biol 44.1: 181-191. 1998.

6. Storch J and Thumser AE. The fatty acid transport function of fatty acid-binding proteins. Biochim Biophys Acta 1486: 28-44, 2000.

7. Glatz JF and van der Vusse GJ. Cellular fatty acid-binding proteins: their function and physiological significance. Prog Lipid Res 35: 243-282, 1996.

8. Bïnas B, Danneberg H, McWhir J, Mullins L and Clark A.J. Reguirement for the heart-type fatty acid binding protein in cardiac fatty acid utilization. Faseb J 13: 805-812, 1999.

9. Schaap FG, Binas B, Danneberg H, van der Vusse GJ and Glatz JF. Impaired long-chain fatty acid utilization by cardiac myocytes isolated from mice lacking the heart-type fatty acid binding protein gene. Circ Res 85: 329-337, 1999. 
10. Kamp I, Hamilton JA and Westerhoff HV. Movement of fatty acids, fatty acid analogues, and bille acids across phosphiolipid bilayers. Biochemistry 32: 11074-11086, 1993.

1. Civelek VN, Hamilton JA, Tornheim $K$, Kelly KL and Corkey BE. Intracellular pH in adipocytes: effects of free fatty acid diffusion across the plasma membrane, lipolytic agonists, and insulin Proc Natl Acad Sci U S A 93: 10139-10144, 1996.

12. Abumrad NA, Park JH and Park CR. Permeation of long-chain fatty acid into adipocytes. Kinetics, specificity, and evidence for involvernent of a membrane protein. J Biol Chem 259: 8945$8953,1984$.

13. Abumrad NA, Perkins RC, Park JH and Park CR. Mechanism of long chain fatty acid permeation in the isolated adipocyte. J Biol Chem 256: 9183-9191, 1981.

14. Sorrentino D, Robinson RB, Kiang CL and Berk PD. At physiologic albumin/oleate concentrations oleate uptake by isolated hepatocytes, cardiac myocytes, and aclipocytes is a saturable function of the unbound oleate concentration. Uptake kinetics are consistent with the conventional theory. J Clin Invest 84: 1325-1333, 1989.

15. Stump DD, Zhou SL and Berk PD. Comparison of plasma membrane FABP and mitochondrial isoform of aspartate aminotransferase from rat liver. An J Physiol 265: G894-G902, 1993.

16. Luiken JJ, wan Nieuwenhoven FA, America G, van der Vusse GJ and Glatz JF. Uptake and metabolism of palmitate by isolated cardiac myocytes from adult rats: involvement of sarcolemmal proteins. J Lipid Res 38: 745-758, 1997.

17. Stremmel W, Strohmeyer G, Borchard F, Kochwa $S$ and Berk PD. Isolation and partial characterization of a fatty acid binding protein in rat liver plasma membranes. Proc Natl Acad Sci U SA 82:4-8, 1985.

18. Abumrad N, Harmon $\mathbf{C}$ and Ibrahimi A. Membrane transport of long-chain fatty acids: evidence for a facillitated process. $J$ Lipid Res 39:2309-2318, 1998.

19. Harmon CM and Abumrad NA. Binding of sulfosuccinimidyl fatty acids to adipocyte membrane proteins: isolation and amino-terminal sequence of an $88-\mathrm{kD}$ protein implicated in transport of long-chain fatty acids. J Membr Biol 133:43-49, 1993.

20. Abumrad NA, el-Maghrabi MR, Amri EZ, Lopez $\mathrm{E}$ and Grimaldi PA. Cloning of a rat adipocyte membrane protein implicated in binding or transport of long-chain fatty acids that is induced during preadipocyte differentiation. Homology with human CD36. J Biol Chem 268:

$17665-17668,1993$.

21. Schaffer JE and Lodish HF. Expression cloning and characterization of a novel adipocyte long chain fatty acid transport protein. Cell 79: 427-436, 1994.

22. Van Nieuwenhoven FA, Verstijnen CP, Abumrad NA, Willemsen PH, van Eys GJ, Van der Vusse GJ and Glatz JF. Putative membrane fatty acid translocase and cytoplasmic fatty acid- 
binding protein are co-expressed in rat heart and skeletal muscles. Biochem Brophys Res Commun 207: 747-752, 1995.

23. Van Nieuwenhoren FA, Willemsen PH, van der Vusse GJ and Glatz JF. Co-expression in dat heart and skeletal muscle of four genes coding for proteins implicated in long-chain fatty acid uptake. In J Biochem Cell Biol 31: 489-498, 1999.

24. Ibrahimi A, Sfeir Z, Magharaie H, Amri EZ, Grimaldi P and Abumrad NA. Expression of the CD36 homolog (FAT) in fibroblast cells: effects on fatty acid transport. Proc Nan ACad Sci U S A 93: $2646-2651,1996$.

25. Hirsch D, Stahl A and Lodish HF. A family of tatty acid transporters conserved from mycobacterium to man. Proc Nafl Acad Sci U S A 95: 8625-8629, 1998.

26. Zhou SL, Stump D, Isola L and Berk PD. Constitutive expression of a saturable transport system for non-esterified fatty acids in Xenopus laevis oocytes. Biochem J297: 315-319. 1994.

27. Zhou SL, Stump D, Sorrentino D, Potter BJ and Berk PD. Adipocyte differentiation of 3T3$\mathrm{L} 1$ cells inwolves augmented expression of a $43-\mathrm{kDa}$ plasma membrane fatty acid-binding protein.

$J$ Biol Chem 267: 14456-14461, 1992.

28. Greenwalt DE, Scheck SH and Rhinehart-Jones T. Heart CD36 expression is increased in murine models of diabetes and in mice fed a high fat diet. $J$ Clin Invest 96:1382-1388, 1995.

29. Pelsers MMAL, Lutgerink JT, Nieuwenhoven FA, Tandon NN, van der Vusse GJ, Arends JW, Hoogenboom HR and Glatx JFC. A sensitive immunoassay for rat fatty acid translocase (CD36) using phage antibodies selected on cell transfectants: abundant presence of fatty acid translocase/CD36 in cardiac and red skeletal muscle and up- regulation in diabetes. Biochem J 337 : $407-414,1999$.

30. Luiken JJ, Turcotte LP and Bonen A. Protein-mediated palmitate uptake and expression of fatty acid transport proteins in heart giant vesicles. J Lipid Res 40: 1007-1016, 1999.

31. Bonen A, Luiken JJ, Liu S, Dyck DJ, Kiens B, Kristiansen S, Turcotte LP, van der Vusse GJ and Glatz JF. Palmitate transport and fatty acid transporters in red and white muscles. An J Physiol 275: E471-E478, 1998.

32. Tanaka $\mathbf{T}$ and Kawamura $\mathbf{K}$. Isolation of myocardial membrane long-chain fatty acid-binding protein: homology with a rat membrane protein implicated in the binding or transport of long-chain fatty acids. J Mol Cell Cardiol 27: 1613-1622, 1995.

33. Greenwalt DE and Mather IH. Characterization of an apically derived epithelial membrane glycoprotein from bovine milk, which is expressed in capillary endothelia in diverse tissues. $J$ Cell Biol 100: 397-408, 1985. 
34. Febbraio M, Abumrad NA, Hajar DP, Sharma $K$, Cheng W, Pearce SF and Silverstein RL. A null mutation in murine CD36 reveals an important role in fatty acid and lipoprotein metabolism. J Blot Chem 274: 19055-19062, 1999.

35. Coburn CT, Knapp FF, Jr, Febbraio M, Beets AL, Silversteín RL and Abumrad NA. Defective uptake and utilization of long chain fatty acids in muscle and adipose tissues of CD36 knockout mice. I Biol Chem 275: 32523-32529, 2000.

36. Belke DD, Larsen TS, Lopaschuk GD and Severson DL. Glucose and fatty acid metabolism in the isolated working mouse heart. Am J Physiol 277: R1210-R 121.7, 1999.

37. Glatz JF, Vork MM and wan der Vusse GJ. Significance of cytoplasmic fatty acid-binding protein for the ischemic heart. Mol Cell Biochem 123: 167-173, 1993. 


\section{Chapter 2}

New insights into long-chain fatty acid uptake by heart muscle: a crucial role for FAT/CD36

Adapted from:

J.F.F. Brinkmann, N.A. Abumrad, A. Ibrahimi, G. J. van der Vusse and J.F.C. Glatz. Biochem J 367(Pt 3):561-70 (2002) 


\section{Abstract}

Long-chain fatty acids are an important source of energy for several cell-types, in particular for the heart muscle cell. Three different proteins, FAT/CD36, FATP and FABP rM have been identified as possible membrane fatty acid transporters. Of these, information especially on the fatty acid transporting function of FAT/CD36 is quickly accumulating. Several experimental models to study the influence of altered FAT/CD36 expression on fatty acid homeostasis have been identified or developed, and underscore the significance of FAT/CD36 for adequate fatty acid transport. These models include the FAT/CD36 null mouse, the spontaneous hypertensive rat and FAT/CD36 deficient humans. The fatty acid transporting role of FAT/CD36 is further demonstrated in muscle-specific FAT/CD36 overexpressing mice and in transgenic mice generated using a genetic rescue approach. In addition, a wealth of information has been gathered about the mechanisms that regulate FAT/CD36 gene expression and the presence of functional FAT/CD36 on the plasma membrane. Available data also indicate that FAT/CD36 may have an important role in the etiology of cardiac disease, especially cardiac hypertrophy and diabetic cardiomyopathy. This chapter discusses our current knowledge of the three candidate fatty acid transporters, the metabolic consequences of alterations in FAT/CD36 levels in different models, and the mechanisms identified for FAT/CD36 regulation.

\section{Introduction}

Long-chain fatty acids (FA) are important to the cell as a source of energy and they are essential components for the synthesis of triacylglycerols, which can be used for storage of metabolic energy. Moreover, they are building blocks for phospholipids. FA, their CoA derivatives and their metabolites (e.g. prostaglandins, leukotrienes and thromboxanes) are able to regulate gene expression and enzyme, ion channel and membrane receptor activity directly or indirectly ${ }^{1-11}$. Under normal physiological conditions, about $60-90 \%$ of the energy that is required for 
adequate contraction of the heart is generated by mitochondrial oxidation of FA 11.12. Because cardiac myocytes, like most cells except for hepatocytes and adipocytes, can synthesize or store FA in limited amounts only, the heart strongly relies on the continuous supply of these compounds from the circulatory system.

FA are poorly soluble in aqueous environments and therefore supplied to the heart either complexed to plasma albumin or esterified in the triacylglycerol core of circulating lipoproteins ${ }^{13}$. Unbound FA, formed by dissociation of the albumin-FA complexes or hydrolysis of triacylglycerols by the action of lipoprotein lipase at the luminal surface of the coronary vascular endothelium, are transferred from the capillary lumen through the capillary endothelium and the interstitial space to the cardiac myocyte. Intracellularly, FA are bound to cytoplasmic fatty acid binding proteins $\left(\mathrm{FABP}_{c}\right.$, heart-type $\mathrm{FABP}_{\mathrm{c}}\left(\mathrm{H}-\mathrm{FABP}_{\mathrm{c}}\right)$ in the cardiomyocyte), which enables transport to their site of action ${ }^{14,15}$. In the cardiomyocyte, FA are converted into fatty acyl-CoA which can bind to acyl-CoA binding proteins ${ }^{16,17}$. The bulk of the COA activated FA molecules are taken up by mitochondria via a carnitine mediated process, and degraded in the $\beta$-oxidation pathway followed by the citric acid cycle. An additional site for $\beta$-oxidation of (very) long-chain acyl-CoA is present in peroxisomes. The remaining part of the fatty acyl moieties is incorporated in the esterified lipid pool, of which triacylglycerols and phospholipids are the main components ".

Tissue energy demands are constantly changing, and cells must match substrate supply with demand ${ }^{18-20}$. Regulation at a rate-limiting membrane transport step is, in general, the most effective way to achieve this ${ }^{9.21}$. Knowledge about the way by which FA cross cellular membranes is evolving and will be discussed in detail in the present chapter. To clearly describe sarcolemmal FA transport in the heart, this chapter will summarize the current knowledge about the common mechanism by which several tissues rather than the heart only transports FA. After describing the proteins initially identified as potential FA transporters, this article will focus on the role of FAT/CD36 in metabolite homeostasis and on the mechanisms known for the regulation of functional FAT/CD36 expression. Several genetic models are 
now available for FAT/CD36 and these, both generated and spontaneously occurring models demonstrate that impairment of membrane FA transport results in a serious disturbance of metabolic homeostasis.

\section{Candidate FA transporters}

It has been clearly shown that FA can diffuse through cellular membranes by a spontaneous diffusional flip-flop process. The use of pyranin fluorescence and both unilamellar vesicles and isolated rat adipocytes demonstrated that uncharged FA move quickly across phospholipid bilayers ${ }^{22,23}$. Cellular studies, however, provided evidence for the presence of an additional, high affinity, proteinfacilitated component in the transport of FA across the cellular membrane in adipose ${ }^{24,25}$, Jiver ${ }^{26.27}$, skeletal muscle and heart tissue ${ }^{28}$. This notion led to the identification of three major potential FA transport proteins named plasma membrane FA binding protein (FABP ${ }_{\mathrm{PM}}{ }^{29}, \mathrm{FAT} / \mathrm{CD} 36,{ }^{30,31}$ and FA transport protein (FATP) ${ }^{32}$. All three proteins are present in the heart and were found to be associated with the plasmalemma of cardiomyocytes ${ }^{33,34}$.

\section{FAT/CD36}

FAT/CD36 was identified as a candidate FA transporter based on its binding of both DIDS (4,4'-diisothiocyanostilbene-2,2'-sulfonate) and reactive sulfo- $N$ succinimidyl FA esters ${ }^{30,3 !}$. These compounds were inhibitors of FA uptake in isolated adipocytes ${ }^{30}$. The corresponding cDNA was isolated from a rat adipose tissue library and encoded FAT (for FA translocase) ${ }^{35}$, the rat homologue of the ubiquitously expressed human platelet CD36 also known as PASIV, GPIV and GPIIIb in the earlier literature ${ }^{36}$. FAT/CD36 is a heavily glycosylated, integral membrane protein. Its apparent molecular mass is $88 \mathrm{kDa}$ and the protein was initially isolated from platelet membranes as a thrombospondin receptor ${ }^{37}$. FAT/CD36 is abundantly expressed in tissues active in FA metabolism such as heart, skeletal muscle, fat and intestine ${ }^{34,35,38}$. Its expression profile coincides with a role in FA uptake and its expression is modulated by conditions that alter lipid 
metabolism, such as diabetes mellitus and high fat feeding ${ }^{34,490}$. Remarkably, FAT/CD36 expression is absent or low in the liver ${ }^{34}$. Expression of FAT/CD36 in fibroblasts normally lacking the protein resulted in an increase in FA uptake ${ }^{41}$. It has to be mentioned, however, that a similar approach using a rat heart musclederived cell line did not yield a direct correlation between the FAT/CD36 protein and FA uptake ${ }^{42}$. The absence of obligatory partner proteins for FA transport in the cells used, with $\mathrm{H}-\mathrm{FABP}_{\mathrm{c}}$ as a likely candidate, might explain this observation.

\section{FATP}

FATP, a 646 amino acid, integral membrane protein with an apparent molecular mass of $63 \mathrm{kDa}$ was identified as a candidate FA transporter by the use of an expression-cloning strategy. A 3T3-L1 adipocyte cDNA library was brought to expression in COS7 cells and screening for fluorescent FA uptake yielded two classes of cDNA clones. One of these encoded the novel protein FATP, the other coded for an isoform of FA acyl-CoA synthetase ${ }^{32}$. FATP is ubiquitously expressed and relatively high levels are present in the brain ${ }^{43,44}$. Recently, FATP was shown to have at least one transmembrane and multiple membrane-associated domains ${ }^{45}$. The cloning of the first FATP (FATP1) led to the discovery of a family of evolutionary conserved proteins, and the presence of at least five different FATP genes in the mouse. These isoforms, FATP 1-5 have different tissue-specific expression-distribution patterns ${ }^{46}$. Analogous to FAT/CD36, expression of FATP1 in fibroblasts, cells that normally lack the protein, resulted in a several fold increase in FA uptake rates. The enhancement of long-chain FA uptake was similar to the enhancement of very long-chain FA uptake in these cells ${ }^{32}$. Other members of the FATP family also increased FA uptake rates in cultured cell systems ${ }^{46}$. In addition, disruption of the FATP1 homolog FAT1 (encoding Fatlp) in the yeast Saccharomyces cerevisiae impairs both FA uptake and growth on media containing FA under conditions where de novo FA synthesis is inhibited 47.48. Complementation of the FAT1 mutant yeast strains with the murine FATP1 restored FA uptake and the growth deficiencies ${ }^{48}$. Interestingly, FATPI expression 
is regulated by both insulin and PPARs (peroxisome proliferator activator receptors) ${ }^{4951}$, and both a functional insulin response sequence and a functional PPAR bindings site (PPRE, peroxisome proliferator-responsive element) were identified in the murine FATPI promoter ${ }^{52,53}$. Moreover, insulin was recently shown to induce the translocation of FATP proteins from an intracellular perinuclear compartment to the plasma membrane in adipocytes ${ }^{54}$. The FATP homologues known to date possess a highly conserved domain which contains an AMP-binding motif. This domain is commonly present in proteins that bind ATP and form adenylated intermediates such as very long-chain FA-acyl-CoA synthetases (VLACSs) and members of the luciferase family ${ }^{46,55-57}$. FATP1 mutated in the ATP binding consensus region loses its ability to enhance FA uptake ${ }^{58,59}$. At the protein level, FATP1 has a high homology (40\% amino acid identity) with VLACS ${ }^{57}$. Recently, FATP1 and FATP4 were reported to be VLACSs ${ }^{60,61}$ and the murine FATP2 turned out to be the mouse homolog of a rat protein initially identified as VLACS ${ }^{46}$. Expression of FATPI in COS1 cells increased the VLACS activity cofractionating with the FATP1 protein "6! Moreover, diruption of FAT1, the yeast FATP1 homolog yields a strain with diminished VLACS activity, increased levels of unbound very long-chain FA and normal long-chain FA-acyl-CoA synthetase activity ${ }^{48,62,63}$. These findings suggest that VLACS activity is the main activity of FATP. It has been proposed though that FATP might be a bifunctional molecule with separate transport and esterification activities ${ }^{48,64}$. Understanding the precise function of FATP in FA uptake and metabolism awaits the development of a model in which FA transport can be measured separately from FATP's FA esterification activity. Recently, such a model has been obtained for the yeast FATP1 homolog Fatlp. Here FAT1 mutant strains with distinguishable FA transport and VLACS activities were constructed using site-directed mutagenesis. The documented findings imply that Fatlp has separate long-chain FA import and very long-chain FA activation activities ${ }^{65}$. 


\section{FABP}

The third of the candidate FA transporters, FABPPM, was identified by its binding of radiolabeled oleate and purified from solubilized rat hepatocyte membranes by oleate-agarose affinity chromatography ${ }^{29}$. This $40 \mathrm{kDa}$ protein is loosely associated with the plasma membrane and was shown to be the membrane bound form of the aspartate aminotransferase mitochondrial isoform (mAspAT) ${ }^{27,66}$. To date, three lines of indirect evidence support the involvement of FABPPM in FA transport. First, an antibody raised against FABPpM or mAspAT could inhibit FA uptake in a variety of cell types including hepatocytes, cardiomyocytes and adipocytes ${ }^{38,66,67}$. Secondly, expression of FABPPM in Xenopus laevis oocytes ${ }^{68}$ and in fibroblasts ${ }^{67}$ results in increased FA uptake rates. The third line of evidence derives from the findings that a variety of conditions where FA transport is altered show concomitant changes in tissue FABP an increase in FA uptake, FABP $P_{P M}$ is induced during differentiation of 3T3-L1 fibroblasts into adipocytes ${ }^{67}$. Both FA utilization and FABPPM expression are increased during fasting ${ }^{69}$, whereas endurance training, a condition which is associated with a raise of skeletal muscle FA uptake, also increases FABP PM levels ${ }^{70}$. Expression of FABP ${ }_{\mathbb{P M}}$ in diabetic and obese Zucker rats is simillarly increased in heart, skeletal muscle, and adipose tissue, and these changes appear to generally correlate with changes in FA uptake rates ${ }^{11,72}$. Dinect evidence for the involvement of FABPPM in FA transport, however, awaits further research.

It has been proposed that FAT/CD36, FABPPM and FATP might act synergistically in FA uptake and a potential model for involvement of the three candidate FA transporters based on presently known protein characteristics is shown in Figure $1^{73}$. Supporting the synergistic concept is the notion that while FA uptake by muscle giant sarcolemmal vesicles could be inhibited by both sulfo- $N$ succinimidyl oleate (SSO), an inhibitor specific for FAT/CD36, and an antiFABPPM $_{P}$ antiserum, applying both agents together did not result in a further reduction of FA uptake ${ }^{38}$. 


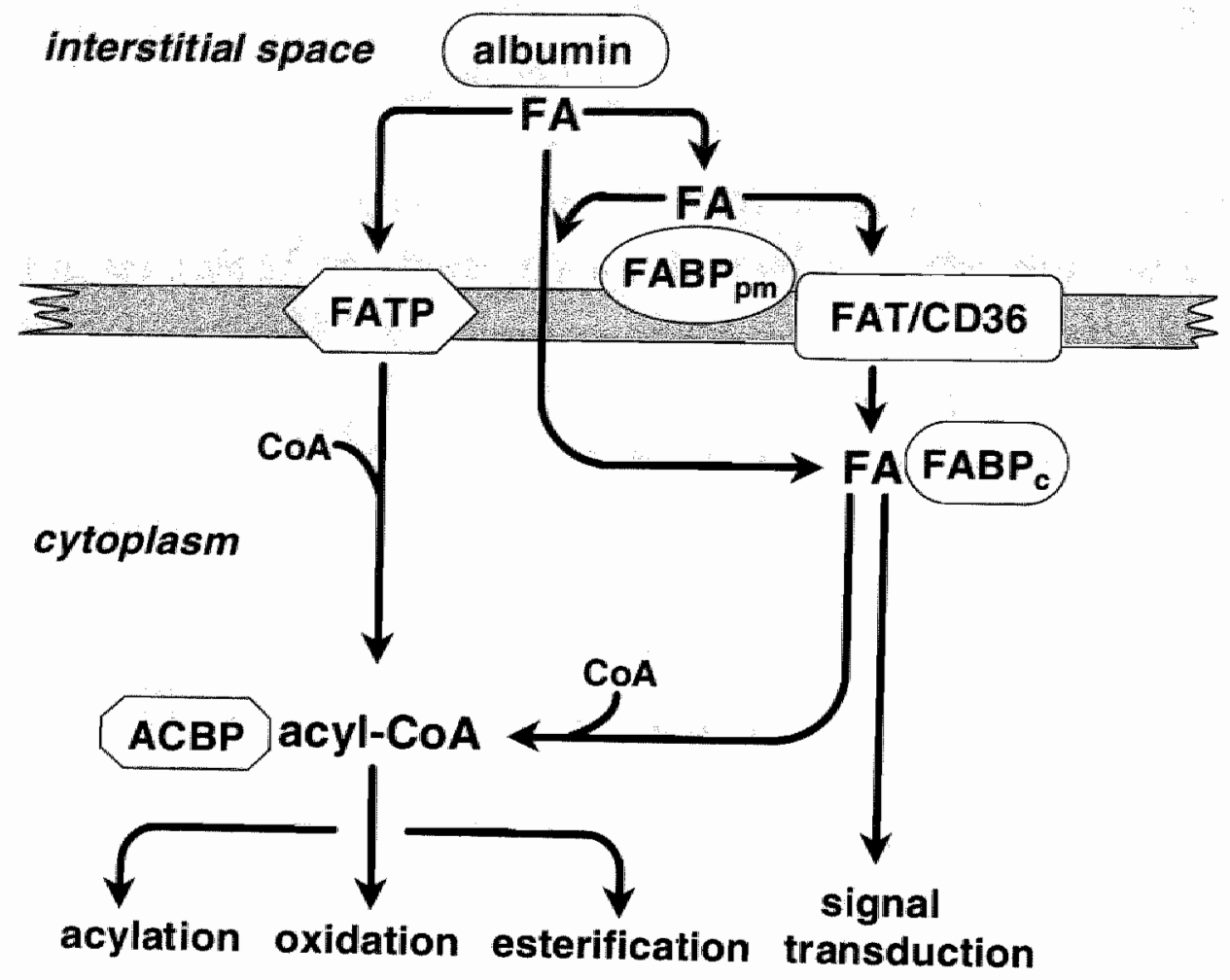

Figure 1: Hypothetical model for the involvement of FA transporters in mamalian FA metabolism. After dissociating from their albumin bindings sites or liberation from lipoproteins by lipoprotein lipase (not shown), FA could either partition directly into the phospholipid bilayer or bind to one of the proteins suggested to function as FA transporter, FATP, FABP pM and FAT/CD36. A wealth of evidence, in detail discussed in the present paper, suggests that the majority of FA is taken up through a FAT/CD36 mediated mechanism in skeletal and heart muscle and in adipose rissue. A smaller fraction of the FA passes the cell membrane probably by spontaneous diffusional flip-flop or facilitated by proteins other than FAT/CD 36. FATP might be involved in FA uptake by functioning as very long-chain acyl COA synthetase, or as an allemative transmembrane FA transporter with very long-chain acyl CaA synthetase activity. $F A B P_{p M}$, as membrane-bound protein, could facilitate FA transport by trapping extracellular FA and channeling them towards FAT/CD36 and/or FATP. To exert it: finction. it might be possible that FAT/CD36 associates with FABP $P_{P M}$ and/or FATP through protein-protein interactions, to form a cluster active in $F A$ uptake. At the inner side of the cell membrane, FA bind to FABP, and after their activation into acyl-coenzyme A, to ACBP. 
Table 1: Overview of transgenic mouse models generated for FATCD36: effect of FAT/CD36 expression on fasted blood parameters

\begin{tabular}{lccc}
\hline & Plasma FA & Plasma TAG & Blood glucose \\
\hline FAT/CD36 overexpression & $\downarrow$ & $\downarrow$ & $\uparrow$ \\
FAT/CD36 null & $\uparrow$ & $\uparrow$ & $\downarrow$ \\
FAT/CD36 rescue & WT & WT & WT \\
\hline
\end{tabular}

Mice were fed a standard chow diet at libitum and ploswa parameters were detemined after an overnight fast.

WT: statistically not different from wild-type levels; : lowered compared to will-type levels

1: increosed compared to wild-type levels. Data obtained from refs. 74 and 75 , and Chapter 4.

\section{Mouse models with altered FAT/CD36 expression}

Knowledge about the role of FAT/CD36 in FA transport has been quickly accumulating since the generation of transgenic mouse lines (Table 1). The first of these models is a mouse overexpressing FAT/CD36 in heart and skeletal muscle 2-4 fold ${ }^{74}$. These mice develop normally, but during the first 6 months of growth their body weight is $13-15 \%$ lower compared to their wild-type littermates. One of the major findings was that isolated soleus muscles from these mice show enhanced muscle FA oxidation rates upon stimulated contraction. While stimulated wild-type muscles showed a 1.9-fold rise in FA oxidation compared to the nonstimulated condition, transgenic muscles showed a 5.6 -fold increase ${ }^{74}$. The increased ability to oxidize FA was accompanied by significant decreases in plasma triacylglycerol (TAG) and FA levels, combined with a general decrease in body fat. These combined findings are indicative of increased muscle FA uptake and oxidation and a decreased FA availability for hepatic TAG synthesis. The decrease in plasma total TAG levels was mainly in the very low density lipoprotein (VLDL) fraction. Plasma cholesterol levels were decreased in the FAT/CD36 overexpressing mice. Blood glucose levels were increased, most likely due to a FA-induced sparing of heart and muscle glucose utilization. The increase in glucose was accompanied by an increase in plasma insulin levels ${ }^{74}$. 
A mouse deficient in FAT/CD36 was generated by targeted gene-disruption ${ }^{75}$. Most interestingly, these mice exhibit a phenotype that is opposite to the phenotype of the FAT/CD36 overexpressing mice in several respects. Upon fasting, FAT/CD36 null mice show significantly increased plasma levels of FA, TAG and cholesterol. This is accompanied by a decrease in blood glucose. These findings are indicative of decreased tissue FA and increased tissue glucose utilization, exactly opposite to the findings in the FAT/CD36 overexpressing mice. VLDL-associated TAG was found to be increased in the FAT/CD36 null, while intermediate density lipoprotein/low density lipoprotein particles were found to be relatively TAG-poor. The increase in cholesterol was reflected in the high density lipoprotein fraction and is most likely an effect caused by the disturbance of peripheral FA utilization ${ }^{75}$. FA uptake in the FAT/CD36 null mice was directly assessed by injecting the iodinated FA analog $\left[{ }^{125} \mathrm{I}\right] \mathrm{BMIPP}(15$-( $p$-iodophenyl)-3( $R, S)$-methyl pentadecanoic acid) into a lateral tail vein. This analysis showed that FAT/CD36 deficiency leads to severe reductions in FA uptake by heart, skeletal muscle and adipose tissue of $40-80 \%$. FAT/CD36 null mice did not show alterations of FA uptake in the liver, an organ with absent or very low FAT/CD36 expression. BMIPP is an FA analog that is slowly metabolized and these results were confirmed using the readily oxidized FA analog IPPA (15-(p-iodophenyl)pentadecanoic acid) ${ }^{76}$. Moreover, in vitro analysis showed that isolated adipocytes lack the high-affinity component of FA transport that is present in wild-type cells ${ }^{75}$.

Recently, a third mouse model was generated, which re-expresses FAT/CD36 in heart and skeletal muscle on the FAT/CD36 null background. These mice, developed using the mouse muscle creatine kinase promoter, show rescue of the main abnormalities mentioned above. Remarkably, they showed an almost complete normalization of plasma parameters. Fasted plasma FA, TAG and glucose levels were not different from the wild-type levels. FA oxidation by isolated soleus muscles, prominently reduced in the FAT/CD36 null mouse, also normalized (Chapter 4). These results show that the reported metabolic phenotypes 
of the FAT/CD36 null and FAT/CD36 overexpressing mice are direct and genespecific effects. The absence of FAT/CD36 thus directly leads to a severe defect in FA transport in the heart, skeletal muscle and in adipose tissue.

\section{Metabolic abnormalities linked to FAT/CD36 deficiency in the spontaneous}

\section{hypertensive rat}

Additional information about the consequences of FAT/CD36 deficiency was obtained with a fourth rodent model. The SHR (spontaneous hypertensive) rat is the most widely studied animal model of essential hypertension and several disturbances of lipid and carbohydrate metabolism in this rat have been reported ${ }^{77-82}$. Genomic screening for loci linked to insulin and catecholamine action in the SHR identified two quantitative trait loci for defective insulin action. One was localized on chromosome 4 and the other on chromosome 12. Both defects in glucose and FA metabolism mapped to the same locus on chromosome $4^{83}$. Congenic mapping and microarray screening identified FAT/CD36 on rat chromosome 4 as a defective SHR gene at the peak of linkage to these quantitative trait loci. The SHR FAT/CD36 cDNA was shown to contain multiple sequence variants, which reflect unequal genomic recombination of a duplicated ancestral gene. The resulting FAT/CD36 deficiency was demonstrated by the fact that the FAT/CD36 protein could not be detected in SHR (SHR/NIH) adipocyte membranes ${ }^{84}$. Surprisingly, a SHR-derived strain that has been maintained in Japan since 1966 (SHR/Izm) was shown not to contain the FAT/CD36 deletion mutation, which also holds true for the stroke-prone SHR rat (SHRP, both the NIH-derived and a Japanese strain SHRP/Izm) ${ }^{85.87}$. These findings are especially remarkable as both the SHR/NIH and the SHR/Izm strain develop insulin resistance. The two strains diverged, however, a long time before they were fully inbred. As a result, they differ throughout their entire genomes, and thus cannot be compared directly ${ }^{85,88}$.

To directly analyze the consequences of FAT/CD36 deficiency in the SHR/NIH rat, first a SHR-Brown Norway congenic strain was developed. Here a 
segment of the Brown Norway chromosome 4 (including FAT/CD36) was transferred onto the SHR background. This rat showed reductions in blood pressure and dietary-induced glucose intolerance, hyperinsulinemia and hyperlipidemia ${ }^{87}$. More direct was the analysis of a FAT/CD36 transgenic SHR rat, in which the protein was re-introduced by a genetic rescue approach. Insulin resistance was improved and plasma FA and insulin levels were lowered also in this rat. Hypertension, on the contrary; was not ameliorated and, though it might be linked to FAT/CD36 deficiency, may be the result of multiple influences ${ }^{88}$.

Analogous to the FAT/CD36 null mice, the absence of FAT/CD36 in the SHR rat leads to decreased FA transport in heart and adipose tissue. Though relatively modest decreases were found using BMIPP, in vivo measurements with the glucose tracer 2-[ ${ }^{18}$ F]FDG (2-fluorodeoxyglucose) showed an impressive compensatory increase in glucose uptake in heart and diaphragm muscle ${ }^{89}$. Basal glucose uptake is also, but to a lesser extent, heightened in adipose tissue and intercostal and hip muscles. The FA transport defect was confirmed using both isolated adipocytes and cardiomyocytes and glucose uptake is normalized in the congenic, FAT/CD36 re-expressing SHR-Brown Norway rat referred to above ${ }^{89}$. That the effects mentioned are specifically caused by the absence of FAT/CD36 is also shown by the fact that rats fed a mix of short- and medium-chain FA showed almost complete normalization of heart glucose uptake and plasma insulin levels ${ }^{89}$. Short and medium-chain FA uptake is not dependent on FAT/CD36 because the saturable, facilitated component of FA uptake does not recognize, and, in addition, highly purified FAT/CD36 does not bind these FA ${ }^{24,89}$. As might be expected from the characterization of the transgenic, FAT/CD36 re-expressing SHR rescue-rat ${ }^{88}$, also the dietary approach did not have an influence on the high blood-pressure present in the SHR rat ${ }^{89}$.

\section{Effect of FAT/CD36 deficiency on cardiac function}

Several mutations leading to FAT/CD36 deficiency in humans have been reported. The prevalence of this deficiency varies from 0.3 to $11 \%$ and the higher incidences 
are found in the Asian and African populations ${ }^{90}$. Recently, an extensive study by Tanaka et al. ${ }^{91}$ analyzed 47 patients with a total defect in myocardial BMIPP uptake. All these patients were shown to carry a mutated FAT/CD36 gene and the FAT/CD36 protein was not detectable on either platelet or monocyte membranes. In total, nine segregated mutations were found ${ }^{91}$. It has been proposed that FAT/CD36 deficiency in the human heart, thus leading to a severe defect in FA transport like in the FAT/CD36 null mouse, might be the basis for the development of hypertrophic cardiomyopathy ( $\mathrm{HCM}$ ). This hypothesis was mainly based on the fact that about $40 \%$ of HCM patients carry FAT/CD36 mutations ${ }^{92}$. The more extensive study mentioned above, however, did not support this hypothesis and indicates that a less specific relation between FAT/CD36 deficiency and an increased susceptibility for a variety of heart diseases might exist ${ }^{91}$.

Remarkably, the development of cardiac hypertrophy in the SHR rat appears mediated by FAT/CD36. A dietary rescue approach by feeding a short-/mediumchain FA supplemented diet did not only reduce hyperinsulinemia as described above, but also alleviated SHR cardiac hypertrophy. As the short-/medium-chain FA supplemented diet restored FA oxidation, this observation links FA-generated energy to the symptoms of hypertrophy ${ }^{89}$. Also notable is the observation that FAT/CD36 null hearts develop dilated cardiomyopathy ${ }^{93}$.

Additional information on the functional consequence of FAT/CD36 deficiency in the heart was recently obtained by further analysis of the FAT/CD36 null mouse. The tolerance to ischemia/reperfusion by isolated FAT/CD36 null hearts was shown to be severely compromised compared to their wild-type counterparts. Hearts re-expressing FAT/CD36 showed an ischemic tolerance comparable to wild-type hearts and it was thus concluded that the decreased tolerance is due to FAT/CD36 deficiency. Furthermore, dietary rescue with shortand medium-chain FA resulted in normalization of FAT/CD36 null heart ischemic tolerance and FAT/CD36 overexpressing hearts showed an increased tolerance to ischemia. This notion led to the concept that cellular energy derived from FAT/CD36 mediated FA uptake is an important determinant of ischemic tolerance 
in the heart. In line with this, both heart and skeletal muscle energy contents are significantly reduced compared to wild-type tissues (Chapter 5). Not surprisingly, the endurance of FAT/CD36 null mice during forced exercise is significantly decreased (Chapter 4). The absence of FAT/CD36 in heart and skeletal muscle thus impacts energy production and the effects become apparent during heightened cellular demands such as ischemia. Another important finding of these studies was that the end-diastolic pressure in FAT/CD36 null hearts is significantly increased in the working heart preparation. Though the transgenic rescue of heart FAT/CD36 expression restored the tolerance to ischemia, it did not normalize the end-diastolic pressure. Because the rescue approach used only restored cardiomyocyte and not endothelial cell FAT/CD36 expression, it could be concluded that the lack of endothelial FAT/CD36 might lead to diastolic dysfunction.

In conclusion, expression of FAT/CD36 has been linked to cardiac hypertrophy, the tolerance to ischemia and diastolic dysfunction in rodent models. Until now, these links could not be established directly in humans though the effect of FAT/CD36 deficiency on FA transport in murine and human hearts seems to be of a comparable magnitude. Deficiency in FAT/CD36, however, is associated with a diversity of heart diseases in humans, and, accompanied by other unknown factors, cardiac hypertrophy might be involved in the development of these diseases ${ }^{91}$. Further exploration of the different rodent models might yield valuable information about the links between FAT/CD36 expression and heart function and failure.

\section{FAT/CD36 expression is regulated by several mechanisms}

Much effort has been invested to gain insight into the mechanisms by which FAT/CD36 expression and function are regulated. One of the first findings was that FAT/CD36 expression parallels the expression of the intracellular FA binding proteins in muscle tissues, intestine and mammary gland ${ }^{33,34,94,95}$. In muscle tissues, both $\mathrm{H}-\mathrm{FABP}_{\mathrm{c}}$ and FAT/CD36 levels correlate with the capacity for FA oxidation, as their expression is high in the heart, lower in red and lowest in white skeletal 
muscle at both the mRNA and protein levels ${ }^{34,40}$. More interestingly, FATTCD36 gene-expression was shown to be altered under conditions that also modulate FA metabolism. For example, FAT/CD36 expression is induced in murine models of diabetes, during heart development and during the differentiation of pre-adipocytes into adipocytes ${ }^{34,39,96}$. Work with cultured adipocytes as model system showed that FAT/CD36 mRNA is strongly and reversibly induced by both saturated and unsaturated FA. Metabolism is not required for this induction as shown by applying the non-metabolized FA analogue 2-bromo-palmitate, and FAT/CD36 induction parallels the induction of other genes involved in FA metabolism by $\mathrm{FA}^{1,96,97}$. This effect is, at least in part, mediated by the lipid-activated nuclear receptors PPARs (peroxisome proliferator activated receptors). Expression of the PPAR $\delta$ isoform in fibroblasts unresponsive to FA conferred FA-specific induction of FAT/CD $36{ }^{98}$ and two functional PPAR bindings sites are present in the murine FAT/CD36 promoter ${ }^{99}$. These two functional bindings sites were shown to drive strong FAT/CD36 promoter activity in adipose cells ${ }^{99}$. The role of PPAR in the heart is underscored by the observation that the expression of several genes involved in FA catabolism is lowered in the hearts of PPAR $\alpha$ null mice. Also, fasting failed to induce most of these genes in the PPAR $\alpha$ deficient hearts ${ }^{100}$. Moreover, heart-specific overexpression of $\operatorname{PPAR} \alpha$ results in a heightened expression of genes, including FAT/CD36, involved in FA uptake and oxidation pathways, combined with increased cardiac FA oxidation rates ${ }^{101}$. A recent study documented a time delay in PPAR-mediated regulation of FAT/CD36 and suggested that FAT/CD36 activation by PPARs is indirect ${ }^{102}$.

An additional mechanism for $\mathbb{F A T} / \mathrm{CD} 36$ regulation was shown to be present at the level of translation in human monocyte-derived macrophages ${ }^{103}$. Cultivated in the presence of high glucose concentrations, these cells show a concentrationdependent increase in functional FAT/CD36 protein expression at their cell membrane. By using RNAse protection assays and by fractionating polysome preparations, it was shown that this effect is due to a greater ribosomal loading of 
the FAT/CD36 transcript. Reporter gene assays with mutated FAT/CD36 5 -untranslated regions (UTRs) identified the corresponding primary mechanism, regulation of the efficiency of reinitiation following translation of upstream open reading frames (uORFs). The FAT/CD36 UTR, with a length of more than $200 \mathrm{bp}$, contains 3 uORFs and the reporter assays indicated that reinitiation following translation of the first of these is responsible for the increase in translational efficiency under hyperglycemic conditions ${ }^{103}$. Translational regulation in response to glucose has also been described in yeast ${ }^{104}$ and glucose is thought to also regulate the translation of several other genes important in glucohomeostasis as proinsulin, glucokinase and FA-synthetase 105-107. This type of FAT/CD36 regulation, presented as a link between diabetes and atherosclerosis, seems to be relevant especially for conditions associated with hyperglycemia.

A thitd FAT/CD36 regulational mechanism is present at the protein level. Skeletal muscle, as a key FA oxidizer and principal site for the removal of FA from the circulation, has a highly variable metabolic rate and should be able to adapt FA transport quickly so as to properly respond to changes in energy demand. By comparing resting and in vivo electrically stimulated skeletal muscles, it was shown that contraction is able to translocate FAT/CD36 from an intracellular pool to the plasma membrane ${ }^{108}$. This way of acutely regulating FA transport is analogous to the manner by which glucose transport is regulated by the transporter GLUT-4 ${ }^{109}$. The translocational mechanism is substantiated by several observations. Most importantly, FA uptake by muscle giant sarcolemmal vesicles is increased already after $5 \mathrm{~min}$ of in vivo electrical stimulation. The giant sarcolemmal vesicle preparation is a model representing the plasma membrane and suitable for measuring FA uptake in the absence of metabolism. Giant vesicle palmitate uptake further increased over a $30 \mathrm{~min}$ contraction period and decreased time-dependent after termination of the electrical stimulus. Moreover, the increase of vesiclular FA uptake was shown to be proportional to the rate of muscle stimulation and could be inhibited by SSO, an inhibitor specific for FAT/CD36. By comparison with GLUT4. lastly, gradient centrifugation showed that FAT/CD36 in skeletal muscle is 
present in both an intracellular and a membrane-associated pool (Fig. 2). Almost equal quantities of FAT/CD36 were found in both pools under basal conditions, and electrical stimulation increased the amount of FAT/CD36 in the sarcolemmal fraction and decreased the amount of FAT/CD36 in the intracellular pool ${ }^{108}$. Recently, insulin was shown also to induce FAT/CD36 translocation in perfused rat hindlimb muscle ${ }^{110}$.

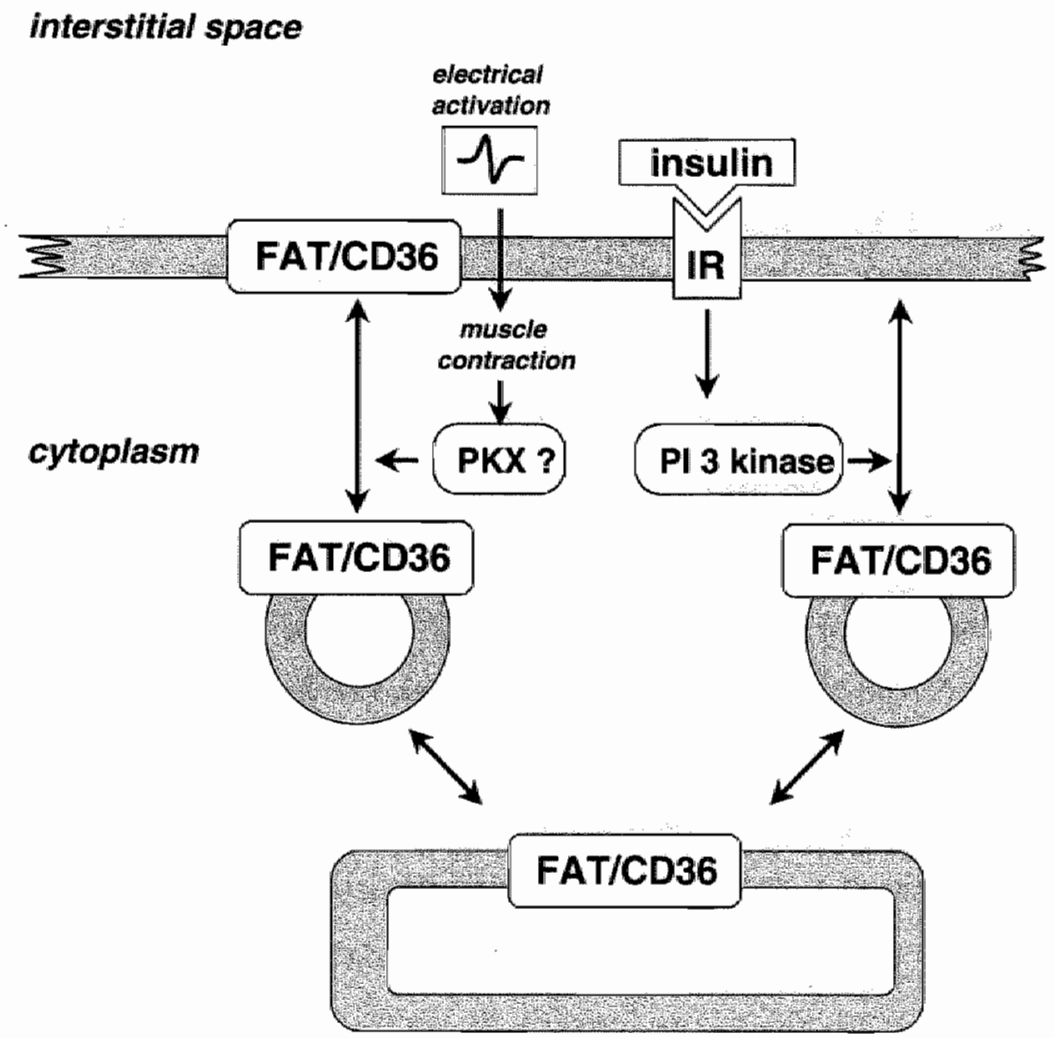

Figure 2: Acute regulation of functional FAT/CD36 expression by protein translocation.

In tissues expressing FAT/CD36, acute regulation of cellular FA uptake involves the cellular redistribution of FAT/CD36 to and from the plasma membrane. This redistribution can be triggered by insulin and by contraction (in muscle). Prelinimary results indicate that the transductional mechanism for electrical activation is different from the nechanism for activation by insulin and this figure reflects the current wiew that the first is mediated by a yet unidentified protein kinase (PKX) and the second by phosphatidylinositol 3-kinase (PI 3 kinase). 
In conclusion, FAT/CD36 is a tightly regulated protein. Regulational mechanisms are present at the level of mRNA, which is mediated by PPARs, and at the translational level. Moreover, FA transport is acutely regulated by translocation of the protein. Post-translational modifications of FAT/CD36, namely glycosylation, palmitoylation and phosphorylation each shown to occur ${ }^{36.111}$, might also play a role in the regulation of FAT/CD36 localization, its activity or interaction with other proteins. An interaction between FAT/CD36 and FABP $\mathrm{c}_{\mathrm{c}}$ was shown to occur in the bovine mamary gland ${ }^{95}$ and FAT/CD36 was found to be associated with protein-tyrosine kinases in human platelets ${ }^{112}$. The heart was reported to regulate FAT/CD36 transcription in response to an altered availability of FA ${ }^{39}$ whereas the role of translational FAT/CD36 regulation in the heart is still to be fully explored. FAT/CD36 translocation has been shown to be altered in the hearts of Zucker rats, wherein the distribution of FAT/CD36 appears to be shifted towards a permanent re-localization at the plasma membrane ${ }^{71}$. Interestingly, abnormalities in all three mechanisms are associated with and might contribute to the development of pathologies. PPAR $\alpha$ overexpressing hearts show a decrease in both glucose uptake and oxidation rates, which is accompanied by the repression of enzymes involved in glucose transport and oxidation. These hearts show ventricular hypertrophy, activation of gene-markers for pathologic hypertrophy, and systolic ventricular dysfunction. Taken together with the alterations in FA metabolism, this phenotype is typically resembling that of the diabetic heart ${ }^{101}$. Glucose mediated regulation of FAT/CD36 translation appears to explain the association between diabetes and the development of accelerated atherosclerosis. As a result of hyperglycemia, the increased FAT/CD36 levels are thought to lead to an increased uptake of oxidized low-density lipoprotein by macrophages, resulting in subsequent foam-cell development ${ }^{103}$. A link between FAT/CD36 translocation and obesity has been established in the Zucker rat ${ }^{71}$. In obese Zucker rats, the FA uptake rates of giant vesicles from heart, skeletal muscle and adipose tissue are higher compared to those isolated from lean control rats. Neither FAT/CD36 mRNA nor total tissue FAT/CD36 protein levels show a consistent quantitative relation with these higher 
uptake rates. The finding that $\mathrm{FA}$ uptake correlated with plasma nembrane FAT/CD36 levels led to the speculation that FAT/CD36 is relocated from an intracellular store to the plasma membrane in obesity. The observation that FAT/CD36 translocation can be induced by insulin also substantiates a role in the pathology of diabetes ${ }^{110}$. Further establishment of the precise regulational mechanisms and the consequences of the resulting FAT/CD36 alterations thus seem extremely relevant to the development of and complications associated with pathologies, especially insulin resistance and diabetes.

\section{Summary and future directions}

Of the three proteins initially identified as candidate membrane FA transporters,

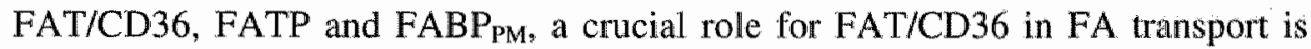
now finally established. Although evidence supporting a role for FATP and for FABP $P_{P M}$ in FA metabolism was obtained, it is at present unclear whether these two proteins have a direct role in FA transport. It has been clearly established that FATP possesses VLACS activity. Whether this activity is accompanied by an additional function in FA transport requires further experimentation. Based on its periferal localization, FABPPM might have a function in the trapping of FA and their subsequent channeling towards FA transporters.

Several models to study the influence of FAT/CD36 on FA transpont, including a method to study the effects of FAT/CD36 deficiency in the human heart, have been generated or identified. Both in vitro and in wivo studies showed that FAT/CD36 mediated FA transport in the heart accounts for 60-80\% of the FA taken up by the cardiomyocyte. In addition, FAT/CD36 is an important mediator of FA uptake in adipose tissue, intestine ${ }^{94}$ and in muscle in general. The molecular mechanism by which FAT/CD36 exerts this action is currently unknown and several possible models have been proposed by Abumrad et al. ${ }^{113}$. In these models, FAT/CD36 might facilitate FA transport by decreasing the activation energy for the movement of the polar FA carboxyl group through the membrane bilayer. This could be achieved through favorable interactions with polar side chains or peptide 
bond dipole moments, and for this FAT/CD36 might form a multimeric pore or channel, or the protein could bind FA at specific sites within the annular lipids directly adjacent to the protein. Alternatively, a hydrophobic segment of FAT/CD36 that extends below the water/lipid interface might mediate the insertion of the carboxyl group within the outer leaflet of the membrane ${ }^{113}$. The possibility that interactions between FAT/CD36 and one or more other proteins are essential for the function of FAT/CD36 in FA uptake still has to be fully explored. Indicative of a possible interaction between cytoplasmic FABP, which acts as intracellular FA transporter, and FAT/CD36 is the finding that an association between $F A T / C D 36$ and $\mathrm{FABP}_{\mathrm{c}}$ has been found in bovine mammary gland ${ }^{95}$. In addition, the phenotype of the mouse null for $\mathrm{H}-\mathrm{FABP}$ is similar to that of the FAT/CD36 null ${ }^{114}$.

Alteration of FAT/CD36 levels in rodent models leads to alterations of plasma metabolites and FAT/CD36 deficiency is directly linked to the development of insulin resistance and cardiac hypertrophy. Furthermore, in humans an association is present between FAT/CD36 deficiency and increased susceptibility for heart diseases. FAT/CD36 was shown to be regulated at several levels. Both the FAT/CD36 mRNA and the FAT/CD36 protein levels are subject to regulation. Moreover, acute regulation of FA transport is accomplished at the protein level through translocation from an intracellular store to the plasma membrane. All three regulational mechanisms appear to be relevant to the development of diseases and their associated complications. Establishing the molecular mechanism by which FAT/CD36 mediates FA transport, the possible involvement of additional proteins and the interactions between the regulational mechanisms, is expected to provide valuable information about the interactions between FA metabolism and the metabolism of other major substrates. This information, in turn, should contribute to a better understanding of the etiology of many life-threatening pathologies like cardiac hypertrophy, heart failure and diabetes. 


\section{References}

1. Amri EZ, Bertrand B, Ailhaud G and Grimaldi P. Regulation of adipose cell differentiation 1 . Fatry acids are inducers of the aP2 gene expression. $J$ Lipid Res 32: 1449-1456, $199 \mathrm{~L}$.

2. Distel RI, Robinson GS and Spiegelman BM. Fatty acid regulation of gene expression. Transcriptional and post-transcriptional mechanisns. J Biol Chem 267: 5937-5941, 1992.

3. Ordway RW, Singer JJ and Walsh JV, Jr. Direct regulation of ion channels by fatty acids. Trends Neurosci 14: 96-100, 1.991.

4. Anderson MP and Welsh MJ. Fatty acids inhibit apical membrane chlonide channels in airway epithelia. Proc Natl Acad Sci U S A 87: 7334-7338, 1990.

5. Mundy DI. Protein palmitoylation in membrane trafficking. Biochem Soc Trans 23: 572-576, 1995.

6. Jackson CS, Zlatkine P, Bano C, Kabouridis P, Mehul B, Parenti M, Milligan G, Ley SC and Magee AI. Dynamic protein acylation and the regulation of localization and function of signaltransducing proteins. Biochem Soc Trans 23: 568-571, 1995.

7. Bouvier M, Loisel TP and Hebert T. Dynamic regulation of Geprotein coupled receptor palmitoylation: potential role in receptor function. Biochen Soc Trans 23: 577-581, 1995.

8. Yamashita A, Sugiura T and Waku K. Acyltransferases and transacylases involwed in fatty acid remodeling of phospholipids and metabolism of bioactive lipids in mammalian cells. $J$ Biochem (Tokyo) 122: 1-16, 1997.

9. Galli $\mathbf{C}$ and Marangoni F. Recent advances in the biology of n-6 fatty acids. Natrition 13: 978$985,1997$.

10. Glatz JFC, Borchers T, Spener F and van der Vusse GJ. Fatty acids in cell signalling: modulation by lipid binding proteins. Prostaglandins Leukot Essent Fatty Acids 52: 121-127, 1995.

11. Van der Vusse GJ, Glatz JFC, Stam HCG and Reneman RS. Fatty acid homeostasis in the nomoxic and ischemic heart. Physiol Rev 72: 881-940, 1992.

12. Neely JR, Rovetto MJ and Oram JF. Myocardial utilization of carbohydrate and lipids. Prog Cardiovasc Dis 15: 289-329, 1972.

13. Spector AA. Plasma lipid transport. Clin Physiol Biochem 2: 123-134, 1984.

14. Storch $\mathbf{J}$ and Thumser $\mathbf{A E}$. The fatty acid transport function of fatty acid-binding proteins. Biochim Biophys Acta 1486: 28-44, 2000.

15. Schaap FG, Binas B, Danneberg H, van der Vusse GJ and Glatz JF. Impaired long-chain fatty acid utilization by cardiac myocytes isolated from mice lacking the heart-type fatty acid binding protein gene. Circ Res 85: 329-337, 1999.

16. Faergeman $\mathrm{NJ}$ and Knudsen $\mathbf{J}$. Role of long-chain fatty acyl-CoA esters in the regulation of metabolism and in cell signalling. Biochem $J 323: 1-12,1997$. 
17. Knudsen J. The role of acyl-CoA binding protein (ACBP) and long-chain acyl-CoA esters in cell regulation and function. In: Proceedings of XVI Washington International Spring Symposium, edited by Vanderhoek IY: Pletim Press, 1996, p4. 73-82.

18. Turcotte LP, Richter EA and Kiens B. Increased plasma FFA uptake and oxidation during prolonged exercise in trained vs. untrained humans. Am J Physiol 262: E791-E799, 1992.

19. Mackie BG, Dudley GA, Kaciuba-Uscilko H and Terjung RL. Uptake of chylomicron trikglycerides by contracting skeletal muscle in rats. $J$ Appl Physiol 49: 851-855, 1980.

20. Martin WH, 3rd, Dalsky GP, Hurley BF, Matthews DE, Bier DM, Hagberg JM, Rogers MA, King DS and Holloszy JO. Effect of endurance training on plasma free fatty acid turnover and oxidation during exercise. An J Physiol 265: E708-E714, 1993.

21. Suxuki K and Kono T. Evidence that insulin causes translocation of glucose transport activity to the plasma membrane from an intracellular storage site. Proc Natl Acad Sci U S A 77: 2542-2545, 1980.

22. Civelek VN, Hamilton JA, Tornheim K, Kelly KL and Corkey BE. Intracellular pH in adipocytes: effects of free fatty acid diffusion across the plasma menbrane, lipolytic agonists, and insulin. Proc Nat Acad Sci U S A 93: 10139-10144, 1996.

23. Kamp F, Hamilton JA and Westerhoff HV. Movement of fatty acids, fatty acid analogues, and bile acids across phospholipid bilayers. Biochenistry 32: 11074-11086, 1993.

24. Abumrad NA, Park JH and Park CR. Permeation of long-chain fatty acid into adipocytes. Kinetics, specificity, and evidence for imvolvement of a membrane protein. J Biol Chem 259: 8945$8953,1984$.

25. Abumrad NA, Perkins RC, Park JH and Park CR. Mechanism of long chain fatty acid permeation in the isolated adipocyte. J Biol Chem 256: 9183-9191, 1981.

26. Sorrentino D, Robinson RB, Kiang $\mathbf{C L}$ and Berk PD. At physiologic albumin/oleate concentrations oleate uptake by isolated hepatocytes, cardiac myocytes, and adipocytes is a saturable function of the unbound olleate concentration. Uptake kinetics are consistent with the conwentional theory. J Clin Invest 84: 1325-1333, 1989.

27. Stump DD, Zhou SL and Berk PD. Comparison of plasma membrane FABP and mitochondrial isoform of aspartate aminotransferase from rat liver. Am J Physiol 265: G894-G902, 1993.

28. Luiken JJ, van Nieuwenhoven FA, America G, van der Vusse GJ and Glatz JF. Uptake and metabolisn of palmitate by isolated cardiac myocytes from adult rats: involvement of sarcolemmal proteins. J Lipid Res 38: 745-758, 1997.

29. Stremmel W, Strohmeyer G, Borchard F, Kochwa $\mathbf{S}$ and Berk PD. Isolation and partial characterization of a fatty acid binding protein in rat liver plasma membranes. Proc Natl Acad Sci U S A 82: $4-8,1985$. 
30. Harmon CM and Abumrad NA. Binding of sulfosuccinimidyl fatty acids to adipocyte membrane proteins: isolation and amino-terminal sequence of an $88-\mathrm{kD}$ protein implicated in transport of long-chain fatty acids. J Membr Biol 133: 43-49, 1993.

31. Abumrad N, Harmon $\mathrm{C}$ and Ibrahimi A. Membrane transport of long-chain fatty acids: evidence for a facilitated process. J Lipid Res 39: 2309-2318, 1998.

32. Schaffer JE and Lodish HF. Expression cloning and characterization of a novel adipocyte long chain fatty acid transport protein. Cell 79: 427 436, 1994 .

33. Van Nieuwenhoven FA, Willemsen PH, van der Vusse GJ and Glatz JF. Co-expression in rat heart and skeletal muscle of four genes coding for proteins implicated in long-chain fatty acid uptake. Int J Biochem Cell Biol 31: 489-498, 1999.

34. Van Nieuwenhoven FA, Verstijnen CP, Abumrad NA, Willemsen PH, van Eys GJ, van der Vusse GJ and Glatz JF. Putative membrane fatty acid translocase and cytoplasmic fatty acid. binding protein are co-expressed in rat heart and skeletal muscles. Biochem Biophys Res Commun 207: 747-752, 1995.

35. Abumrad NA, el-Maghrabi MR, Amri EZ, Lopez E and Grimaldi PA. Cloning of a rat adipocyte membrane protein implicated in binding or transport of long-chain fatty acids that is induced during preadipocyte differentiation. Homology with human CD36. J Biol Chem 268: 17665$17668,1993$.

36. Greenwalt DE, Lipsky RH, Ockenhouse CF, Ikeda H, Tandon NN and Jamieson GA. Membrane glycoprotein CD36: a review of its roles in adherence, signal transduction, and transfusion medicine. Blood 80: 1105-1115, 1992.

37. Asch AS, Barnwell J, Silverstein RL and Nachman RL. Isolation of the thrombospondin membrane receptor. J Clin Invest 79: 1054-1061, 1987.

38. Luiken JJ, Turcotte LP and Bonen A. Protein-mediated palmitate ujtake and expression of fatty acid transport proteins in heart giant vesicles. J Lipid Res 40: 1007-1016, 1999.

39. Greenwalt DE, Scheck SH and Rhinehart-Jones T. Heart CD36 expression is increased in murine models of diabetes and in mice fed a high fat diet. $J$ Clin Invest 96: 1382-1388, 1995.

40. Pelsers MM, Lutgerink JT, van Nieuwenhoven FA, Tandon NN, van der Vusse GJ, Arends JW, Hoogenboom HR and Glatz JF. A sensitive immunoassay for rat fatty acid translocase (CD36) using phage antibodies selected on cell transfectants: abundant presence of fatty acid translocase/CD 36 in cardiac and red skeletal muscle and up- regulation in diabetes. Biochem J 337 : $407-414,1999$.

41. Ibrahimi A, Sfeir Z, Magharaie H, Amri EZ, Grimaldi $P$ and Abumrad NA. Expression of the CD36 homolog (FAT) in fibroblast cells: effects on faity acid transport. Proc Nati Acad Sci U SA 93: $2646-2651,1996$. 
42. Van Nieuwenhoven FA, Luiken JJ, De Jong YF, Grimaldi PA, wan der Vusse GJ and Glatz

IF. Stable transfection of fatty acid translocase (CD36) in a rat heart muscle cell line (H9c2). $J$ Lipid Res 39: 2039-2047, 1998.

43. Utsunomiya A, Owada $\mathbf{Y}$, Yoshimoto $\mathbf{T}$ and Kondo $\mathbf{H}$. Localization of mRNA for fatty acid transport protein in developing and mature brain of rats. Brain Res Mol Brain Res 46: 217-222, 1997.

44. Schaap IG, Hamers L, wan der Vusse G.J and Glatz JE. Molecular cloning of fatty acidtransport protein cDNA from rat. Biochim Biophys Acta 1354: 29-34, 1997.

45. Lewis SE, Listenberger LL, Ory DS and Schaffer JE. Membrane topology of the murine fatty acid transport protein 1. J Biol Chem 276: 37042-37050, 2001.

46. Hirsch D, Stahl A and Lodish HF. A family of fatty acid transporters conserved from mycobacterium to man. Proc Natl Acad Sci U SA 95: 8625-8629, 1998.

47. Faergeman $N_{\mathfrak{J}}$, DiRusso $\mathbf{C C}$, Elberger $\mathbf{A}$, Knudsen $J$ and Black PN. Disruption of the Saccharomyces cerevisiae homologue to the murine fatty acid transport protein impairs uptake and growth on long-chain fatty acids. J Biol Chem 272: 8531-8538, 1997.

48. Dirusso CC, Connell EJ, Faergeman NJ, Knudsen J, Hansen JK and Black PN. Murine FATP alleviates growth and biochemical deficiencies of yeast fat 1Delta strains. Eur J Biochem 267: $4422-4433,2000$.

49. Man MZ, Hui TY, Schaffer JE, Lodish HF and Bernlohr DA. Regulation of the murine adipocyte fatty acid transporter gene by insulin. Mol Endocrinol 10: 1021-1028, 1996.

50. Martin G, Schoonjans K, Lefebvre AM, Staels B and Auwerx J. Coordinate regulation of the expression of the fatty acid transport protein and acyl-COA synthetase genes by PPARalpha and PPARgamma activators. J Biol Chem 272: 28210-28217, 1997.

51. Motojima K, Passilly P, Peters JM, Gonzalez FJ and Latruffe N. Expression of putative fatty acid transporter genes are regulated by peroxisome proliferator-activated receptor alpha and gamma activators in at tissue- and inclucer-specific manner. J Biol Chem 273: 16710-16714, 1998.

52. Frohnert BI, Hui TY and Bernlohr DA. Identification of a functional peroxisome proliferatorresponsive element in the murine fatty acid transport protein gene. J Biol Chem 274: 3970-3977, 1999.

53. Hui TY, Frohnert BI, Smith AJ, Schaffer JE and Bernlohr DA. Characterization of the murine fatty acid transport protein gene and its insulin response sequence. J Biol Chem 273: 27420-27429, 1998

54. Stahl A, Evans JG, Pattel S, Hirsch D and Lodish HE. Insulin causes fatty acid transport protein translocation and enlanced fatty acid uptake in adipocytes. Dev Cell 2: 477-488, 2002.

55. Berger J, Truppe C, Neumann $\mathbf{H}$ and Forss-Petter $\mathbf{S}$. A novel relative of the very-long-chain acyl-CoA synthetase and fatty acid transporter protein genes with a distinct expression pattern. Biochem Bioplys Res Commun 247: 255-260, 1998. 
56. Berger J, Truppe C, Neumann $H$ and Forss-Petter S. CDNA cloning and mRNA distribution of a mouse very long-chain acyl-CoA synthetase. FEBS Lett 425: 305-309, 1998.

57. Uchiyama A, Aoyama $T$, Kamijo $K$, Uchida $Y$, Kondo $N$, Orii $T$ and Hashimoto $T$. Moleculai cloning of cDNA encoding rat wery long-chain acyl-CoA synthetase. $J$ Biol Chem 271: 30360-30365, 1996.

58. Stuhlsata-Krouper SM, Bennett NE and Schaffer JE. Substitution of alanine for serine $250 \mathrm{in}$ the murine fatty acid transport protein inhibits long chain fatty acid transport. I Biol chen 273 : $28642-28650,1998$.

59. Stuhlsatz-Krouper SM, Bennett NE and Schaffer JE. Molecular aspects of fatty acid transport: mutations in the IYTSGTTGXPK motif impair fatty acid transport protein function. Prostaglandins Leukot Essent Fatty Acids 60: 285-289, 1999.

60. Herrmann T, Buchkremer F, Gosch I, Hall AM, Bernlohr DA and Stremmel W. Mouse fatty acid transport protein 4 (FATP4): characterization of the gene and functional assessment as a very long chain acyl-CoA synthetase. Gene 270: 31-40, 2001.

61. Coe NR, Smith AJ, Frohnert BI, Watkins PA and Bernlohr DA. The fatty acid transport. protein (FATP1) is a very long chain acyl-CoA synthetase. J Biol Chem 274: 36300-36304, 1999.

62. Watkins PA, Lu JF, Steinberg S.J, Gould SJ, Smith KD and Braiterman LT. Disruption of the Saccharomyces cerevisiae FAT1 gene decreases very long-chain fatty acyl-CoA synthetase activity and elevates intracellular very long-chain fatty acid concentrations. J Biol Chem 273: 18210 $18219,1998$.

63. Choi JY and Martin CE. The Saccharomyces cerevisiae FATI gene encodes an acyl-CoA synthetase that is required for maintenance of very long chain fatty acid levels. J Biol Chem 274: $4671-4683,1999$.

64. Schaffer JE. Fatty acid transport: the roads taken. Am J Physiol Endocrinol Metab 282: E239E246., 2002.

65. Zou $Z$, DiRusso CC, Ctrnacta $V$ and Black PN. Fatty acid transpott in Saccharomyces cerevisiae. Directed mutagenesis of FATI distinguishes the biochemical activities associatted with Fat l p. J Biol Chem 277: 31062-31071, 2002.

66. Berk PD, Wada F, Horio Y, Potter BJ, Sorrentino D, Zhou SL, Isola LM, Stump D, Kiang CL and Thung S. Plasma membrane fatty acid-binding protein and mitochondrial glutamic oxaloacetic transaminase of rat liver are related. Proc Natl Acad Sci U S A 87: 3484-3488, 1990.

67. Zhou SL, Stump D, Sorrentino D, Potter BJ and Berk PD. Adipocyte differentiation of 3T3L1 cells involves augmented expression of a 43-kDa plasma membrane fatty acid-binding protein.

J Biol Chem 267: 14456-14461, 1992.

68. Zhou SL, Stump D, Isola $\mathbf{L}$ and Berk PD. Constitutive expression of a saturable transport system for non-esterified fatty acids in Xenopus laevis oocytes. Biochem J 297: 315-319, 1994. 
69. Turcotte LP, Sriwastava AK and Chasson JL. Fasting increases plasma membrane fatty acidbinding protein ( $\mathrm{AABP}(\mathrm{PM})$ in red skeletal muscle. Mol Cell Biochem 166: $153-158.1997$.

70. Kiens B, Kristiansen $\mathbf{S}$, Jensen P, Richter EA and Turcotte LP. Membrane associated fatty acid binding protein (FABPpm) in human skeletal muscle is increased by endurance training. Biochem Biophys Res Commisn 231: 463-465, 1997.

71. Luiken JJ, Arumugam Y, Dyck DJ, Bell RC, Pelsers MM, Turcotte LP, Tandon NN, Glatz IF and Bonen A. Increased rates of fatty acid uptake and plasmalemmal fatty acid transporters in obese Zucker rats I Biol Chem 276: 40567-40573, 2001.

72. Berk PD, Zhou SL, Kiang CL, Stump D, Bradbury M and Isola LM. Uptake of long chain free fatty acids is selectively up-regulated in adipocytes of Zucker rats with genetic obesity and noninsulin-dependent diabetes mellitus. J Biol Chen 272: 8830-8835, 1997.

73. Glatz JF, wan Niteuwenhoven FA, Luiken J.I, Schaap FG and van der Vusse GJ. Role of membrane-associated and cytoplasmic fatty acid-binding proteins in cellular fatty acid metabolism. Prostaglandins Leukot Essent Fatry Acids 57: 373-378, 1997.

74. Ibrahimi A, Bonen A, Blinn WD, Hajri T, $\mathbf{L i} X$, Zhong $K$, Cameron $R$ and Abumrad NA. Muscle-specific overexpression of FAT/CD36 enhances fatty acid oxidation by contracting muscle, reduces plasma triglycerides and fatty acids, and increases plasma glucose and insulin. $J$ Biol Chem 274: $26761-26766,1999$.

75. Febbraio M, Abumrad NA, Hajjar DP, Sharma K, Cheng W, Pearce SF and Silverstein RL. A null mutation in murine CD36 reveals an important role in fatty acid and lipoprotein metabolism.

J Biol Chem 274: 19055-19062, 1999.

76. Coburn CT, Knapp FF, Jr., Febbraio M, Beets AL, Silverstein RL and Abumrad NA. Defective uptake and utilization of long chain fatty acids in muscle and adipose tissues of CD36 knockout mice: J Biol Chem 275: 32523-32529, 2000.

77. Reaven GM and Chang H. Relationship between blood pressure, plasma insulin and triglyceride concentration, and insulin action in spontaneous hypertensive and Wistar-Kyoto rats. Am J Hypertens 4: $34-38,1991$.

78. Reaven GM. Insulin resistance, hyperinsulinemia, hypertriglyceridemia, and hypertension. Parallels between human disease and radent models. Diabetes Care 14: 195-202, 1994.

79. Reaven GM, Chang H, Hoffman BB and Azhar S. Resistance to insulin-stimulated glucose uptake in adipocytes isolated from spontaneously hypertensive rats. Diabetes 38: 1155-11160, 1989.

80. Mondon CE and Reaven GM. Evidence of abnormalities of insulin metabolism in rats with spontaneous hypertension. Metabolism 37: 303-305, 1988.

81. Horl WH, Schaefer RM and Heidland A. Abnormalities of carbohydrate metabolism in spontaneously hypertensive rats. Klin Wochenschr 66: 924-927, 1988. 
82. Rao RH. Insulin resistance in spontaneously hypertensive rats. Difference in unterpretation based on insulin infusion rate or on plasma insulin in glucose clamp studies. Diabetes 42: 1364-1371, 1993.

83. Aitman TJ, Gotoda T, Evans AL, Imrie H, Heath KE, Trembling PM, Truman H, Wallace CA, Rahman A, Dore C, Flint J, Kren V, Zidek V, Kurtz TW, Pravenec M and Scett J. Quantitative trait loci for cellular defects in glucose and fatty acid metabolism in hypertensive rats. Nat Gentet 16: 197-201, 1997.

84. Aitman TJ, Glazier AM, Wallace CA, Cooper LD, Norsworthy PJ, Wahid FN, Al-Majali KM, Trembling PM, Mann CJ, Shoulders CC, Graf D, St Lezin E, Kurtz TW, Kren V, Pravenec M, Ibrahimi A, Abumrad NA, Stanton LW and Scott J. Identification of Cd 36 (Fat) as an insulin-resistance gene causing defective fatty acid and glucose metabolism in hypertensive rats. Nat Genet 21: 76-83, 1999.

85. Gotoda T, Lizuka Y, Kato N, Osuga J, Bihoreau MT, Murakami T, Yamori Y, Shimano H, Ishibashi S and Yamada N. Absence of Cd36 mutation in the original spontaneously hypertensive rats with insulin resistance. Nat Genet 22: 226-228, 1999.

86. Collison M, Glazier AM, Graham D, Morton JJ, Dominiczak MH, Aitman TJ, Connell JM, Gould GW and Dominiczak AF. Cd36 and molecular mechanisms of insulin resistance in the stroke-prone spontaneously hypertensive rat. Diabetes 49:2222-2226, 2000.

87. Pravenec M., Zidek V, Simakova M, Kren V, Krenova D, Horky K, Jachymova M, Mikova B, Kaxdova L, Aütman TJ, Churchill PC, Webb RC, Hingarh NH, Yang Y, Wang JM, Lezin EM and Kurtz TW. Genetics of $\mathrm{Cd} 36$ and the clustering of multiple cardiovascular risk factors in spontaneous hypertension. J Clin Invest 103: 1651-1657, 1999.

88. Pravenec M, Landa V, Zidek V, Musilowa A, Kren V, Kazdova L, Aitman TJ, Glazier AM, Ibrahimi A, Albumrad NA, Qi N, Wang JM, St Lezin EM and Kurtz TW. Transgenic rescue of defective $\mathrm{Cd} 36$ ameliorates insulin resistance in spontaneously hypertensive rats. Nat Genet 27: 156 $158,2001$.

89. Hajri T, Ibrahimi A, Coburn CT, Knapp FF, Jr., Kurtz T, Pravenec M and Abumrad NA. Defective fatty acid uptake in the spontaneously hypertensive rat is a primary determinant of altered glucose metabolism, hyperinsulinemia, and myocardial hypertrophy. I Biol Chem 276: 23661-23666, 2001 .

90. Lee K, Godeau B, Fromont P, Plonquet A, Debili N, Bachir D, Reviron D, Gourin J, Fernandez E, Galacteros F and Bierling P. CD36 deficiency is frequent and can caluse platelet immunization in Africans. Transfusion 39: 873-879, 1999.

91. Tanaka T, Nakata T, Oka T, Ogawa T, Okamoto F, Kusaka Y, Sohmiya K, Shimamoto K and Itakura $\mathbf{K}$. Defect in human myocardial long-chain fatty acid uptake is caused by FAT/CD36 mutations. J Lipid Res 42: 751-759, 2001. 
92. Okamoto $\mathbf{F}$, Tamaka T, Sohmiya $\mathrm{K}$ and Kawamura $\mathrm{K}$ CD36 abnormality and impaired myocardial long-chain fatty acid uptake in patients with hypertrophic cardiomyopathy. Jpn Circ J 62 : 499-504, 1998.

93. Hahn RT, Febbraio M, Bella IN and Silverstein RL. The role of CD36 in cardiac size and function: a possible murine model of dilated cardiomyopathy. Circulation 98: 1-236, Supplement I, 1998.

94. Poirier H, Degrace P, Niot I, Bernard A and Besnard P. Localization and regulation of the putative membrane fatty-acid transporter (FAT) in the small intestine. Comparison with fatty acidbinding proteins (FABP). Eur J Biochem 238: 368-373, 1996,

95. Spitsberg VL, Matitashvili $\mathbf{E}$ and Gorewit RC. Association and coexpression of fatty-acidbinding protein and glycoprotein CD36 in the bovine mammary gland. Eur J Biachem 230: 872-878, 1995.

96. Sfeir Z, Ibrahimi A, Amri E, Grimaldi P and Abumrad N. Regulation of FAT/CD36 gene expression: further evidence in support of a role of the protein in fatty acid binding/transport. Prostaglandins Leukot Essent Fatty Acids 57: 17-21, 1997.

97. Amri EZ, Ailhaud $G$ and Grimaldi P. Regulation of adipose cell differentiation. II. Kinetics of induction of the aP2 gene by fatty acids and modulation by dexamethasone. $J$ Lipid Res 32: 1457 $1463,1991$.

98. Amri EZ, Bonino F, Ailhaud G, Abumrad NA and Grimaldi PA. Cloning of a protein that mediates transcriptional effects of fatty acids in preadipocytes. Homology to peroxisome proliferatoractivated receptors. J Biol Chem 270: 2367-2371, 1995.

99. Teboul L, Febbraio M, Gaillard D, Amri EZ, Silverstein $R$ and Grimaldi PA. Structural and functional characterization of the mouse fatty acid translocase promoter: activation during adipose differentiation. Biochem $J$ 360: 305-312, 2001 .

100. Leone TC, Weinheimer CJ and Kelly DP. A critical role for the peroxisome proliferatoractivated receptor alpha (PPARalpha) in the cellular fasting response: the PPARalpha-null mouse as a model of fatty acid oxildation disorders. Proc Natl Acad Sici U S A 96: 7473-7478, 1999.

101. Finck BN, Lehman JJ, Leone TC, Welch MJ, Bennett MJ, Kovacs A, Han X, Gross RW, Kozak R, Lopaschuk GD and Kelly DP. The cardiac phenotype induced by PPARalpha overexpression mimics that caused by diabetes mellitus. J Clin Invest 109: 1.21-130, 2002.

102. Sato O, Kuriki C, Fukui $\mathbf{Y}$ and Motojima $\mathbf{K}$. Dual promoter structure of mouse and human FAT/CD36 genes and unique transcriptional activation by PPAR alpha and gamma Ligands. $J$ Biol Chem 277: 15703-15711, 2002.

103. Griffin E, Re A, Hamel N, Fu C, Bush H, McCaffrey $T$ and Asch AS. A link between diabetes and atherosclerosis: Glucose regulates expression of CD36 at the level of translation. Nat Med 7: 840-846, 2001 . 
104. Ashe MP, De Long SK and Sachs AB. Glucose depletion rapidly inhibits translation initiation in yeast. Mol Biol Cell Ill: $833-848,2000$.

105. Skelly RH, Schuppin GT, Ishihara H, Oka $\mathbf{Y}$ and Rhodes CI. Glucose-regujated translational control of proinsulin biosynthesis with that of the proinsulin endopeptidases $\mathrm{PC} 2$ and $\mathrm{PC} 3$ in the insulin-producing MIN6 cell line. Diabetes 45: 37-43, 1996.

106. Iynedjian PB, Pilot PR, Nouspikel T, Milburn JL, Quaade C, Hughes S, Uda C and Newgard CB. Differential expression and regulation of the glucokinase gene in liver and islets of Langerhans. Proc Nall Acad Sci U S A 86: 7838-7842, 1989.

107. Semenkovich CF, Coleman T and Fiedorek FT, Jr. Human fatty acid synthase mRNA: tissue distribution, genetic mapping, and kinetics of decay after glucose deprivation. $J$ Lipid Res 36: 1507$1521,1995$.

108. Bonen A, Luiken JJ, Arumugam Y, Glatz JF and Tandon NN. Acute regulation of fatty acid uptake involves the cellular redistribution of fatty acid translocase. $J$ Biol Chem 275: 14501-14508, 2000.

109. Goodyear LI and Kahn BB. Exercise, glucose transport, and insulin sensitivity. Annu Rev Med 49: $235-261,1998$.

110. Luiken JJ, Dyck DJ, Han XX, Tandon NN, Arumugam Y, Glatz JF and Bonen A. Insulin induces the translocation of the fatty acid transporter FAT/CD36 to the plasma membrane. Am $J$ Physiol Endocrinol Metab 282: E491-E495, 2002.

111. Asch AS, Liu I, Briccetti FM, Barnwell JW, Kwakye-Berko F, Dokun A, Goldberger J and Pernambuco M. Analysis of $\mathrm{CD} 36$ binding domains: ligand specificity controlled by dephosphorylation of an ectodomain. Science 262: 1436-1440, 1993.

112. Huang MM, Bolen JB, Barnwell JW, Shattil SJ and Brugge JS. Membrane glycoprotein IV (CD36) is physically associated with the Fyn, Lyn, and Yes protein-tyrosine kinases in human platelets. Proc Nat Acad Sci U S A 88: 7844-7848, 1991.

113. Abumrad N, Coburn $\mathbf{C}$ and Ibrahimi A. Membrane proteins implicated in long-chatin fatty acid uptake by mammalian cells: CD36, FATP and FABPm. Biochim Biophys Acta 1441: 4-13, 1999. 114. Binas B, Danneberg H, McWhir J, Mullins L and Clark AJ. Requirement for the heart-type fatty acid binding protein in cardiac fatty acid utilization. FASEB J 13: 805-812, 1999. 


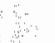




\section{Chapter 3}

\section{Purification, immunochemical}

\section{quantification and localization of fatty acid}

\section{translocase (FAT)/CD36 from \\ rat heart}

J.F.F. Brinkmann, M.M.A.L. Pelsers, F.A. van Nieuwenhoven, G.J. van der Vusse, and J.F.C. Glatz: submitted for publication 


\section{Abstract}

Evidence is accumulating that the heavily glycosylated integral membrane protein fatty acid translocase (FAT/CD36) is involved in the transport of long-chain fatty acids across the sarcolemma of heart muscle cells. The aim of this study was to analyze the distribution between FAT/CD36 present in cardiac myocytes and endothelial cells. We therefore developed a method to purify FAT/CD36 from total rat heart tissue and isolated cardiomyocytes, and used the proteins as standards in an immunochemical assay.

Two steps, chromatography on wheat germ agglutinin-agarose and anionexchange chromatography on Q-Sepharose fast flow, were sufficient for obtaining the protein in a $>95 \%$ pure form. When used to isolate FAT/CD36 from total heart tissue, the FAT/CD36 yield of the method was $9 \%$ and the purification factor was 64 . Purifying FAT/CD36 from isolated cardiomyocytes yielded the same $88 \mathrm{kDa}$ protein band on SDS-PAGE gels and reactivity of this band on western blots was comparable to that of the FAT/CD36 isolated from total hearts.

Quantifying FAT/CD36 contents by western blotting showed that the amounts of FAT/CD36 present in isolated cardiomyocytes $(10 \pm 3 \mu \mathrm{g} / \mathrm{mg}$ protein) and total hearts (14 $\pm \mu \mathrm{g} / \mathrm{mg}$ protein) are of comparable magnitude. Immunofluorescence labeling showed that at least a part of the FAT/CD36 present in the cardiomyocyte is associated with the sarcolemma.

This study established that FAT/CD36 is a relatively abundant protein in the cardiomyocyte. Furthermore, the further developed purification procedure is the first method for isolating FAT/CD36 from rat heart and cardiomyocyte FAT/CD36.

\section{Introduction}

Long-chain fatty acids (FA) are the major source of energy for the heart. The molecular mechanism for the uptake of these compounds by cardiac myocytes, however, is incompletely understood. Some investigators favor diffusion of FA 
through the phospholipid bilayer as the main transsarcolemmal transfer process ${ }^{1-3}$, while others reported data suggesting that the transfer is mediated by proteins 4,5 . Kinetic studies on palmitate uptake by isolated cardiomyocytes indicated that, under physiological conditions, the majority of transsarcolemmal FA transport occurs via a protein mediated mechanism, and only a minor part via diffusion through the phospholipid bilayer ${ }^{6}$. Three distinct proteins have been postulated as membrane FA transporters, and each of these proteins is present on the sarcolemma of cardiomyocytes ${ }^{7,8}$. One of them is fatty acid translocase (FAT/CD36) ${ }^{9,10}$, a heavily glycosylated, $88 \mathrm{kDa}$, integral membrane protein that is identical to CD36 and also known as platelet glycoprotein IV, platelet glycoprotein IIIlb and PAS IV in the earlier literature. The protein has been purified and characterized from various sources, i.e. human platelets ${ }^{11.12}$, human and bovine milk fat globule membranes ${ }^{13,14}$, rat adipocytes ${ }^{15}$ and bovine heart ${ }^{16,17}$.

Studies using immunohistochemical labeling techniques have shown that FAT/CD36 is expressed by capillary endothelial cells in the heart ${ }^{14,18}$. Whether cardiac myocytes express FAT/CD36 has been doubted, because cardiomyocytes were not labelled with FAT/CD36 specific antibodies in these studies ${ }^{18}$. However, several other experiments indicating the presence of FAT/CD36 on the sarcolemma of heart muscle cells have been reported. Firstly, isolated adult rat cardiac myocytes have been found to express the FAT/CD36 mRNA ${ }^{10}$. Secondly, histological autoradiography studies with a sulfo- $N$-succinimidyl derivative of palmitate showed significant labeling of cardiomyocyte cell membranes, while only binding of the fatty acid derivative to FAT/CD36 could be observed by SDS-PAGE ${ }^{17}$.

To enable the quantification of the FAT/CD36 protein, a sensitive immunoassay was recently developed ${ }^{19}$. Using this phage-antibody-based sandwich-type ELISA, the FAT/CD36 contents of rat cardiac and skeletal muscle were found to be of similar magnitude as the respective levels of cytoplasmic hearttype fatty acid-binding protein (H-FABP). This implies that the heart FAT/CD36 content is relatively high, as H-FABP is known to be an abundant protein that is 
involved in the transport of FA in the cytoplasm ${ }^{20}$. It has to be noted, however, that the standard protein that was used in this study was a recombinant, histidine tagged rat FAT/CD36 ((His) $)_{6}$ FAT/CD36) derived from adipose tissue. This protein with a lowered apparent molecular mass ${ }^{21}$ might also have antigenic properties that differ from those of FAT/CD36 in the heart, which implies that the reported FAT/CD36 contents might not reflect the true values.

The main objective of this study was to analyze the distribution of FAT/CD36 between cardiac myocytes and endothelial cells in the heart. Because immortalized endothelial cell lines obtained from adult rat heart show no detectable FAT/CD36 expression ${ }^{19}$, a direct comparison of these cells with cardiomyocytes is not possible. Therefore we used two approaches. The first was to compare the amount of FAT/CD36 that is present in isolated rat cardiomyocytes with the amount that is present in total rat heart tissue. To enable a proper immunochemical quantifation we first purified the protein from isolated cardiomyocytes and compared it to FAT/CD36 isolated from total (blood-free) rat heart tissue. Possible differences in the antigenicity of the cardiomyocyte protein and the protein expressed by other cell-types present in the heart could thereby be identified. A rapid purification protocol was developed, and the purified protein was used as standard in an immunoassay. The second approach was to analyze rat heart tissue sections by using immunofluorescence labeling with a FAT/CD36 specific antibody. The results presented in this study show that FAT/CD36 is an abundant protein in the cardiomyocyte. In addition, to our knowledge, the further developed purification method for FAT/CD36 is the first to be reported for isolating the protein from rat heart and isolated cardiomyocytes. 


\section{Materials and Methods}

WGA-agarose ( $7 \mathrm{mg} / \mathrm{ml}$ settled gel) was obtained from Vector Laboratories Inc. (Burlingame, CA, U.S.A) and Q-Sepharose Fast Flow from Pharmacia Biotech AB (Uppsala, Sweden). Peroxidase-conjugated rabbit anti-mouse IgG P0161 was purchased from DAKO (Glostrup, Denmark). Triton X-100, Triton X-100 reduced and Triton X-114 were obtained from Sigma. Other chemicals used were of analytical grade. Column chromatography was carried out using a Bio Rad (Hercules, CA, U.S.A.) Econo System. SDS-PAGE and protein blotting were carried out using the Mini-Protean II Electrophoresis System from Bio-Rad.

\section{Purification of FAT/CD36}

All purification procedures were carried out at $4^{\circ} \mathrm{C}$ unless mentioned otherwise and all buffers used were adjusted to $\mathrm{pH}$ at room temperature. FAT/CD36 was isolated from both total heart tissue and isolated cardiomyocytes. Total heart tissue was obtained from adult Lewis rats which were fed ad libitum and anaesthetised by i.p. injection of sodium pentobarbital, while heparin was combined with the anaesthetic. Because platelets express a significant amount of FAT/CD $36^{12}$, blood was removed by Langendorff perfusion, where after hearts were stored at $-70^{\circ} \mathrm{C}$ until used. Cardiomyocytes were isolated from adult Lewis rat hearts as described by Luiken et al. ${ }^{6}$.

Total heart tissue samples or cardiomyocytes were homogenized using an Ultra-Turrax homogeniser (IKA Werke, Breisgau, Germany) in 10 volumes (v/w) homogenisation buffer ( $20 \mathrm{mM}$ Tris- $\mathrm{HCl}, 1 \mathrm{mM}$ phenylmethylsulfonyl fluoride, 1 mM EDTA, 1 mM EGTA, 2 mM B-mercaptoethanol and $1 \%$ Triton X-1 14 pH 7.4). The homogenates were then sonicated four times for $15 \mathrm{~s}$ (Soniprep 150; Sanyo Gallenkamp PLC, Leicester, U.K.; amplitude $12 \mu \mathrm{m}$ ) and centrifuged at $105,000 \mathrm{~g}$ for $60 \mathrm{~min}$ to remove the non-solubilized material.

Hydrophobic membrane proteins were extracted from the supernatant by phase partitioning into Triton X-114 (14). For this, the supernatant was cooled to $0^{\circ} \mathrm{C}$, 
warmed at $37^{\circ} \mathrm{C}$ for $10 \mathrm{~min}$ followed by centrifugation at $1,800 \mathrm{~g}$ for $5 \mathrm{~min}$. The aqueous phase that was formed on top of the detergent phase was removed, $1 \%$ Triton $\mathrm{X}-114$ was added and the extraction procedure was repeated. Both detergent phases then were pooled and diluted 1:4 with $10 \mathrm{mM}$ Tris- $\mathrm{HCl}$, pH 7.4.

The diluted extracts were directly loaded onto a WGA-agarose column $(0.7 \times 10$ $\mathrm{cm}$ ) that had been equilibrated with $20 \mathrm{mM}$ Tris- $\mathrm{HCl}, 0.1 \%$ Triton X-100 pH 7.4 (TT buffer) and was operated at a flow rate of $0.5 \mathrm{ml} / \mathrm{min}$. The column was washed with $1 \mathrm{M} \mathrm{NaCl}$ in TT buffer to remove non-specifically bound protein followed by extensive washing with TT buffer. Triton X-100 reduced was added to the latter TT buffer and to the buffers used during subsequent purification steps to diminish background $A_{280}$. Bound proteins were eluted with $250 \mathrm{mM} \mathrm{N}$-acetyl-Dglucosamine (nAcGlc) in TT buffer ( 20 column volumes).

The protein fraction eluted from the WGA-agarose column using nAcGlc was directly loaded onto a Q-Sepharose Fast Flow column $(0.7 \times 10)$ that had been equilibrated with TT buffer and was operated at a flow rate of $0.5 \mathrm{ml} / \mathrm{min}$. The column was washed with TT buffer until absorbance at $280 \mathrm{~nm}$ had dropped and stabilized indicating that all non-binding proteins and sugar (nAcGlc) had been removed. Thereafter, bound protein was eluted with 20 column volumes of 150 $\mathrm{mM} \mathrm{NaCl}$ in TT buffer and $3 \mathrm{ml}$ fractions were collected. FAT/CD36 containing fractions were pooled and $1 \mathrm{mM}$ of both EDTA and EGTA were added to prevent proteolysis. This preparation was stored at $-20^{\circ} \mathrm{C}$ and used for further measurements. The Q-Sepharose column was recycled by washing with $2 \mathrm{M} \mathrm{NaCl}$.

\section{Immunohistochenical detection of FAT/CD36}

Immunofluorescence and immunogold labeling analysis were carried out using a monoclonal antibody that was raised against non-denatured human FAT/CD36 (Mol31.4, a gift from Dr. N. N. Tandon, Otsuka America Pharmaceutical Inc., Rockville, MD). Human heart tissue samples were obtained from autopsie cases at the Academic Hospital Maastricht (Dept. Pathology, Maastricht, the Netherlands). For immunofluorescence labeling, hearts of anaesthetized adult male Lewis rats were 
quickly excised, small fragments of the tissue were mounted on cork and frozen in isopentane that was cooled with liquid nitrogen. Sections of $4-8 \mu \mathrm{m}$ were cut using a cryostat. Sections were air-dried and incubated with the monoclonal antibody 131.4 (5 $\mu \mathrm{g} / \mathrm{ml}$ in PBS $/ 1 \%$ BSA) at room temp for $60 \mathrm{~min}$. After washing three times with PBS/0.1\% BSA, sections were incubated with Rabbit anti Mouse lgG that was conjugated with FITC. Control sections were treated identical but with the omission of 131.4 antibody.

\section{Quantification procedures}

Western blotting using a monoclonal antibody raised against SDS-denatured human FAT/CD36 (Mo25, a gift from Dr. N. N Tandon, Otsuka America Pharmaceutical Inc., Rockville, MD) ${ }^{22}$ was carried out according to the procedure described by Van Nieuwenhoven et al. ${ }^{21}$, except that blots were incubated in PBS containing $1 \%$ non-fat dry milk instead of BSA to avoid non-specific binding of antibodies. Detection of peroxidase activity on western blots intended for quantitative measurements was carried out using SuperSignal West Dura Extended Duration Substrate (Pierce, Rockford, IL, U.S.A.). Chemiluminescence was directly measured using a Bio Rad Fluor-S Multilmager (Hercules, CA, U.S.A.) and immunoreactive FAT/CD36 bands were quantified using the Bio Rad Quantity One software.

FAT/CD36 content of blood-free total heart tissue homogenate and of isolated cardiac myocyte samples were determined by comparing the immunoreactive FAT/CD36 band that was present in these samples with a linear standard curve (Fig.1) obtained by analyzing the signal of different amounts (between 50 and 700 ng) of the purified rat heart protein. FAT/CD36 contents of 4 total heart and 4 isolated cardiomyocyte samples were determined and for each sample 3 different amounts of protein were analyzed. Because variation of the quantification procedure was larger than the variation between different samples, 


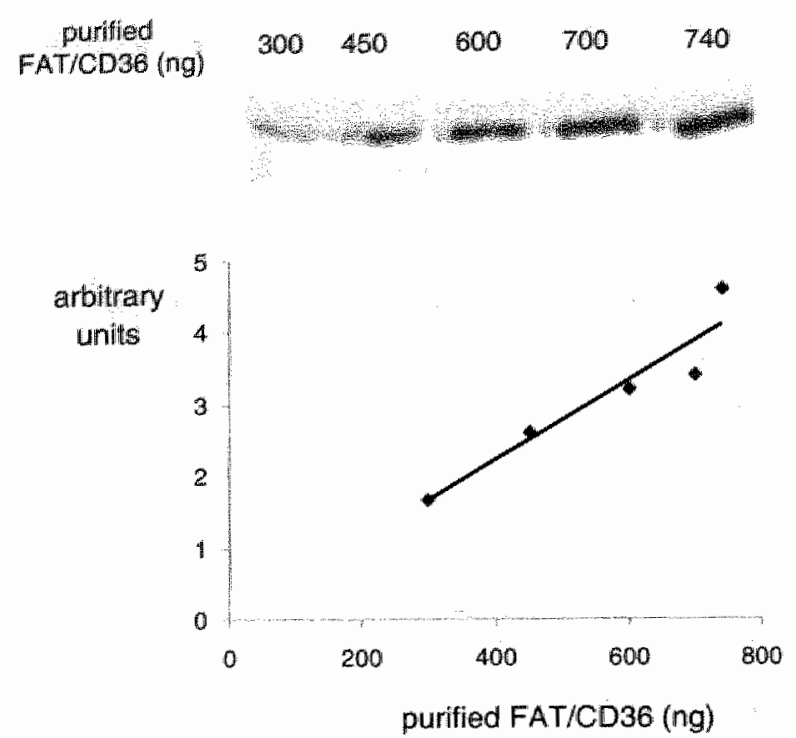

Figure 1: Standard curve for quantification experiments using western blot analysis. This figure represents a typical example of a standard curve that was used to quantify FAT contents or rat heart and isolated cardionyocyte samples. Different amounts of the purified rat heart FAT were separated by $9 \%$ SDS-polyacrylamide gel electrophoresis under reducing conditions and detected by western bloning using a monoclonal anibody raised against SDS-denatured human CD36. Chemiluminescence was directly measured and the signals shown in the upper panel were quantified using Quantity One softhware (Bio Rad).

all total heart or cardiomyocyte data were pooled (which resulted in $n=12$ ) and the average FAT/CD36 content and standard deviation were determined. A similar western blot analysis with the recombinant (His) ${ }_{6}$-tagged FAT/CD36 instead of the isolated rat heart FAT/CD36 was carried out as previously described ${ }^{21}$. FAT/CD36 content of 2 blood-free total heart homogenate and 2 isolated cardiomyocyte samples were determined in triplicate, all homogenate or cardiomyocyte data were pooled and analyzed.

\section{Other analytical techniques}

Total protein content of tissue or cell homogenates and fractions obtained during the purification of FAT/CD36 was determined with the micro-bicinchoninic acid kit (Protein Assay No. 23235; Pierce, Rockford, IL, U.S.A.). Before assay, the 
proteins in cell or tissue homogenates were solubilized by addition of $1 \mathrm{M} \mathrm{NaOH}$ (final concentration), incubating $60 \mathrm{~min}$ at $37^{\circ} \mathrm{C}$ and centrifuging for $1 \mathrm{~min}$ to remove cell debris. $\mathrm{NaOH}$ concentration in the final assay mixture was $<25 \mathrm{mM}$. Fractions obtained during purification and the isolated FAT/CD36 preparations were analyzed on protein content after precipitation with $0.0125 \%$ sodium deoxycholate and $5.8 \%$ trichloro-acetic acid. The pellets were directly resuspended in the bicinchoninic acid reagent of the micro-bicinchoninic acid kit.

SDS-PAGE was carried out using the discontinuous system described by Laemmli ${ }^{23}$. Molecular weight standards were provided by the Pharmacia Low Molecular Weight Electrophoresis Calibration Kit (Pharmacia Biotech AB, Uppsala, Sweden) and SDS-PAGE gels were stained with silver using the procedure that has been described by Marshall ${ }^{24}$.

\section{Results and Discussion}

Using a recombinant (His) $)_{6}$-tagged FAT/CD36 as a standard protein for ELISA measurements we have previously found remarkably high levels of FAT/CD36 to be present in isolated cardiac myocytes ${ }^{19}$. The (His) ${ }_{6}$-FAT/CD36 used was derived from rat adipose tissue and had been brought to expression in SF9 insect cells. By SDS-PAGE its molecular mass has been found lower than that of the heart protein, probably due to cell type-specific glycosylation ${ }^{21}$. In order to exclude possible distortions that might be caused by antigenic differences and to ensure the quantification of $F A T / C D 36$ using a representative standard, we decided to purify FAT/CD36 from both total rat heart tissue and from isolated cardiomyocytes.

\section{Purification of FAT/CD36}

Several relatively simple and straightforward procedures for the isolation of FAT/CD36 from human platelets ${ }^{11,12,25}$, milk fat globule membranes (MFGM) 13,14,26 and adipocytes ${ }^{15}$ have been developed. In contrast, reported procedures for the isolation of FAT/CD36 from bovine heart appears to be more difficult ${ }^{17}$, or made use of immunoaffinity chromatography ${ }^{16}$. Only commercial antibodies were 
avallable in sufficient amounts and the suitability of these antibodies for isolating the rat heart protein was uncertain because they are raised against the human platelet derived FAT/CD36. Therefore, immunoaffinity chromatography did not seem to be a good choice to start with. The procedure described by Tanaka and Kawamura ${ }^{17}$ used sequentially hydroxyapatite, DE-32, Concanavalin A- (ConA-) Sepharose and DEAE-Sepharose chromatography to purify the bovine heart FAT/CD36. We started the development of our isolation method by testing lectin affinity chromatography on ConA-Sepharose and anion exchange chromatography based on this protocol. In addition, we tested the method phase partitioning into Triton X-114, which is often included in FAT/CD36 (and other integral membrane protein) purification protocols 11-16,25,27, and the usefulness of cholesteryl hemisuccinate-agarose, a material which was used by Kronenberg et al. ${ }^{25}$ in a twostep platelet FAT/CD36 purification method.

Detergent phase partitioning and anion exchange chromatography on QSepharose Fast Flow proved to be valuable for isolating the rat heart protein. Chromatography on cholesteryl hemisuccinate-agarose according to the method of Kronenberg et al. did not result in a clear FAT/CD36 protein band eluting from the column and no further experiments were carried out using this material. The rat heart FAT/CD36 appeared to bind to the column strongly, as was also the case when the rat heart FAT/CD36 was applied to ConA-Sepharose. Using this material according to the procedure described by Tanaka and Kawamura ${ }^{17}$, only a minor part of the FAT/CD36 applied to the column was eluted. Incubating the ConASepharose in elution buffer overnight followed by washing repeatedly resulted in a somewhat higher FAT/CD36 yield, and both switching from methyl- $\alpha-D-$ glucopyranoside to methyl- $\alpha$-D-mannopyranoside as eluting agent and increasing the eluens concentration did not improve the results. Replacing ConA-Sepharose by WGA-agarose yielded a useful purification step.

Combining Triton X-114 phase partitioning, chromatography on WGA-agarose, and Q-Sepharose anion-exchange chromatography resulted in a method for 
obtaining FAT/CD36 from rat heart and isolated cardiomyocytes in a $>95 \%$ pure form (Fig. 2). With this purification method FAT/CD36 was efficiently solubilized using Triton X-114 and sonication. By western blotting no clear FAT/CD36 signal could be detected in non-solibilized debris separated from the homogenate by ultracentrifugation. The next step, phase partitioning into Triton X-114, resulted in a FAT/CD36 enriched fraction, as FAT/CD36 partitioned most favorably in the hydrophobic detergent phase. WGA-agarose showed to be a well suited material for the next purification step. Diluted Triton X-114 detergent phase could be loaded directly onto a WGA-agarose column, and washing with $\mathrm{NaCl}$ removed non-specifically bound proteins from the column effectively. Most of the FAT/CD36 remained bound to the column and was eluted with $250 \mathrm{mM} \mathrm{N}$-acetylD-glucosamine (Fig. 2A, lane 3). Raising the sugar concentration to $500 \mathrm{mM}$ did not appear to elute a larger FAT/CD36 fraction, and a minor amount could only be eluted by lowering the $\mathrm{pH}$ using $250 \mathrm{mM} \mathrm{N}$-acetyl-D-glucosamine in $10 \mathrm{mM}$ Trisacetate buffer $\mathrm{pH}$ 4.5. The latter fraction was not used for further purification. Anion-exchange chromatography at $\mathrm{pH} 7.4$ was an efficient method for removing the contaminating proteins that were still present in the WGA-agarose eluate. Pilot experiments using the Q-Sepharose column had shown that FAT/CD36 eluted from the column between 50 and $150 \mathrm{mM} \mathrm{NaCl}$, and that a step-wise gradient of respectively 50,100 and $150 \mathrm{mM} \mathrm{NaCl}$ eluted FAT/CD36 of equal purity. Furthermore, applying a linear salt-gradient did not improve this purity and resulted in a low, broad protein peak (results not shown).

In the final purification procedure FAT/CD36 was therefore eluted from the QSepharose column by a step-wise raise to $150 \mathrm{mM} \mathrm{NaCl}$ only, in order to obtain a FAT/CD36 preparation as concentrated as possible. FAT/CD36 eluted from the QSepharose column in a $>95 \%$ pure form as judged on silver stained SDS-PAGE gels (Fig. 2A, lane 5 and 6 ). Contaminating protein was eluted with the higher salt 
A

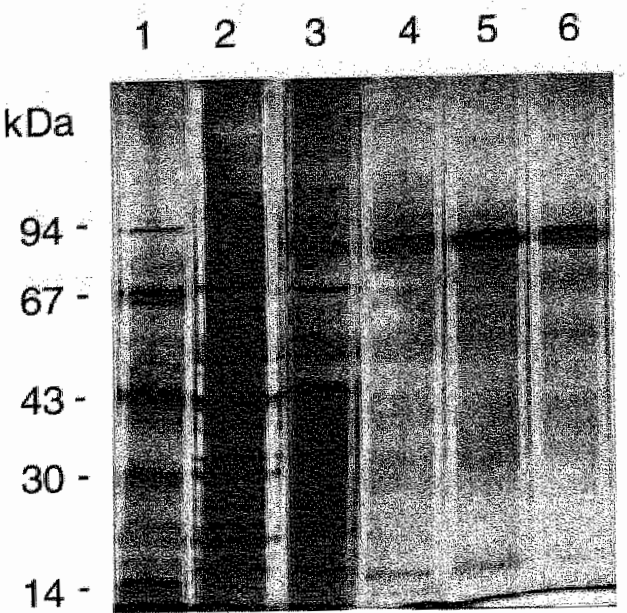

B

$123 \quad 4 \quad 5$

Figure 2: Purification of FAT/CD36 from perfused rat hearis and isolated cardiompocytes. Proteins were separated by $9 \%$ SDS-polyacrylamide gel electrophoresis ander reducing conditions and stained with silver (panel A) or detected by western bloting (panel B).

Panel A: Lane I, LMW warker; Lane 2, homogenized heart; Lane 3, WGA-agarose eluate; Lane 4, FAT/CD 36 purified fram total heart without including Triton X-114 phase partitioning: Lane 5 , FAT/CD 36 purified from isolated cardiomyocytes; Lane 6. FAT/CD36 purified from total heart.

Panel B: Lane 1, homogenized heart; Lane 2, FAT/CD36 purified from total heart; Lane 3-5, analysis of $300 \mu g$ protein from the different isolated FAT/CD36 preparations; Lane 3, FAT/CD36 purffed from total hear without including Triton X-114 phase partitioning; Lane 4, FAT/CD36 purified from isolated cardiomyocyles; Lane 5. FAT/CD36 purified from total heart.

concentration of $200 \mathrm{mM}$ and a minor amount of FAT/CD36 did not bind to the QSepharose column.

Using the procedure described above FAT/CD36 was isolated from both total, blood-free rat heart and from isolated cardiomyocytes. Purification from total rat heart resulted in a FAT/CD36 yield of approximately $5 \%$ (as determined by western analysis) and $0.2 \mathrm{mg}$ of protein was isolated from $250 \mathrm{mg}$ of total heart protein. 
Applying the procedure on homogenized cardionyocytes yielded $11 \%$ of the FAT/CD36 that was initially present in the pure form (as determined by western analysis). Starting with $190 \mathrm{mg}$ of cardiomyocyte protein, $0.2 \mathrm{mg}$ protein was present in the pure FAT/CD36 preparation. Both preparations contained FAT/CD36 in a $>95 \%$ pure form as judged on silver stained SDS-PAGE gels (Fig. $2 \mathrm{~A}$, lane 5 and 6 ), and both preparations contained the same $88 \mathrm{kDa}$ immunoreactive FAT/CD36 band. The antigenicity of the two purified FAT/CD36 preparations was comparable as determined by western blotting (Fig 2B, lane 4-5).

The yield of our purification method appears to be quite acceptable. However, a proper comparison with other FAT/CD36 isolation methods is not possible, as FAT/CD36 has not been quantified in reported procedures.

\section{Further improvement of the purification procedure}

A critical step in the purification protocol was the Triton X-114 detergent phase partitioning step, because warming the extract, which is required to obtain phase separation, resulted in some aggregate formation. The aggregate was clearly visible as a whitish band that was present in the detergent phase after centrifuging, and might be the result of using a total heart homogenate instead of a crude membrane extract as starting material. Diluting the Triton phase for the next purification step yielded a turbid solution and the aggregate could only be removed by incorporating an additional centrifugation step. Western analysis of the pellet that was herewith obtained showed that a significant amount of FAT/CD36 was present in the aggregate. Both diluting the homogenate that was used for the isolation (to a 5 instead of a 10\% homogenate) and adding a higher amount of Triton X-114 before starting the phase separation procedure (up to 5 instead of $1 \%$ Triton X-114) did not prevent aggregate formation. Therefore we also isolated FAT/CD36 from total rat heart tissue without including the phase partitioning step. Triton $\mathrm{X}-114(1 \%)$ in the homogenisation buffer was replaced by $2 \%$ Triton X-100 and the extract 
Chapter 3

Table 1. Purification of FAT/CD 36 frow isclated blood-free gat heart

\begin{tabular}{|c|c|c|c|c|c|}
\hline $\begin{array}{l}\text { Purification } \\
\text { step }\end{array}$ & $\begin{array}{l}\text { Protein } \\
\text { (mig) }\end{array}$ & $\begin{array}{c}\text { FAT/CD36 } \\
\text { (mg) }\end{array}$ & $\begin{array}{c}\text { (FAT/CD 36)/ } \\
\text { protein } \\
(\mu \mathrm{g} / \mathrm{mg})\end{array}$ & $\begin{array}{l}\text { Purification } \\
\text { factor }\end{array}$ & $\begin{array}{c}\text { FAT/CD36 } \\
\text { yield } \\
(\%)\end{array}$ \\
\hline Heart homogenate & 210.8 & 3.3 & 15.7 & 1 & 100 \\
\hline WGA-agarose & 29.2 & 2.8 & 95.9 & 6 & 85 \\
\hline Q-Sepharose & 0.3 & 0.3 & 1000 & 64 & 9 \\
\hline
\end{tabular}

1): Amounts of FAT/CD 36 were determined by western blotting using the purified FAT/CD36 as siandard

after ultracentrifugation was directly loaded onto the WGA-agarose column. This isolation procedure also resulted in a $>95 \%$ pure FAT/CD36 preparation (Fig. $2 \mathrm{~A}$, lane 3), the protein was purified 64 times and FAT/CD36 yield was 9\% (Table 1). The antigenicity of the preparation towards the FAT/CD36 specific antibody was comparable to those of the other two isolated FAT/CD36 preparations (Fig. 2B, lane 3). Because exclusion of the Triton X-114 phase partitioning step does result in a lowered purity of the finally obtained preparation, we prefer this second method.

\section{FAT/CD36 content of the rat heart and cardiac myocyte}

Though several experiments indicated that FAT/CD36 is present on the sarcolemma of heart muscle cells ${ }^{10,17}$, immunohistochemical labeling studies with a FAT/CD36 specific antibody only stained capillary endothelial cells and not the myocytes in the heart. Hence, FAT/CD36 expression by the cardiomyocyte has been doubted ${ }^{14,18}$. Immortalized endothelial cell lines obtained from adult rat heart show no detectable FAT/CD36 expression on both the protein and the mRNA level, which might be due to culturing these cells ${ }^{10,19}$. To analyze the distribution of FAT/CD36 in the rat heart, a direct comparison of these cells with isolated cardiomyocytes is thus not possible. 
Therefore, we first determined FAT/CD36 protein contents of total heart tissue and isolated cardiomyocyte samples by western blot analysis using the purified rat heart FAT/CD36 as standard. As mentioned above, FAT/CD36 purified from total hearts showed both the same apparent molecular mass on SDS-PAGE gel and the same antigenicity on western blots as FAT/CD36 purified from isolated cardiomyocytes (Fig. 2B). Deviations due to possible differences between cardiomyocyte FAT/CD36 and FAT/CD36 that is expressed by other cellitypes present in the heart could therefore be excluded. In Table 2 is shown that isolated cardiomyocytes were found to contain FAT/CD36 in an amount that is of comparable order of magnitude as the amount that is present in total (perfused) rat heart.

Table 2: Quantification of FAT/CD36 in total heart tissue and isolated cardiomyocytes

\begin{tabular}{lcc}
\hline & \multicolumn{2}{c}{ FAT/CD36 content $(\mu \mathrm{g} / \mathrm{mg}$ protein) } \\
\cline { 2 - 3 } Origin & \multicolumn{2}{c}{ assay standard } \\
\hline Total heart & Purified FAT/CD36 & (His) 6 -FAT/CD36 \\
Cardiomyocytes & $14 \pm 4$ & $11 \pm 3$ \\
\hline
\end{tabular}

FAT/CD36 contents of 4 respectively 2 perfused rat heart homogenate and cardiomyocyle samples

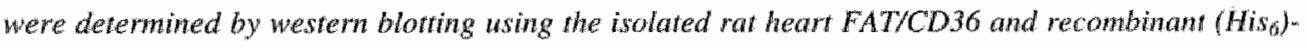
FAT/CD 36 as standards. Data are expressed in $\mu \mathrm{g}$ per mg of total protein and represent man $t S . D$

A similar western blotting procedure using the recombinant (His) 6 - FAT/CD 36 was carried out to verify whether this protein is a representative standard, and this yielded FAT/CD36 amounts very similar to those found using the isolated FAT/CD36 preparations (Table 2). These values are significantly higher than those previously reported $(2.9 \pm 0.4$ and $3.1 \pm 1.2 \mu \mathrm{g}$ FAT/CD36/mg protein for isolated cardiomyocytes and perfused total rat heart respectively) ${ }^{19}$ which were determined by using an ELISA method. The fact that the previously reported rat cardiomyocyte and heart FAT/CD36 contents are lower that those found in the 
present study can be explained by the use of different antibodies. The first were determined using an ELISA nethod with Mo131.4 as a catcher antibody, and this is a monoclonal antibody that recognizes the native FAT/CD36 only. The present study used Mo25, and this monoclonal antibody recognizes only the denatured FAT/CD $36^{22}$. Recognition of the denatured protein may be more complete. In this study we used western analysis instead of the ELISA method to quantify FAT/CD36 levels, because, in contrast to the reactivity on western blots, the isolated FAT/CD36 preparations showed a highly variable reactivity during ELISA analysis. This is probably due to conformational differences.

\section{Immunohistochemical studies of FAT/CD36 in the rat heart}

The second approach to investigate cardiomyocyte FAT/CD36 expression in this study was to make use of immunohistochemistry. In contrast to the studies of both the bovine and the mouse heart that have been reported by Greenwalt et al. ${ }^{14,18}$, immunofluorescence labeling of fixed rat heart tissue sections with a FAT/CD36 specific antibody resulted in an intense and specific staining of the cardiomyocte sarcolemma (Fig. 3). For this analysis, we used a monoclonal antibody that had been raised against FAT/CD36 purified from human platelets ${ }^{22}$. The same experiment was therefore also carried out on fixed human heart tissue samples to serve as an extra control. The staining pattern of the human heart was fully comparable to that of the rat heart (Fig. 3).

\section{Conchinding remarks}

The data in this study establish that FAT/CD36 is an abundant protein in the cardiomyocyte. First, the protein could be purified from isolated cardiomyocytes in a significant amount. Secondly, the amounts of FAT/CD36 that are present in the rat cardiomyocyte and total heart are of comparable magnitude, and, furthermore, these amounts are also comparable to the H-FABP content of the heart $\left(5.7 \pm 1.1 \mathrm{mg} / \mathrm{g}\right.$ of protein, $\left.{ }^{19}\right)$. 
H-FABP is known to be an abundant protein in the heart, and its levels amount to circa $1.4 \%$ of the total cardiomyocyte protein pool ${ }^{28}$. Immunoflurescence labeling confirmed the presence of FAT/CD36 in the cardiomyocyte, and showed that at least part of the FAT/CD36 pool is associated with the sarcolemma.
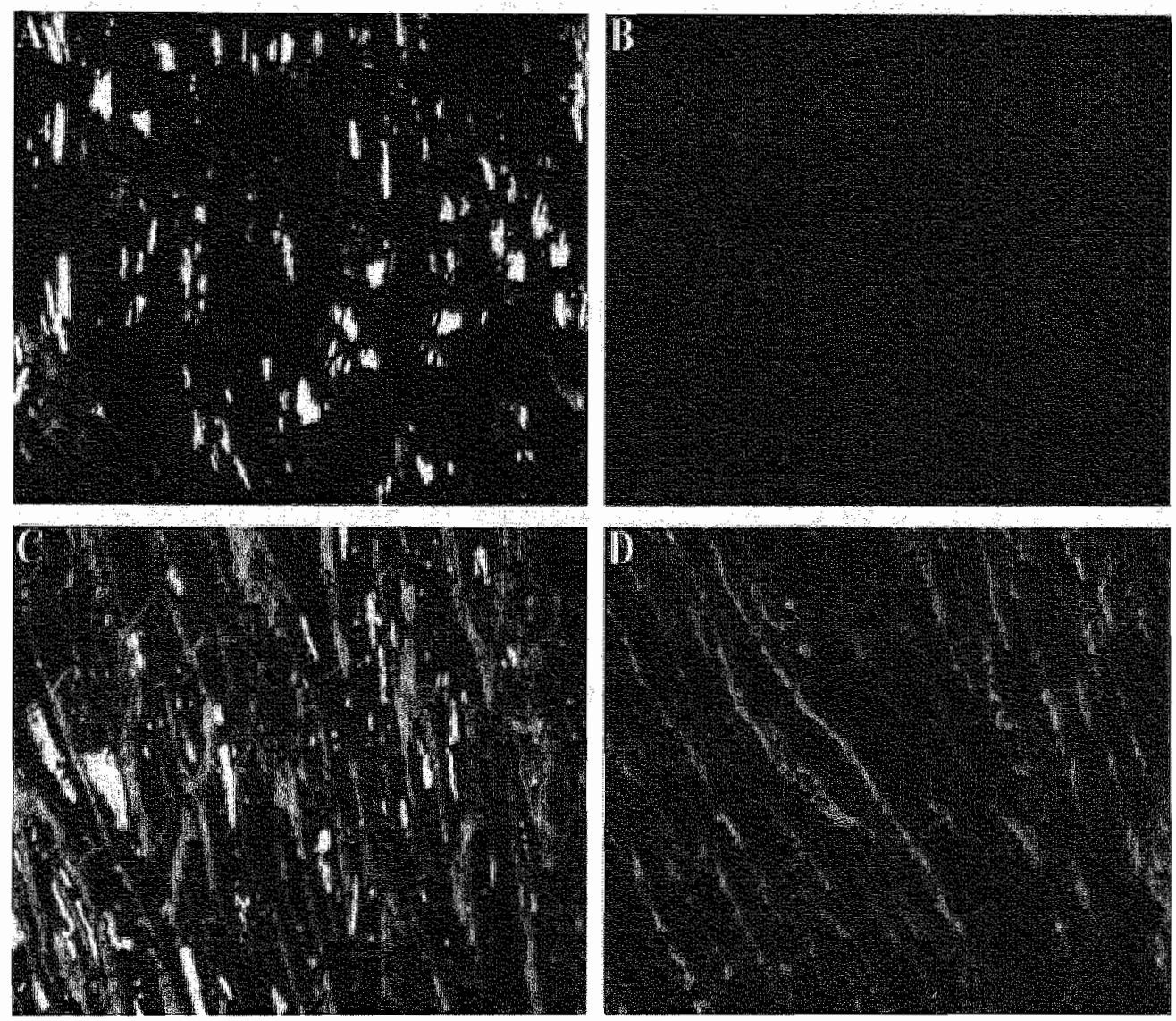

Figure 3: Lacalization of FAT/CD36 in the haman and rat heart. Heart tissue sectionss were labeled using monoclonal 131.4 as primary and FTrC-labelled rabbit anti-mouse IgC as secondary antibody. Panel A and B: human respectively rat heart tissue sections labeled with omission of the primary 131.4 antibody and serving as negative controls. Panet $C$ : specific staining of the cardiomyacye sarcolemma in human heart vissue sections (gray). The lightroolored autofluorescence is due to the accumulation of lipofuscin. Panel D. specific staining of the cardiomyocyte sarcolemma in rat heart tissue sections. $A, B, C$ and $D x 40$. 
In conclusion, FAT/CD36 is present in both the cardiac myocyte and the capillary endothelial cell in the heart. The abundance of the protein in the cardiomyocyte strongly suggest an important physiological role for this protein in cardiac function. To identify this role, in particular in FA transport, requires further experiments.

\section{Acknowledgements}

We would like to thank Dr. Narendra N. Tandon, Otsuka America Pharmaceutical Inc., Rockville, MD, for kindly sharing his experience with FAT/CD36 purification procedures and for providing the antibodies that were used.

\section{References}

1. Rose $\mathbf{H}$, Hennecke $\mathbf{T}$ and Kammermeier $\mathbf{H}$. Sarcolemmal fatty acid transfer in isolated cardiomyocytes governed by albumin/membrane-lipid partition. $J$ Mol Cell Cardiol 22: 883-892, 1990 .

2. Kamp F, Zakim D, Zhang F, Noy $\mathbf{N}$ and Hamilton JA. Fatty acid flip-flop in phospholipid bilayers is extremely fast. Biochemistry 34: 11928-11937, 1995.

3. Zakim D. Fatty acids enter cells by simple diffusion. Proc Soc Exp Biol Med 212: 5-14, 1996.

4. Sorrentino D, Stump D, Potter BJ, Robinson RB, White R, Kiang CL and Berk PD. Oleate uptake by cardiac myocytes is carrier mediated and involves a $40-\mathrm{kD}$ plasma membrane fatty acid binding protein similar to that in liver, adipose tissue, and gut. J Clin Invest 82: 928-935, 1988.

5. Stremmel W. Fatty acid uptake by isolated rat heart myocytes represents a carrier- mediated transport process. J Clin invesi 81: 844-852, 1988.

6. Luiken JJFP, van Nieuwenhoven FA, America G, van der Vusse GJ and Glatz JFC. Uptake and metabolism of palmitate by isolated cardiac myocytes from adult rats: involvement of sarcolemmal proteins. J Lipid Res 38: 745-758, 1997.

7. Luiken JJ, Schaap FG, van Nieuwenhoven FA, van der Vusse GJ, Bonen A and Glatz JF. Celluliar fatty acid transport in heart and skeletal muscle as facilitated by proteins. Lipids 34: S169S175, 1999.

8. Abumrad N, Coburn $\mathbf{C}$ and Tbrahimi A. Membrane proteins implicated in long-chain fatty acid uptake by mammalian cells: CD36, FATP and FABPm. Biochim Biophys Acta 1441: 4-13, 1999. 
9. Abumrad NA, El-Maghrabi MR, Amri EZ, Lopez E and Grimald PA. Cloning of a rat adipocyte membrane protein implicated in binding or transport of long chan fatty acids that is induced during preadipocyte differentiation. Homology with human CD36. J Biol Chen 268: 17665$17668,1993$.

10. Van Nieuwenhoven FA, Verstijnen CPHJ, Abumrad NA, Willemsen PHM, van Eys GJM, van der Vusse GJ and Glatz JFC. Putative membrane fatty acid translocase and cytoplasmic fatty acid- binding protein are co-expressed in rat heart and skeletal muscles. Biochem Biophys Res Commun 207: 747-752, 1995.

11. MeGregor JL, Catimel B, Parmentier S, Clezardin P, Dechavanne M and Leung LLK. Rapid purification and partial characterization of human platelet glycoprotein IIIb. Interaction witli thrombospondin and its role in platelet aggregation. J Biol Chem 264:501-506, 1989.

12. Tandon NN, Lipsky RH, Burgess WH and Jamieson GA: Isolation and characterization of platelet glycoprotein IV (CD36). J Biol Chem 264: 7570-7575, 1989.

13. Greenwalt DE, Watt KWK, So OY and Jiwani N. PAS IV, an integral membrane protein of mammary epithelial cells, is related to platelet and endothelial cell CD36 (GP IV). Biochemistry 29: 7054-7059, 1990.

14. Greenwalt DE and Mather IH. Characterization of an apically derived epithelial membrane glycoprotein from bowine milk, which is expressed in capillary endothelia in diverse tissues. $J$ Cell Biol 100: 397-408, 1985.

15. Baillie AGS, Coburn CT and Abumrad NA. Reversible binding of long-chain fatty acids to purified FAT, the adipose CD36 homolog. J Membr Biol 153: 75-81, 1996.

16. Greenwalt DE, Watt KWK, Hasler T, Howard RJ and Patel S. Structural, functional, and antigenic differences between bovine heart endothelial CD36 and human platelet CD36. J Biol Chem 265: 16296-16299, 1990.

17. Tanaka T and Kawamura K. Isolation of myocardial membrane long-chain faity acid-binding protein: homology with a rat membrane protein implicated in the binding or transport of long-chain fatty acids. J Mol Cell Cardiol 27: 1613-1622, 1995.

18. Greenwalt DE, Scheck SH and Rhinehart-Jones $\mathbf{T}$. Heart CD36 expression is increased in murine models of diabetes and in mice fed a high fat diet. J Clin Invest 96: 1382-1388, 1995.

19. Pelsers MMAL, Lutgerink JT, Nieuwenhoven FA, Tandon NN, wan der Vusse G.J, Arends IW, Hoogenboom IIR and Glatz JFC. A sensitive immunoassay for tat fatty acid translocase (CD36) using phage antibodies selected on cell transfectants: abundant presence of fatty acid translocase/CD 36 in cardiac and red skeletal muscle and up. regulation in diabetes. Biochem J 337: $407-414,1999$. 
20. Schaap FG, Binas B, Danneberg H, van der Vusse GJ and Glatz JFC. Impaired long-chain fatty acid utilization by cardiac myocytes isolated from mice lacking the heart-type fatty acid binding protein gene. Circ Res 85: 329-337, 1999.

21. Van Nieumenhoven FA, Luiken JJFP, De Jong YF, Grimaldi PA, Van der Vusse GJ and Glatz JFC Stable transfection of fatty acid translocase (CD36) in a rat heart muscle cell line (H9c2). JLipid Res 39: 2039-2047, 1998.

22. Matsuno K, Diaz-Ricart M, Montgomery RR, Aster RH, Jamieson GA and Tandon NN. Inhibition of platelet adhesion to collagen by monoclonal anti-CD36 antibodies. Br J Haematol 92: $960-967,1996$.

23. Laemmli UK. Cleavage of structural proteins during the assembly of the head of bacteriophage T4. Nature 227: 680-685, 1970.

24. Marshall T. Detection of protein in polyacrylamide gels using an improved silver stain. Anal Biochem 136: 340-346, 1984.

25. Kronenberg A, Grahl H and Kellrel B. Human platelet CD36 (GPIIb, GPIV) binds to cholesteryl-hemisuccinate and can be purified by a simple two-step method making use of this property. Thromb Haemost 79: 1021-1024, 1998.

26. Greenwalt DE. A one-step procedure for purification of bovine mammary epithelial cell CD36. Protein Expr Purif 4: 72-75, 1993.

27. Bordier C. Phase separation of integral membrane proteins in Triton X-114 solution. J Biol Chem 256: 1604-1607, 198I.

28. Glatz JF and van der Vusse GJ. Cellular fatty acid-binding proteins: their function and physiological significance. Prog Lipid Res 35: 243-282, 1996. 


\title{
Chapter 4
}

\section{Metabolic abnormalities of FAT/CD36 null}

\author{
mice are normalized by restoring
}

\section{FAT/CD36 expression in heart and skeletal}

\author{
muscle
}

J.F.F. Brinkmann, N.A. Abumrad, W. Jou, J.A. Johnson, G.J. van der Vusse, J.F.C.

Glatz and A. Ibrahimi: submitted for publication 


\section{Abstract}

FAT/CD36 is a membrane protein that facilitates long-chain fatty acid (FA) transport by muscle tissues. We have examined the role of muscle FAT/CD36 expression in overall metabolism and its impact on muscle function by studying two mice models; the FAT/CD36 null mouse (KO) and the newly generated FAT/CD36 null rescued for FAT/CD36 expression in heart and muscle using the muscle creatine kinase promoter (gene rescued, GR).

PCR was performed using specific primers to discriminate between the null (KO), wild-type (WT) and GR mice. Specific expression of FAT/CD36 protein was confirmed by western blot and immunofluorescence. FAT/CD36 null mice had fasting hypoglycemia while GR mice did not. Plasma triacylglycerol and FA levels, which are increased in the KO mice were also restored to WT levels by heart/muscle FAT/CD36 expression.

The FA oxidation rate of soleus muscle isolated from GR mice was significantly higher than that of FAT/CD36 null muscle and comparable to that of wild type. Dipyridamole stimulation increased oxidation rates in wild type and GR muscles but did not affect oxidation in FAT/CD36 muscle confirming the role of FAT/CD36 in FA metabolism by muscle. Glycogen, triacylglycerol and ATP levels were significantly decreased in FAT/CD36 null muscles and fully normalized to WT levels in GR muscles.

To examine the effect of FAT/CD36 on in vivo muscle function, the mice were subjected to forced swimming tests. FAT/CD36 null mice had a drastically reduced ability to endure exercise in comparison to wild type and GR mice.

The muscle-targeted rescue of FAT/CD36 expression in FAT/CD36 null mice reverses the main abnormalities of FA metabolism and the ability to exercise is severely affected in FAT/CD36 null mice. In contrast to the rescue of FA utilization in skeletal muscle, a normallization of FA oxidation was not observed in isolated GR hearts and GR cardiomyocytes. Both isolated FAT/CD36 null and GR hearts and their isolated cardiomyocytes showed drastically reduced FA oxidation rates compared to the wild-type. 


\section{Introduction}

Early work with isolated rat adipocytes provided evidence for the presence of a protein-facilitated component in the transport of long-chain fatty acids (FA) across the cellular membrane ${ }^{1}$, and a heavily glycosylated $88-\mathrm{kDa}$ integral membrane protein was identified as a candidate FA transporter using reactive sulfo- $N$ succinimidyl derivatives of long-chain FA ${ }^{2}$. The corresponding cDNA, isolated from a rat adipose tissue library, encoded FAT (for FA translocase) ${ }^{3}$, which is the rat homologue of the human platelet CD36, also known as PASIV, GPIV and GPIIIb in earlier literature ${ }^{4}$. FAT/CD36 is abundantly expressed in tissues active in FA metabolism such as heart, skeletal muscle, fat and intestine, and its expression profile coincides with a role in FA uptake ${ }^{3,5,6}$. Conditions that alter lipid metabolism such as diabetes mellitus and high fat feeding modulate FAT/CD36 expression ${ }^{7,8}$.

Strong evidence supporting the role of FAT/CD36 in FA uptake was recently obtained by generating mouse models in which FAT/CD36 expression was manipulated. First, mice overexpressing FAT/CD36 in heart and skeletal muscle show enhanced muscle FA oxidation rates upon stimulated contraction ?. This increased ability to utilize FA is accompanied by decreases in plasma FA, triacylglycerol (TAG) and cholesterol levels, whereas blood glucose levels are increased ${ }^{9}$. Second, FAT/CD36 null mice, generated by targeted gene-disruption, exhibit the opposite changes in plasma metabolite levels. Plasma FA, TAG and cholesterol levels are increased, while blood glucose levels are decreased ${ }^{10}$. FA uptake by the heart, skeletal muscle and adipose tissue is strongly reduced in vivo, and isolated adipocytes lack the high-affinity component of FA transport that is present in wild-type cells ${ }^{10,11}$.

In the FAT/CD36 deficient spontaneously hypertensive (SHR) rat, defective FA uptake is accompanied by a large shift towards glucose metabolism, hyperinsulinemia, insulin resistance and the development of myocardial hypertrophy ${ }^{12,13}$. All these defects were improved in congenic and transgenic rats 
re-expressing $\mathrm{FAT} / \mathrm{CD} 36$, and are thus directly attributable to the $\mathrm{FAT} / \mathrm{CD} 36$ gene $^{12-14}$.

FAT/CD36 deficiency is also known to occur in humans, and several mutations resulting in this condition have been observed ${ }^{15}$. The prevalence of FAT/CD36 deficiency varies from 0.3 to $11 \%$ and the higher incidences are found in the Asian and African populations ${ }^{16}$. Humans with FAT/CD36 deficiency have a severe defect in myocardial FA uptake ${ }^{15,17}$ that is very similar to the defect observed in the FAT/CD36 null heart ". In humans, FAT/CD36 deficiency may underlie some forms of cardiac diseases such as hypertrophic cardiomyopathy ${ }^{15,18}$.

To be able to further dissect the direct and possibly secondary effects of FAT/CD36 deficiency, a new transgenic mouse line was generated using a genetic rescue approach, and here we describe the generation and characterization of this new model. By restricting FAT/CD36 expression to heart and skeletal muscle we were able to correct, and thus further specify the main abnormalities of FA metabolism in the FAT/CD36 null mouse. We report that absence of FAT/CD36 severely impacts muscle energy production and leads to a lowered endurance during high intensity exercise.

\section{Materials and Methods}

Immun-Star Detection Kit was from Bio-Rad. Immobilon PVDF transfer membranes were from Millipore. Enzymes for DNA manipulation were from Roche Molecular Biochemicals. The polyclonal FAT/CD36 antibody F2-35 was generated in rabbits against rat adipocyte FAT/CD36. Kodak films, FA, and all other chemical products were from Sigma.

\section{Animals}

Animals received proper care in compliance with the "Principle of Laboratory Animal Care" formulated by the National Society for Medical Research and the "Guideline for the Care and Use of Laboratory Animals" prepared by the National Academy of Sciences and the National Institutes of Heaith (NIH publication No. 
85-23, revised 1985). Mice used in experiments were 2-3 months of age and were weight, age and sex matched. They were housed in a facility equipped with a 12 -h light cycle, had unlimited access to water and were fed a standard pelleted diet $a d$ libitum.

\section{Generation and identification of FAT/CD36 gene-rescued mice}

FAT/CD36 null mice were generated by targeted gene-disruption and backcrossed 4 times to $\mathrm{C} 57 \mathrm{Bl} / 6^{10}$. Wild-type control littermates were bred from the same cross as the nulls and were therefore of identical genetic background.

FAT/CD36 gene rescued (GR) mice were generated on the FAT/CD36 null background using the same approach as previously reported ${ }^{9}$. A linear Sall FAT/CD36 mini-gene was injected into the male pronucleus of fertile eggs from superovulated females of the FAT/CD36 null line. These females had been mated with FAT/CD36 null males and microinjected eggs were transferred into the oviducts of surrogate FAT/CD36 null females. The mini-gene contained the fulllength rat FAT/CD36 cDNA including the poly-adenylation signal, controlled by the regulatory sequences $(3.3 \mathrm{~kb})$ of the mouse muscle creatine kinase gene (MCK). GR founders were identified by southern blot on genomic DNA from tail biopsies as previously described ${ }^{9}$. Transgenic offspring was identified by PCR amplification using the primers: 5'-[GGCTGCGATCGGAACTGTGGGC]-3' and 5"-[CGATCGGAACTGTGGGCTCATTAC]-3'. These primers amplify a 400-bp segment of the transgene.

\section{Protein analysis}

FAT/CD36 protein expression was examined by western analysis. Muscle or heart tissue was homogenized in $1 \mathrm{ml}$ of ice-cold TES buffer ( $20 \mathrm{mM}$ Tris-HCl, $1 \mathrm{mM}$ EDTA, $250 \mathrm{mM}$ sucrose, $\mathrm{pH}$ 7.4) and a microsomal pellet was obtained by centrifuging at $350,000 \times \mathrm{g}$. Samples from this pellet $(20-50 \mu \mathrm{g}$ of protein) were subjected to SDS-PAGE according to Laemmli ${ }^{19}$ followed by transfer to a PVDF membrane. The membrane was blocked with $5 \%$ non-fat dry milk and incubated 
with a poly anti-FAT/CD 36 antibody for $2 \mathrm{~h}$. After washing, immunodetection was carried out using the horseradish peroxidase conjugated goat anti-rabbit antibody (1.h, 1:10,000 dilution) of an Immun-Star Detection Kit according to the manufactures manual.

\section{Immunohistochemistry}

Tissues, quickly rinsed in saline, were immersed for 48 hours in formalin followed by sucrose ${ }^{20}$. Cryosections on glass slides were washed with PBS (PBS: $100 \mathrm{mM}$

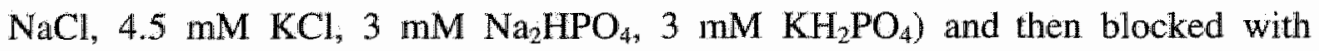
normal goat serum at room temperature for $1 \mathrm{~h}$. Subsequently to PBS washing, primary polyclonal antibodies anti-FAT/CD36 (F2-35) was added. Incubations were conducted overnight at $4^{\circ} \mathrm{C}$. The slides were then washed with PBS and secondary antibodies were applied in blocking buffer for $1 \mathrm{~h}$ at room temperature. The secondary antibodies were fluorescein (FITC)-conjugated goat anti-rat IgG from Jackson Immunoresearch Laboratories Inc. The slides were then washed with PBS, mounted with Vectashield (VECTOR), and examined using either a standard fluorescence microscope or a confocal microscope.

\section{Analysis of Blood Parameters}

Blood parameters were analyzed from ovemight $(16 \mathrm{~h})$ fasted animals. Tail vein blood was collected in EDTA-rinsed tubes and plasma was prepared immediately. Tiacylglycerol levels were determined using the Infinity enzymatic kit from Sigma Diagnostics (St. Louis, MO) and determination of plasma FA levels was carried out with the Wako kit (Wako Chemicals, Richmond, VA). Glucose was measured in whole blood with a MediSense glucose analyzer.

\section{Triacylglycerol, Glycogen and ATP levels in muscle}

Hind limbs of fasted mice were quickly rinsed in saline, clamped between aluminum tongs precooled in liquid nitrogen and stored at $-80^{\circ} \mathrm{C}$. Muscle ATP was measured after extraction in perchloric acid. ATP concentration was determined by 
standard enzymatic assay using a kit from Sigma (St. Louis, MO). Muscle glycogen was measured as glucose after hydrolysis with $\mathrm{KOH}(30 \%)$ and $\mathrm{HCL}$ $(0.6 \mathrm{~N})^{21}$. Triacylglycerol content was determined enzymatically after lipid extraction as previousely described ${ }^{22}$. Tissue protein was determined according to the method of Markwell et al. ${ }^{23}$.

\section{Fatty acid oxidation by isolated soleus muscles}

Krebs-Henseleit buffer (KHB) used in these experiments consisted of $118.5 \mathrm{mM}$ $\mathrm{NaCl}_{3} 4.7 \mathrm{mM} \mathrm{KCl}, 1.2 \mathrm{mM} \mathrm{MgSO}, 1.2 \mathrm{mM} \mathrm{KH}_{2} \mathrm{PO}_{4}, 2.5 \mathrm{mM} \mathrm{CaCl}_{2}, 0.5 \mathrm{mM}$ EDTA and $25 \mathrm{mM} \mathrm{NaHCO}$, supplemented with $5 \mathrm{mM}$ D-glucose. All bovine serum albumin (BSA) and palmitate/BSA complexes used had been dialyzed extensively against KHB and all buffers were continuously gassed with $95 \% \mathrm{O}_{2} /$ $5 \% \mathrm{CO}_{2}$. Gassing was started at least $15 \mathrm{~min}$ prior to use.

The soleus muscles, including the tendons were quickly and carefully excised from the animals and places in a capped $10 \mathrm{ml}$ vial containing $5 \mathrm{ml} \mathrm{KHB}$ supplemented with $2 \%$ BSA. After 20 min incubation in a shaking water bath (150 strokes/min) at $30^{\circ} \mathrm{C}$, the muscles were quickly transferred to new vials (1 soleus/vial) containing $3 \mathrm{ml}$ KHB with $0.2 \mathrm{mM}$ palmitate and $0.45 \mu \mathrm{Ci} / \mathrm{ml}$ $\left[1-{ }^{14} \mathrm{C}\right]$ palmitate (ICN, Irvine, CA) complexed to $2 \%$ BSA. An antibiotic/antimyocytic solution (Sigma, St. Louis, MO) was added to the latter medium to prevent bacterial growth. The vials were capped and $30^{\circ} \mathrm{C}$ incubation was continued for $30 \mathrm{~min}$. The incubation medium was quickly transferred to new vials (Kontes, Vineland., NJ) thereafter. The rubber caps of these vials were equipped with a center well filled with $200 \mu l$ of ethanolamine/ethylene glycol $(\mathbb{1}: 2$, vol:vol). Perchloric acid was added through the cap to a final concentration of $0.6 \mathrm{M}$ and the vials were incubated overnight with light shaking. The amount of $\mathrm{CO}_{2}$ produced was determined by liquid scintillation counting of the ethanolamine/ethylene glycoll mixture. Dipyridamole (dissolved in DMSO at $100 \times$ final concentration) was added after the initial 20 min incubation at $30^{\circ} \mathrm{C}$. 
Fatty acid oxidation by isolated perfused hearts

Hearts were quickly excised from the animals, their aorta was mounted on a cannula, and they were perfused in the Langendorff (retrograde) mode with continuously gassed KHB supplemented with $11 \mathrm{mM}$ D-glucose. Flow rate was 2.1 $\mathrm{ml} / \mathrm{min}$ and constant throughout the experiments. Heart temperature was maintained at a temperature of $38.5^{\circ} \mathrm{C}$ by the use of a heated water jacket surrounding the heart. After an initial 10 min equilibration period, the perfusion buffer was switched to KHB, supplemented with $11 \mathrm{mM}$ D-glucose and $0.4 \mathrm{mM}$ palmitate complexed to $3 \% \mathrm{BSA}$, which contained $0.45 \mu \mathrm{Ci} / \mathrm{ml}\left[1-{ }^{14} \mathrm{C}\right]$ palmitate (ICN, Irvine, $\mathrm{CA}$ ), and had been extensively dialized. Perfusion was continued for an additional 50 minutes, samples of the coronary effluent $(2 \mathrm{ml})$ were collected, vials were capped, and $\mathrm{CO}_{2}$ production was determined by base trapping into ethanolamine/ethylene glycol as described in the previous section. The production of $\mathrm{CO}_{2}$ reached a plateau approximately 20 minutes after switching the buffers, and this plateau value was maintained for at least an additional 25 minutes. Palmitate oxidation rates were calculated from these maximum values.

\section{Fatty acid oxidation by isolated cardiomyocytes}

Cardiomyocytes were isolated from adult mouse hearts by enzymatic digestion according to the procedure described by Schaap et al. ${ }^{24}$. This method yielded 30 $40 \mathrm{mg}$ wet mass per heart, and cell suspensions used for experiments contained at least $50 \%$ of clearly striated, rod-shaped cells, and this percentage remained constant throughout the experiments. All mouse groups showed comparable cell yields, and the percentage of rod shaped, viable, cells was comparable among the groups. Palmitate oxidation rates were determined by incubating cardiomyocytes in closed vials (Kontes, Vineland, NJ) with $0.2 \mathrm{mM}$ palmitate (with $0.45 \mu \mathrm{Ci} / \mathrm{ml}$ $\left[1-{ }^{14} \mathrm{C}\right]$ palmitate (ICN, Irvine, CA)) complexed to $2 \%$ BSA. An atmosphere of $95 \% \mathrm{O}_{2} / 5 \% \mathrm{CO}_{2}$ was maintained inside these vials, the rubber stops were equipped with a center well filled with ethanolamine/ethylene glycol, and reactions 
were stopped by adding a final concentration of $0.6 \mathrm{M}$ perchloric acid through the cap. The trapping of $\mathrm{CO}_{2}$ was enabled by the procedure described above.

\section{Forced swimming test}

Mice were individually forced to swim in a transparent glass vessel by attachment of a weight equivalent to $6.67 \%$ of the mouse body weight. The water temperature was maintained at $30^{\circ} \mathrm{C}$. To swim, mice need to move their legs permanently to keep their heads above the water, and they were considered to be exhausted when they showed the first signs of stopping this movement. Time to reach exhaustion was recorded. Mice were forced to swim 4 repetitive times with 15 min intervals of rest.

\section{Statistical analysis}

Data are expressed as mean \pm SEM. The significance of the difference in mean values was evaluated using the two-tailed, unpaired Student's $t$ test assuming equal variance. Significance was accepted at $\mathrm{p}<0.05$.

\section{Results}

Generation of a transgenic mouse model re-expressing FAT/CD36 in heart and skeletal muscle on the FAT/CD36 null background

Fig. 1A shows the results of a PCR on genomic DNA from animals positive for the FAT/CD36 mini-gene. Using primers specific for the injected construct, no signal was detectable in DNA from FAT/CD36 null mice and wild-type littermates. GR mice developed normally with no incidence of disease noted. Their body weight at mature age $(25.2 \pm 2.4 \mathrm{~g}, \mathrm{n}=10)$ did not differ significantly from the weight of wild-type control littermates $(25.2 \pm 2.2 \mathrm{~g}, \mathrm{n}=13)$. Re-expression of the FAT/CD36 protein in heart and skeletal muscle fromGR mice was examined by western analysis. Fig. 1B shows that membrane associated FAT/CD36 levels in GR 
A

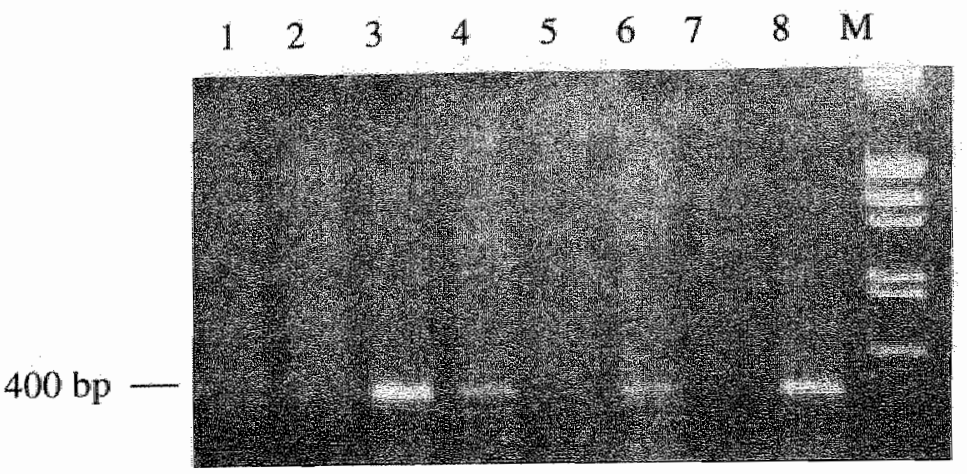

B

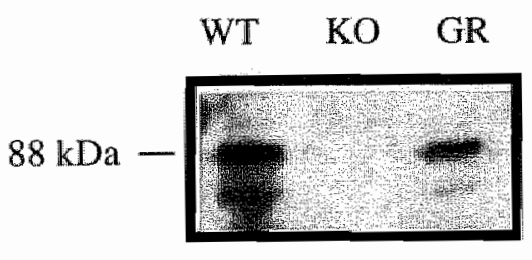

Figure 1: Generation of transgenic $G R$ mice re-expressing $F A T / C D 36$ in muscle tissues.

Panel A-Specific primers (see experimental procedures) designed from the published rat FAT/CD36 cDNA sequence were used ro amplify a 400 bp of the MCK-FAT/CD36 transgene. No fragment was obtained from wild type mice (WT, Lanes l and 5) and FAT/CD36 wull mice (KO, Lanes 2 and 7). Gene-rescued (GR) animals were positive for the transgene and showed a 400 bp band (Lanes $3,4,6$ and 8). M: DNA standard marker.

Panel B- FATCD36 protein expression was analyzed by western blot. Proteins were prepared as described in experimental procedures. FAT/CD36 protein levels in wild type (WT). FAT/CD36 null (KO) and gewe-rescued (GR) skeletal muscles were detected using a monoclonal antibody against FAT/CD36. Incubation with pre-immune sera did not yield any detectable signal (not shown). Immwnodetection was by Immun-Star Detection kit.

muscles were comparable to wild-type levels, while the FAT/CD36 protein was undetectable in FAT/CD36 null muscles. GR tissues other than heart and muscle were negative for the FAT/CD36 protein (results not shown). 

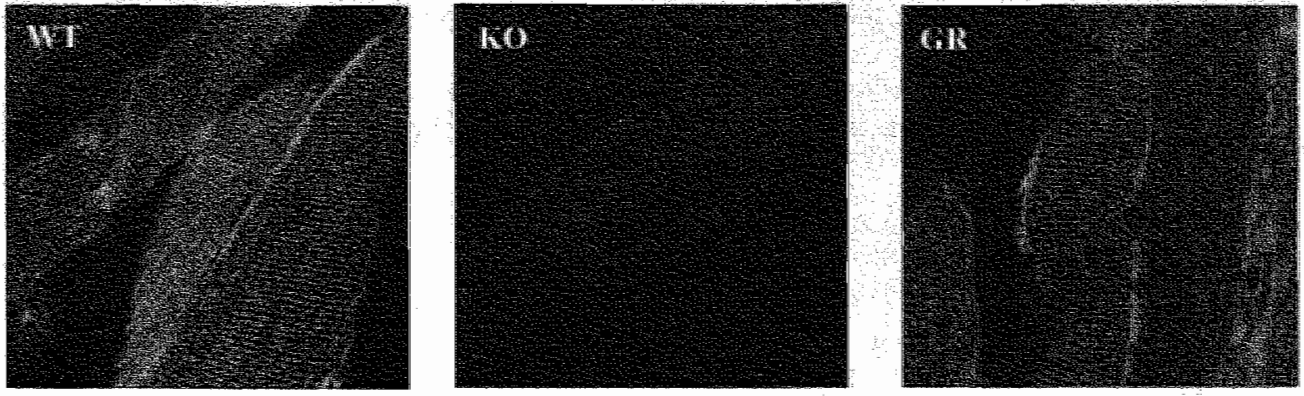

Figure 2: Immunofluorescence studies of FAT/CD36 expression in the hearts of different animal models. Tissue sections prepared from wild type (WT), FAT/CD36 null (KO) and gene-rescued (GR) hearts were incubated with rabbit polyclonal antibodies against FAT/CD36 followed by a fluorescein-conjugated goat anti-rabbit IgG. Sections were analyzed whder a confocal microscope.

In order to confirm the expression of FAT/CD36 in GR mice, we examined heart tissue sections from different animal models for FAT/CD36 expression by immunohistochemistry. GR mice (Fig. 2) showed high expression of FAT/CD36 on the membranes comparable to the wild type mice. Muscle from FAT/CD36 null mice showed no expression of FAT/CD36 confirming the total absence of the protein in these mice (Fig. 2).

Rescue of the FAT/CD36 null phenotype in GR mice

Upon fasting, FAT/CD36 null mice show hypoglycemia and elevated plasma levels of FA and TAG (Table 1). Re-expression of FAT/CD36 in heart and muscle of GR mice resulted in normalization of these parameters, as plasma glucose, FA and TAG levels in fasted GR mice were similar to their wild-type control values (Table 1).

Measuring palmitate oxidation by isolated soleus muscles directly assessed the rescue of FA metabolism in the GR mice. 
Table 1. Plasma levels of FA, triacylglycerol and glucose in wild-tope, FAT/CD36 null and GR mite

\begin{tabular}{lccc}
\hline & $\begin{array}{c}\text { Plasma FA } \\
(\mathrm{mM})\end{array}$ & $\begin{array}{c}\text { Plasma TAG } \\
(\mathrm{mM})\end{array}$ & $\begin{array}{c}\text { Blood Glucose } \\
(\mathrm{mM})\end{array}$ \\
\hline Wild type & $1.85 \pm 0.10(9)$ & $1.10 \pm 0.07(9)$ & $6.03 \pm 0.29(12)$ \\
FAT/CD36 null & $2.91 \pm 0.08(10)^{*}$ & $1.48 \pm 0.11(12)^{*}$ & $4.37 \pm 0.27(15)^{*}$ \\
GR & $1.92 \pm 0.09(13)$ & $1.22 \pm 0.05(16)$ & $5.09 \pm 0.27(15)$ \\
\hline
\end{tabular}

Age- and ser-matched 6.16 weeks old mice were fasted overnight. Blood was collected from the tail wein into EDTA-coated twbes and cenrifuged to separate otut plasma, which was used to determine FA and TAG. Glucose Levels were determined on whole blood. Data are mean $\pm S E M$ and $n$ is shown in-beween brackets. "Significantly differen from wild-rype.

A

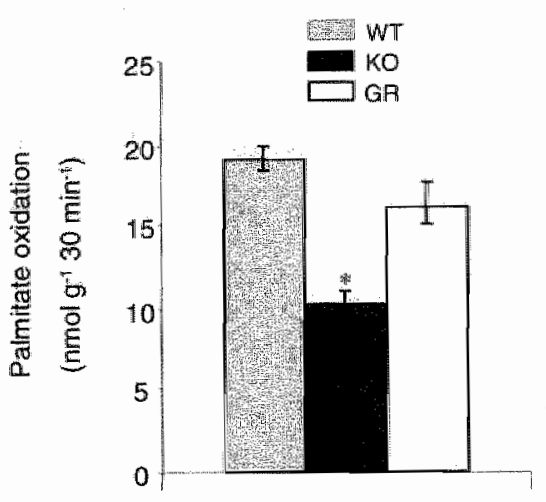

$B$

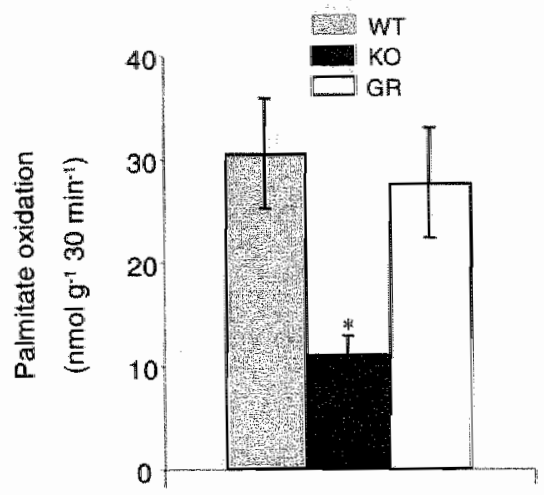

Figure 3: Palmitate oxidation by soleus muscles of different animal models. Palmitate oxidation rates of isolated soleus muscles from wild-type (WT), FAT/CD36 null (KO) and gene-rescued (GR) mice were determined at a FA/BSA ratio of 0.67 . Incubations were carried out at $30^{\circ} \mathrm{C}$ and oxidation rafes were determined over a 30 min interval Panel A represents fatty acid oxidation of nonstimulated muscles ( $n=3$ per group). In panel $B$ faty acid oxidation was stimulated by addition of 100 HM dipyridamole ( $=3$ per group). Data are wean \pm SEM. "Significantly different from wild-type.

As shown in Figure $3 \mathrm{~A}$, the palmitate oxidation rate of the GR soleus was significantly higher compared to the FAT/CD36null muscle, and somewhat, but insignificantly lower compared to the wild-type control muscle. Significant differences in soleus weights were absent (results not shown). To measure FA 
oxidation under stimulated conditions, dipyridamole was added to the muscle incubations. This compound was recently shown to induce the translocation of FAT/CD36 protein from an intracellular compartment to the plasma membrane through a pathway that is also used for the induction of FAT/CD36 translocation by cellular contractions ${ }^{28}$. Addition of dipyridamole increased palmitate oxidation by both the wild-type control and the GR soleus, but did not show an effect on the FAT/CD36 null muscle (Fig. 3B). Wild-type and GR oxidation rates were indistinguishable after dipyridamole stimulation.

Tissue TAG, glycogen and ATP levels were drastically reduced in the CD36null muscles and normalized in the muscles of the GR mice, as they were fully comparable to the wild-type levels (Table 2).

\section{Endurance during exercise}

Since muscle ability to perform work is highly dependent on energy from FA oxidation, we tested if FAT/CD36 expression impacts exercise. Forced swimming tests were used to examine wild-type, FAT/CD36 null, and GR mouse tolerance to high intensity exercise (Fig. 4). FAT/CD36 null mice showed a drastically reduced ability to undergo forced swimming. Gene-rescued GR mice endured the repeated swimming comparable to their wild-type controls (Fig. 4).

Table 2: Glycogen and triacylglycerol levels in wild-type, CD36 null and GR mice

\begin{tabular}{lccc}
\hline & $\begin{array}{c}\text { Glycogen } \\
(\mu \mathrm{g} / \mathrm{mg} \text { protein })\end{array}$ & $\begin{array}{c}\text { Triacylglycerol } \\
(\mu \mathrm{g} / \mathrm{mg} \text { protein })\end{array}$ & $\begin{array}{c}\text { ATP } \\
(\mu \text { mol/g wet weight })\end{array}$ \\
\hline Wild type & $1.52 \pm 0.51$ & $38.41 \pm 5.64$ & $15.1 \pm 2.7$ \\
FAT/CD36 null & $0.43 \pm 0.10^{*}$ & $19.64 \pm 4.01^{*}$ & $9.1 \pm 1.7^{*}$ \\
GR & $1.83 \pm 0.38$ & $41.47 \pm 7.21$ & $14.1 \pm 2.0$ \\
\hline
\end{tabular}

Muscle tissues were collected from different animal models and levels of glycogen, triglycerides and ATP were determined as described in experimental procedures. Data are mean $\pm S E M$ and $n$ was 5 for each mouse group. "Significantly different from wild-type. 


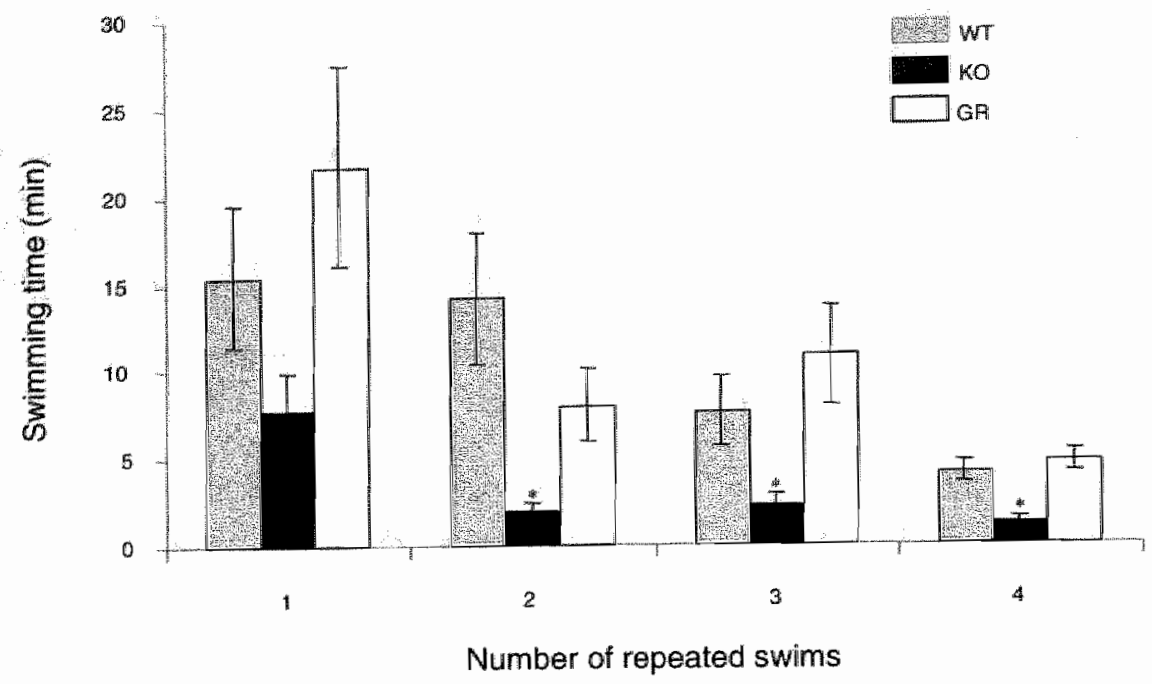

Figure 4: Forced swimming test of different animal models. Wild-type (WT), FAT/CD36 null (RO) and gene-rescued (GR) mice $(n=6$ per group) were forced to swim until exhaustion as described in experimental procedures. Time to reach exhaustion was recorded and swimming was repeated 4 times with $15 \mathrm{~min}$ intervals. Data are mean $\pm S E M .{ }^{*}$ Significantly different from wild-type.

Palmitate oxidation by isolated hearts and cardiomyocytes

Because both skeletal (Figure 1) and heart (Figure 2) muscle demonstrated the reexpression of FAT/CD36 in the GR mice, cardiac FA oxidation by wild-type, FAT/CD36 null and GR hearts and isolated cardiomyocytes was also evaluated at physiologically relevant FA/BSA ratio's. Where both the palmitate oxidation rates of perfused FAT/CD36 null hearts and FAT/CD36 null cardiomyocytes showed a prominent reduction compared to the wild-type, signs of normalization were absent for GR hearts and cardiomyocytes. In contrast to the findings in isolated soleus muscles (Figure 3) both the isolated perfused GR heart and isolated GR cardiomyocytes displayed palmitate oxidation rates fully comparable to the FAT/CD36 null values and drastically reduced compared to the wild-type levels (Figure 5). 
A

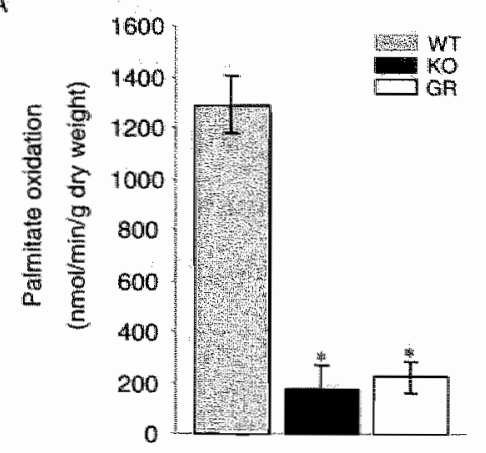

日

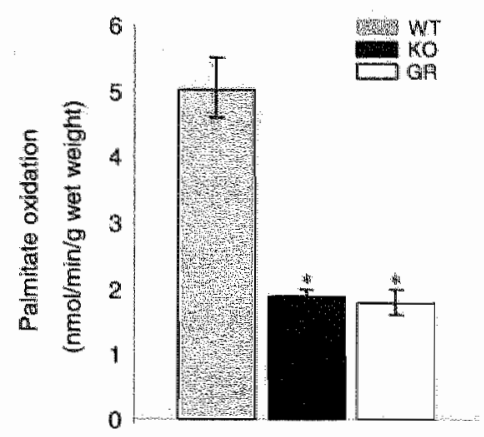

Figure 5: Palmitate oxidation by isolated perfused hearts and isolated cardiomyocytes of different animal models. Panel A- Wild-type (WT), FAT/CD36 null (KO) and gene-rescued (GR) hearts ( $n=3$ per groupl were perfused with KHB plus $11 \mathrm{mM}$ D-glucose and $0.4 \mathrm{mM}$ palmitate complexed to 0.44 mM BSA. Palmitate oxidation was determined at $38.5{ }^{\circ} \mathrm{C}$ as described in experimental procedures. Data are mean \pm SEM. "Significantly different from wild-type. Panel B-Cardiomyocytes were isolated from wild-type (WT), FAT/CD36 mull (KO) and gene-rescued (GR) mice ( $n=3$ for each mouse groupl and palmitate oxidation rates were determined at a palmitate/BSA ratio of 0.67 . Incubations were carried out at $37^{\circ} \mathrm{C}$ and oxidation rates were determined over a 20 min interval. Data are mean \pm SEM. "Significantly different from wild-type.

\section{Discussion}

The present study showed that FAT/CD36-facilitated FA transport in skeletal muscle plays a key role in the ability to exercise. The re-expression of FAT/CD36 in heart and skeletal muscle reversed the main abnormalities in FA metabolism previously described in FAT/CD36 null mice. Gene-rescued GR mice showed normal blood parameters, and FA oxidation rates by isolated soleus muscles were comparable to the WT rates. FAT/CD36 null animals displayed both significantly decreased muscle FA oxidation rates and a drastically lowered ability to undergo high intensity forced exercise. The muscle-targeted rescue of FAT/CD36 expression in GR mice resulted in a completely normalized endurance to forced exercise. The decreased tolerance to exercise of FAT/CD36 null animals is essentially due to a decreased ability to store metabolic energy, thereby impacting energy expenditure during exercise. This was demonstrated by the observation that muscle TAG, glycogen and ATP contents are significantly decreased in FAT/CD36 
muscles, whereas these levels in wild-rype and GR muscles were fully comparable. All these findings are consistent with the concept that cellular energy derived from FAT/CD36-mediated FA uptake is a determinant for the ability to exercise.

Muscle, especially that rich in red oxidative fibers, has a high dependence on energy from FA oxidation. As a result, it is understandable that FAT/CD36 expression in muscle, which mediated FA uptake and utilization, impacts the ability of muscle to perform work. Coburn et al. ${ }^{11}$ demonstrated that mice null for FAT/CD 36 have a more than $60 \%$ reduction in FA uptake by the heart and red muscles. Recently, it was demonstrated that this reduction is compensated by a large increase in glucose utilization ${ }^{25}$. However, this increase is apparently not sufficient to maintain normal metabolic energy storage and energy production, and the effects become apparent at heightened cellular demands such as occur during forced exercise.

Bonen et al. ${ }^{26}$ recently documented some of the molecular mechanisms involved in regulating FA utilization by muscular activity. The acute regulation of FA uptake by muscle activity involves the translocation of FAT/CD36 from intracellular stores to the sarcolemma, analogous to the regulation of glucose uptake by membrane recruitment of GLUT-4 ${ }^{27}$. In our experiments, adding dipyridamole to the muscle incubations did not show an effect on the FA oxidation rate of the FAT/CD36 null soleus. However, dypiridamole enlarged the difference between the FAT/CD36 null and wild-type, respectively, GR muscles to levels approximately three times higher than the FAT/CD36 null. Dipyridamole presumably exerts its action by inducing FAT/CD36 protein translocation from an intracellular compartment to the plasma membrane by activating a phosphatidylinositol-3 kinase-independent signaling pathway ${ }^{28}$. This pathway is also used for the induction of FAT/CD36 protein translocation by cellular contractions ${ }^{28}$. The absence of an effect of dipyridamole on the FAT/CD36 null soleus further substantiates this mode of action.

Our data also elegantly demonstrate the key role for muscle in the maintenance of FA homeostasis. Alterations in FAT/CD36 facilitated FA transport, and subsequently in FA utilization in muscles are directly reflected in the blood, because 
both the defect in muscle FA oxidation and the alterations in plasma FA and TAG levels present in FAT/CD36 null mice, could be reversed by muscle-targeted FAT/CD36 re-expression. Skeletal muscle, being a key FA oxidizer through its large mass, is the principal site for the removal of FA from the circulation, and this removal is mediated by FAT/CD36.

Interestingly, the findings might also imply that, at least in skeletal muscle, the expression of FAT/CD36 by the striated muscle cells only is sufficient for maintaining normal FA uptake rates. Because the GR mice were raised using a construct containing the FAT/CD36 cDNA controlled by the muscle-specific regulatory sequences of the mouse muscle creatine kinase gene ${ }^{29}$, it is likely that endothelial cells remain FAT/CD36 deficient in these mice. Nevertheless, the plasma FA and TAG levels in GR mice were almost completely normalized.

Whereas both GR skeletal and heart muscle showed the re-appearance of the FAT/CD36 protein at levels comparable to the wild type, normalization of FA metabolism in the GR mouse could only be observed for skeletal muscle. In line with the 60-80\% decrease in cardiac FAT/CD36 null FA transport as assessed in vivo and reported by Coburn et al. ${ }^{~}{ }^{11}$, both the isolated perfused FAT/CD36 null beart and isolated FAT/CD36 null cardiomyocytes showed severly decreased abilities to oxidize palmitate. FA oxidation by GR hearts and GR cardiomyocytes, however, did not display any signs of normalization, and was fully comparable to the FAT/CD36 null FA oxidation rates. This finding is especially remarkable because the cardiac FAT/CD36 re-expression in GR mice was eveluated by using immunohistochemistry, and this showed that FAT/CD36 was expressed on the sarcolemma at a level comparable to the wild-type. These findings appear to directly contradict the findings described in Chapter 5, notably the normalization of both cardiac ischemic tolerance and cardiac ATP levels by FAT/CD36 re-expression in the GR heart. Especially the latter normalization of cardiac ATP levels is strongly indicative of a rescued FAT/CD36 function. Because the differences between FAT/CD36 null and wild-type cardiac FA utilization were clearly demonstrated by our studies, the absence of electrostimulation in the in vitro experiments, which 
generally increases the metabolic demand of heart and muscle, appears not to underlie the conflicting results. Further addressing this question awaits the comparison of cardiac FAT/CD36 null and GR FA transport in vivo by assaying BMIPP uptake.

In conclusion, the present study indicates that FAT/CD36 expression levels significantly impact muscle function and performance. It would therefore be informative to determine if alterations in FAT/CD36 levels brought about by genetic or environmental factors determine muscular performance and athletic ability in humans.

\section{Acknowledgements}

The authors would like to thank Dr. T. Rosenquist for technical help in generating the transgenic animals.

\section{References}

1. Abumrad NA, Perkins RC, Park JH and Park CR. Mechanism of long chain fatty acid permeation in the isolated adipocyte. $J$ Biol Chem 256: 9183-91.91, 1981.

2. Harmon CM and Abumrad NA. Binding of sulfosuccinimidyl fatty acids to adipocyte membrane proteins: isolation and amino-terminal sequence of an $88-\mathrm{kD}$ protein implicated in transport of longchain fatty acids. J Membr Biol 133: 43-49, 1993.

3. Abumrad NA, el-Maghrabi MR, Amri EZ, Lopez E and Grimaldi PA. Cloning of a rat adipocyte membrane protein implicated in binding or transport of long-chain fatty acids that is induced during preadipocyte differentiation. Homology with human CD36. J Biol Chem 268: 1766517668,1993

4. Greenwalt DE, Lipsky RH, Ockenhouse CF, Ikeda H, Tandon NN and Jamieson GA. Membrane glycoprotein CD36: a review of its roles in adherence, signal transduction, and transfusion medicine. Blood 80: 1105-1115, 1992.

5. Van Nieuwenhoven FA, Verstijnen CP, Abumrad NA, Willemsen PH, van Eys GJ, van der Vusse GJ and Glatz JF. Putative membrane fatty acid translocase and cytoplasmic fatty acidbinding protein are comexpressed in rat heart and skeletal muscles. Biochem Biophys Res Commun 207: 747-752, 1995 .

6. Luilken JJ, 'Turcotte LP and Bonen A. Protein-mediated palmitate uptake and expression of fatty acid transport proteins in heart giant vesicles. J Lipid Res 40: 1007-1016, 1999. 
7. Greenwalt DE, Scheck SH and Rhinehart-Jones T. Heart CD 36 expression is increased in murime models of diabetes and in mice fed a high fat diet. J Clin fnves $96: 13821388,1995$.

8. Pelsers MM, Lutgerink JT, Nieuwenhoven FA, Tandon NN, wan der Vusse GJ, Arends JW, Hoogenboom MR and Glatz JF. A sensitive immunoassay for rat fatty acid translocase (CD36) using phage antibodies selected on cell transfectants: abundant presence of fatty acid translocase/CD36 in cardiac and red skeletal muscle and up- regulation in diabetes. Biochem $J 337$ : $407-414,1999$.

9. Ibrahimi A, Bonen A, Blimn WD, Hajri T, Li X, Zhong K, Cameron R and Abumrad NA. Muscle-specific overexpression of FAT/CD36 enhances fatty acid oxidation by contracting muscle, reduces plasma triglycerides and fatty acids, and increases plasma ghcose and insulin. $J$ Biol Chem 274: 26761-26766, 1999.

10. Febbraio M, Abumrad NA, Hajjar DP, Sharma K, Cheng W, Pearce SF and Silverstein RL. A null mutation in murine CD36 reveals an important role in fatty acid and lipoprotein metaloolism. $J$ Biol Chem 274: 19055-19062, 1999.

11. Coburn CT, Knapp FF, Jr., Febbraio M, Beets AL, Silverstein RL and Abumrad NA. Defective uptake and utilization of long chain fatty acids in muscle and adipose tissues of CD36 knockout mice. J Biol Chem 275: 32523-32529, 2000.

12. Pravenec M, Landa V, Zidek V, Musilova A, Kren V, Kazdova L, Aitman TJ, Glazier AM, Ibrahimi A, Abumrad NA, Qi N, Wang JM, St Lezin EM and Kurtz TW. Transgenic rescue of defective $\mathrm{Cd} 36$ ameliorates insulin resistance in spontaneously hypertensive rats. Nat Genet 27: 156158,2001 .

13. Hajri T, Ibrahimi A, Coburn CT, Knapp FF, Jr., Kurtz T, Pravenec M and Abumrad NA. Defective fatty acid uptake in the spontaneously hypertensive rat is a primary determinant of altered glucose metabolism, hyperinsulinemia, and myocardial hypertrophy. J Biol Chem 276: 23661-23666, 2001.

14. Pravenec M, Zidek V, Simakova M, Kren V, Krenova D, Horky K, Jachymova M, Mikova B, Kazdova L, Aitman TJ, Churchill PC, Webb RC, Hingarh NH, Yang Y, Wang JM, Lezin EM and Kurtx TW. Genetics of Cd36 and the clustering of multiple cardiovascular risk factors in spontaneous hypertension. J Cin Invest 103: 1651-1657, 1999.

15. Tanaka T, Nakata T, Oka T, Ogawa T, Okamoto F, Kusaka Y, Sohmiya K, Shimamoto K and Itakura $\mathbf{K}$. Defect in human myocardial long-chain fatty acid uptake is caused by FAT/CD36 mutations. J Lipid Res 42: 751-759, 2001.

16. Lee K, Godeau B, Fromont P, Plonquet A, Debili N, Bachir D, Reviron D, Gourin J, Fernandez E, Galacteros F and Bierling P. CD36 deficiency is firequent and can cause platelet immunization in Africans. Transfusion 39: 873-879, 1999. 


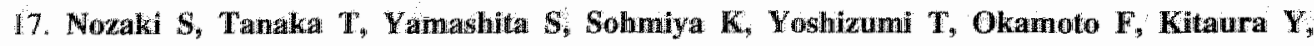
Kotake $C$, Nishida I, Nakata $A$, Nakagawa T, Mafsumoto K, Kameda-Takemura K, Tadokoro S, Kunata $\mathbf{Y}$, Tomiyama $\mathbf{Y}$, Kawamura $K$ and Matsuzawa $\mathbf{Y}$ : CD36 mediates long-chain faty acid tramsport in human myocardium: complete myocardial accumulation defect of radiolabeled long-chain fatty acid analog in subjects with CD36 deficiency. Mal Cell Biochem 192: 129-135, 1999.

18. Tanaka $\mathbb{T}$, Sohmiya $\mathbf{K}$ and Kawamura $K$. 1 SD36 deficiency an etiology of hereditary hypertrophic candiomyopathy? I Mol Cell Cardiol 29: 121-127, 1997.

19. Latemmli UK. Cleavage of structural proteins during the assembly of the head of bacteriophage T4. Name 227:680-685, 1970.

20. Yang $\mathbf{Y}$, Min JY, Rana JS, Ke Q, Cai J, Chen Y, Morgan JP and Xiao YF. VEGF enhances functional improvement of postinfarcted hearts by transplantation of ESC-differentiated cells. $J$ Appl Physiol 93: 1140-1151,2002.

21. Passonneau JV and Lauderdale VR. A comparison of three methods of glycogen measurement in tissues. Anal Fiochem 60:405-412, 1974

22. Folch $I$, Lees $M$ and Sloane Stanty GH. A simple method for the isolation and purification of total lipids from animal tissues. J Biol Chem 226:497-509, 1957.

23. Markwell MA, Haas SM, Bifeber LI, and Tolbert NE. A modification of the Lowry procedure to simplify protein detemination in membiane and lipoprotein samples. Anal Biochem 87: 206-210, 1978.

24. Schaap FG, Binas B, Danneberg H, wan der Vusse GJ and Glatz JF. Impaired long-chain fatty acid utilization by cardiac myocytes isolated from mice lacking the heart-type fatty acid binding protein gene. Circ Res 85: 329-337, 1999.

25. Hajri T, Han XX, Bomen A and Abumrad NA. Defective fatty acid uptake modulates insulin responsiveness and metabolic responses to diet in CD36-null mice. J Clin Invest 109: 1381-1389, 2002.

26. Bonen A, Iubiken JJ, Arumugam Y, Glatz IF and Tandon NN. Acute regulation of fatty acid uptake involves the cellulat redistribution of fatty acid translocase. $J$ Biol Chem 275: 1.4501-14508, 2000 .

27. Watson RT and Pessin JE. Subcellular compartmentalization and trafficking of the insulinresponsive glucose transporter, GLUT4. Exp Cell Res 271: 75-83, 2001.

28. Iuiken J.J, Willems J, Coort SL, Coumans WA, Bonen A, van der Vusse GJ and Glatz JF. Effects of CAMP modulators on long chain faty acid uptake and utilization by electrically stimulated rat cardiac myocytes. Biochen $J, 367: 881-887,2002$.

29. Levak-Frank $\mathbf{S}$, Radner $\mathbf{H}$, Walsh A, Stollberger $\mathbf{R}$, Knipping G, Hoenler $\mathbf{G}$, Sattler W, Weinstock PH, Breslow JL and Zechner R. Muscle-specific overexpression of lipoprotein lipase cutuses a severe myopathy characterized by prolliferation of mitochondria and peroxisomes in tramsgenic mice. J Clin Imwest 96: 976-986, 1995. 


\section{Chapter 5}

\section{The FAT/CD36 protein is a modulator of ischemic tolerance in the murine heart}

H. Irie, I.B. Krukenkamp, J.F.F. Brinkmann, G.R. Gaudette, A.E. Saltman, W. Jou, N.A. Abumrad and A. Ibrahimi: accepted for publication by Proc Natl Acad Sci $U S A$ 


\section{Abstract}

The membrane protein FAT/CD36 facilitates myocardial long chain fatty acid (FA) transport, which is markedly reduced in FAT/CD36 deficient rodents and humans. We examined the role of FAT/CD36 mediated FA uptake in post ischemic functional recovery of the heart.

Heart function, before and after ischemia/reperfusion, was compared in working hearts from wild type, FAT/CD36 null and FAT/CD36-rescued mice. To dissect out the role of FA uptake during the perfusions, experiments were done in the absence and presence of FAs in the perfusate. In addition, the ischemic tolerance of hearts over-expressing FAT/CD36 was also examined.

In the absence of FA, FAT/CD36 null hearts had similar cardiac output and higher end-diastolic pressure than wild type hearts. After ischemia, cardiac output was significantly lower and end-diastolic pressure significantly higher in FAT/CD36 null versus wild-type hearts. Both defects were corrected by rescuing heart FAT/CD36 expression. Moreover, hearts over-expressing FAT/CD36 displayed an increased tolerance to ischemia-reperfusion compared to their wildtype controls.

Addition of palmitate to the perfusate improved heart functional recovery from ischemia in wild-type and FAT/CD36-rescued, as well as in FAT/CD36 null hearts, but much more significantly in wild-type and FAT/CD36-rescued hearts as compared with the FAT/CD36 null hearts.

The data document that FAT/CD36-mediated FA uptake is important for optimal myocardial recovery from ischemia and FAT/CD36 deficient hearts are more likely to fail following short ischemic episodes. This may reflect the decreased ATP and glycogen levels of FAT/CD36 deficient hearts and their impaired ability to oxidize palmitate during recovery.

\section{Introduction}

Early work with rat adipocytes provided evidence for a carrier mediated component of long-chain fatty acid (FA) uptake that is specific for FA with more 
than 8-10 carbons ${ }^{1}$. Harmon and Abumrad ${ }^{2}$ identified an 88-kDa glycoprotein, FAT, later shown ${ }^{3}$ to be a homolog of human $\mathrm{CD} 36^{4,5}$ as a candidate FA transporter by labeling with transport inhibitors such as sulfo- $N$-succinimidyl derivatives of FA ${ }^{1,2}$. FAT/CD36 mRNA is abundant in tissues with active FA metabolism such as heart, skeletal muscle, adipose tissue, and intestine ${ }^{3.6-8}$.

There is strong evidence for a physiological role of FAT/CD36 in FA uptake by muscle. It was reported that muscle-targeted overexpression of FAT/CD36 in mice enhanced FA oxidation in response to contraction and decreased fasting blood levels of FA and triacylglycerol (TAG) ${ }^{9}$. Febbraio et al. generated a FAT/CD36 null mouse ${ }^{10}$ and documented significant increases in blood levels of the above lipids. Subsequent studies by Coburn et al. ${ }^{11}$ established that FA transport into the murine heart, in vivo, is largely dependent on FAT/CD36 and its deficiency decreases uptake by greater than $60 \%$. Incidence of FAT/CD36 deficiency in humans can reach $18.5 \%$ in some populations ${ }^{12}$. Humans with FAT/CD36 deficiency have a myocardial defect in FA uptake ${ }^{13,14}$ that is of a very similar magnitude to that observed in the mouse ${ }^{15}$. An association between FAT/CD36 deficiency and hypertrophic cardiomyopathy has been reported in humans ${ }^{16}$. In addition, the recently reported link between FAT/CD36 expression levels and susceptibility to insulin resistance ${ }^{17}$ suggests that it may under some conditions contribute to the etiology of diabetic cardiomyopathy. However, despite the important role of FAT/CD36-mediated FA uptake in heart metabolism, there is no documentation of how the deficiency affects heart function under unfavorable conditions such as an episode of underperfusion. Ischemia rapidly leads to a depression of FA utilization ${ }^{18,19}$, which results in the accumulation of FA in ischemic myocardium ${ }^{20}$. The high tissue FA levels during ischemia and reperfusion are likely to cause cellular damage ${ }^{20,21}$, and based on its role in FA uptake, the expression of FAT/CD36 might influence the process of FA accumulation and, in turn, cardiac recovery from ischemia.

We examined the role of FAT/CD36-facilitated FA uptake in cardiac function during ischemia-reperfusion using three mouse models with different levels of 
FAT/CD36 expression, and perfused hearts with and without FA. Cardiac output, peak developed pressure, and end-diastolic pressure was evaluated prior to and after ischemia to yield a first characterization of heart function in a model of defective FA metabolism. Our data indicate that FAT/CD36 expression, by facilitating FA uptake and utilization, enables the storage of metabolic energy in the myocytes, which would facilitate functional recovery after ischemia and reperfusion.

\section{Materials and methods}

\section{Animal Protocols}

Animals were maintained and used following the protocol approved by State University of New York at Stony Brook in accordance with New York state and Federal guidelines (IACUC\#01-0514 and IACUC\#01-0834).

\section{Animal models}

Three mouse models of altered FAT/CD36 expression were used. FAT/CD36 null mice (KO) were generated by targeted homologous recombination and backcrossed 4 times to $\mathrm{C} 57 \mathrm{BL} / 6^{10}$. FAT/CD36 null mice rescued for FAT/CD36 in heart and skeletal muscle (GR) were generated from the KO mice using the muscle creatine kinase (MCK) promoter as described in Chapter 4. Their cardiomyocytes show FAT/CD36 expression levels comparable to the wild-type, which was demonstrated by immunohistochemistry (Chapter 4). The wild-type (WT) mice for these two models had the C57BL/6 background, and were bred from the same cross as the FAT/CD36 nulls. Mice over-expressing FAT/CD36 in heart and skeletal muscle (MCK/CD36) were generated on the FVB strain background as previously described ${ }^{9}$. Their wild-type control littermates were bred from the same cross as the MCK/CD36 and, therefore, had the same FVB background. 


\section{Ischemia and reperfusion of working hearts}

Hearts were mounted on the perfusion apparatus, as previously described ${ }^{22}$, and perfused with bicarbonate buffer (KB) (in $\mathrm{mM} / \mathrm{L}, \mathrm{NaCl}, 135 ; \mathrm{NaHCO}_{3}, 25 ; \mathrm{KCl}$, $4.7 ; \mathrm{MgSO}_{4}, 1.2 ; \mathrm{KH}_{2} \mathrm{PO}_{4}, 1.2 ; \mathrm{CaCl}_{2}, 2.5 ; \mathrm{pH} 7.4$ ) containing $11 \mathrm{mM}$ glucose. In some experiments, as indicated, the buffer contained $1.2 \mathrm{mM}$ palmitate bound to $3 \%(0.44 \mathrm{mM}) \mathrm{BSA}$. The perfusate was oxygenated $\left(95 \% \mathrm{O}_{2} / 5 \% \mathrm{CO}_{2}\right)$ and maintained at a temperature of $38.5^{\circ} \mathrm{C}$ using heated water jackets (Figure 1, panel A). As shown in the figure 1 (panel A) the perfusion system could be used in two settings; retrograde (Langendorff mode) with perfusion via the aorta and antegrade (working mode), with perfusion via the left atrium. Hearts were equilibrated for 5 minutes in the Langendorff mode and were then switched to the working mode against an afterload of $50 \mathrm{~mm} \mathrm{Hg}$ (Figure 1, panel B). A 24 gauge plastic cannula, connected to a pressure catheter probe (Millar Instruments Inc), was placed in the left ventricular cavity via the apex to continuously measure endsystolic and end-diastolic pressures. Coronary flow was determined by collecting effluent from the heart and aortic flow by collecting aortic effluent from a height of $50 \mathrm{~mm} \mathrm{Hg}$ (Fig.1, panel A). Cardiac output was determined by adding the aortic and the coronary flow, and heart rates were continuously evaluated.

Preload was gradually increased from $5 \mathrm{~mm} \mathrm{Hg}$ to $25 \mathrm{~mm} \mathrm{Hg}(5 \mathrm{~mm} \mathrm{Hg}$ intervals) by rising the height of the preload reservoir and data were acquired 30 seconds after changing preload pressure at each setting. The time at each preload was less than 90 seconds and the total duration of the measurements averaged 8 minutes (Figure 1, panel B).

To examine ischemic tolerance, hearts were subjected to 6 minutes of global ischemia by occluding perfusate inflow and outflow and this was followed by 8 minutes of reperfusion, which included 5 minutes in the Langendorff mode and 3 minutes in the working mode. Then the same preload-dependent experiment was repeated, as described above (Figure 1, panel B). The mounted hearts were not paced and any heart exhibiting unstable pressure (greater than $50 \%$ variation in pressure at steady state over 120 seconds) was excluded from the study. 
A

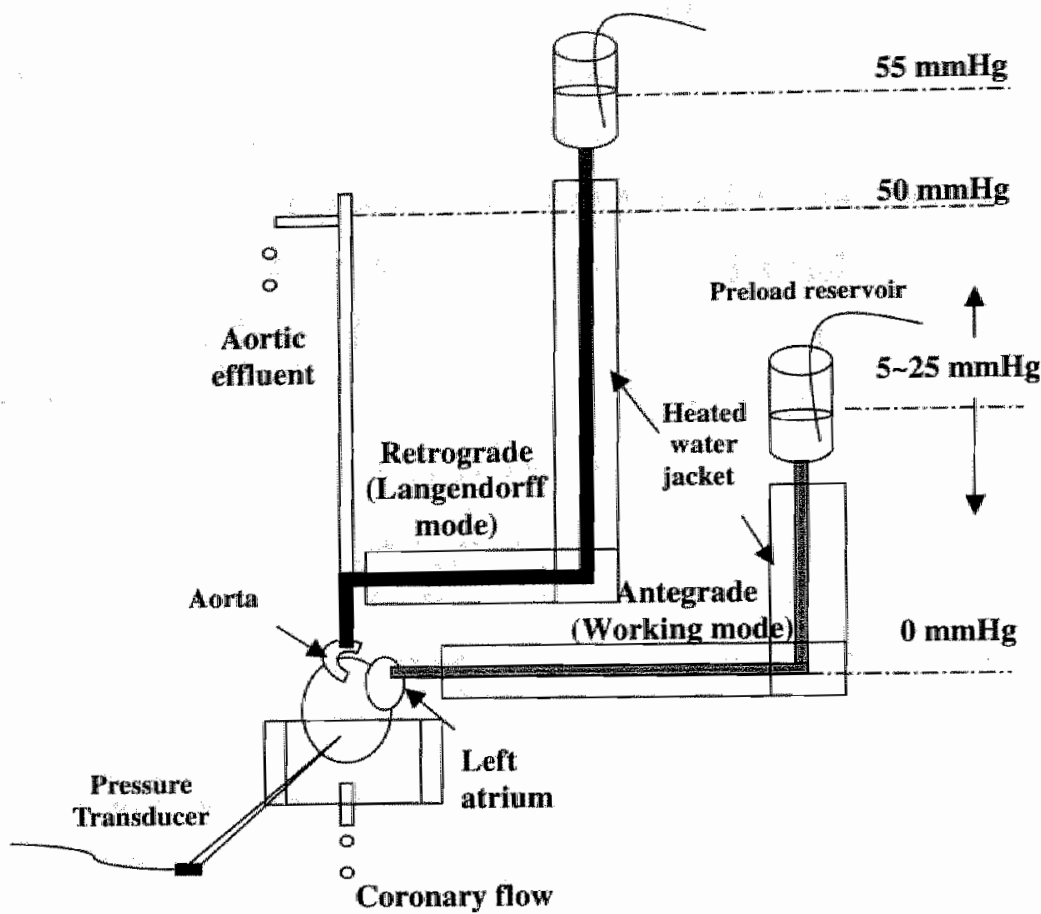

B

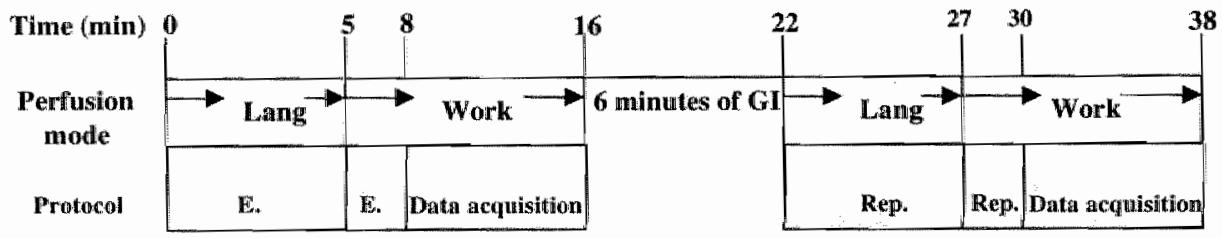

Figure 1, panel A: Experimental setting. The perfusion apparatus is shown to consist of an antegrade system, which perfuses via the left atrium (Working mode) and a retrograde system, which perfises via the aorta (Langendarff mode). Oxygenated KH was maintained at a temperature of $38.5^{\circ} \mathrm{C}$ using heated water jackets, which were installed at both perfusion lines. In the Langendorff mode, perfusion pressure was maintained at $55 \mathrm{~mm} \mathrm{Hg}$. In the working mode preload-pressure was gradually increased from $5 \mathrm{~mm} . \mathrm{Hg}$ to $25 \mathrm{~mm} \mathrm{Hg}$ by raising the height of the reservoir against $50 \mathrm{~mm}$ Hg after load pressure. Data were acquired at different preload-pressures ( $5 \mathrm{~mm} \mathrm{Hg}$ intervals).

Figure 1, panel B: Experimental protocol. A typical experimental protocol is shown. The heart is subjected to 6 minutes of global ischemia followed by 8 minutes of reperfusion. Data are acquired over the subsequent 8 min reperfusion period and cardiac performance prior to and after ischemia is evaluated. Lang: Langendorff mode, Work: Working mode, E: equilibration, GI: glabal ischewia, Rep.: reperfusion. 
ATP assay

Hearts were harvested from anesthetized mice, quickly rinsed in saline, clamped between aluminum tongs precooled in liquid nitrogen and extracted in perchloric acid. ATP concentration was determined by standard enzymatic assay using a kit from Sigma (St Louis, MO).

\section{Statistical analysis}

Comparisons between groups were made with ANOVA. As indicated, differences for pre- and post- ischemic data within groups were analyzed with the Tukey posthoc test. Significance was taken at the level of $\mathrm{p}<0.05$. Data are presented as means \pm SEM.

\section{Results}

\section{Optimal period of ischemic insult}

A 6 min period of ischemia was chosen for the studies based on extensive preliminary work, which documented that this time period was sufficient to produce ischemic injury and it was associated with recovery of the majority of hearts tested. Although longer ( 20 and $30 \mathrm{~min}$ ) periods of ischemia have been used with the rat heart ${ }^{23,24}$, they were inadequate for mice hearts. A 12 min of ischemia was associated with failure of murine hearts, as shown in Table 1 and in agreement with findings in a recent report ${ }^{25}$. Decreasing the ischemic episode to $8 \mathrm{~min}$ was still associated with relatively poor recovery of wild type hearts (43\%, Table 1) while with $6 \mathrm{~min}$ of ischemia, the majority recovered. However, recovery of hearts from KO mice after 6 min ischemia remained lower than that from wild-type and GR hearts. As shown in Table 1, 27 and $20 \%$ of wild type and GR hearts failed to recover after $6 \mathrm{~min}$ of ischemia as compared with $45 \%$ of KO hearts. 
Table 1: Percentage of heart survival following global ischemia.

\begin{tabular}{lcccc}
\hline Time of & & & & \\
global ischemia: & $0 \mathrm{~min}$ & $6 \mathrm{~min}$ & $8 \mathrm{~min}$ & $12 \mathrm{~min}$ \\
\hline WT & $100 \%(20)$ & $73 \%(14)$ & $43 \%(9)$ & $0 \%(5)$ \\
KO & $100 \%(20)$ & $55 \%(22)$ & N/A & $0 \%(5)$ \\
GR & $100 \%(20)$ & $80 \%(10)$ & N/A & $0 \%(5)$ \\
\hline
\end{tabular}

Hearts were subjected to different periods of ischemia and the percentage of heart survival is shown: The hearts were considered failing when they had ventricle arrhythmia (persistent ventricular fibrillations (VF) or absence of any aortic flow (against $55 \mathrm{~mm} \mathrm{Hg}$ after load pressure, the left veritricle was incapable of producing any forward pressure). The number of cases is between parentheses. N/A: data not available.

\section{FAT/CD36 deficiency and ischemic tolerance}

Cardiac function prior to and post-ischemia was evaluated in working hearts isolated from KO ( $n=10)$, WT $(n=9)$ and GR $(n=5)$ mice. There were no differences in body and heart weights among the groups (Table 2). However, the heart/body weight ratio was significantly higher in FAT/CD36 $\mathrm{KO}$ mice as compared to WT mice (Table 2). The hearts of all three groups showed a stable heart rate throughout the experiment, and differences in heart rates, either before or after ischemia were not observed.

Table 2: Body and heart weights for wild-type (WT), FAT/CD36 null (KO) and FAT/CD36 generescued mice (GR)

\begin{tabular}{lccc}
\hline Group (Number) & Body weight $(\mathrm{g})$ & Heart weight $(\mathrm{g})$ & Heart/Body (X 100) \\
\hline WT $(\mathrm{n}=15)$ & $26.6 \pm 0.8$ & $0.24 \pm 0.01$ & $0.91 \pm 0.02$ \\
KO $(\mathrm{n}=15)$ & $25.4 \pm 0.7$ & $0.26 \pm 0.01$ & $1.01 \pm 0.03 *$ \\
GR $(\mathrm{n}=10)$ & $26.0 \pm 0.9$ & $0.24 \pm 0.02$ & $0.94 \pm 0.04$ \\
\hline
\end{tabular}

Data are mean ( $\pm S E M)$. All hearts were weighted at the end of the experiments. * $p<0.05 ; W T$ vs. KO. 
Cardiac output--Figure 2 shows cardiac output as a function of preload pressure. Prior to ischemia (Figure 2, panel A, left), cardiac output generally increased as preload pressure was increased. After global ischemia (Figure 2, panel A, right), the cardiac output decreased in all groups but the decrease was most dramatic in the $\mathrm{KO}$ mice. A direct comparison across groups of cardiac output at $15 \mathrm{~mm} \mathrm{Hg}$ preload pressure is shown in panel B of Figure 2. Prior to ischemia, there was no significant difference in cardiac output between the groups. Following the ischemic insult, cardiac output decreased significantly in WT ( $<<0.05$, vs. pre-ischemia) and KO mice ( $p<0.01$, vs. pre-ischemia). On the other hand, the decrease in cardiac output was less pronounced and did not reach statistical significance in GR mice. Across the groups, cardiac output in KO was significantly lower when compared to both WT $(\mathrm{p}<0.05)$ and $\mathrm{GR}(\mathrm{p}<0.01)$

End-diastolic pressure-- Figure 3 (panel A) shows end-diastolic pressure as a function of preload pressure. Prior to ischemia, end-diastolic pressure gradually increased with raising preload pressure. KO mice had higher end-diastolic pressure as compared with WT and GR mice. The increase in end-diastolic pressure observed in hearts from KO mice was partially corrected in GR mice. After ischemia (Figure 3, panel A, right), end-diastolic pressures increased in all groups but the effect was most pronounced in hearts from FAT/CD36 null mice. A comparison across groups is shown for $15 \mathrm{~mm} \mathrm{Hg}$ preload pressure in panel $B$ of Figure 3. Prior to ischemia, end-diastolic pressure was significantly higher $(p<0.01)$ in KO compared with WT. Following the ischemic insult, end-diastolic pressure increased significantly only in $\mathrm{KO}$ mice $(\mathrm{p}<0.05)$ and was higher than that for WT $(p<0.01)$ and GR $(p<0.05)$, documenting the more severe impact of the ischemic insult on hearts from FAT/CD36 null mice.

The above findings show that, under non-ischemic conditions, FAT/CD36 deficient hearts have a slightly lower cardiac output but a significantly increased end-diastolic pressure. FAT/CD36 deficiency significantly reduced tolerance to ischemia and this could be reversed by rescuing FAT/CD36 expression in cardiomyocytes. 


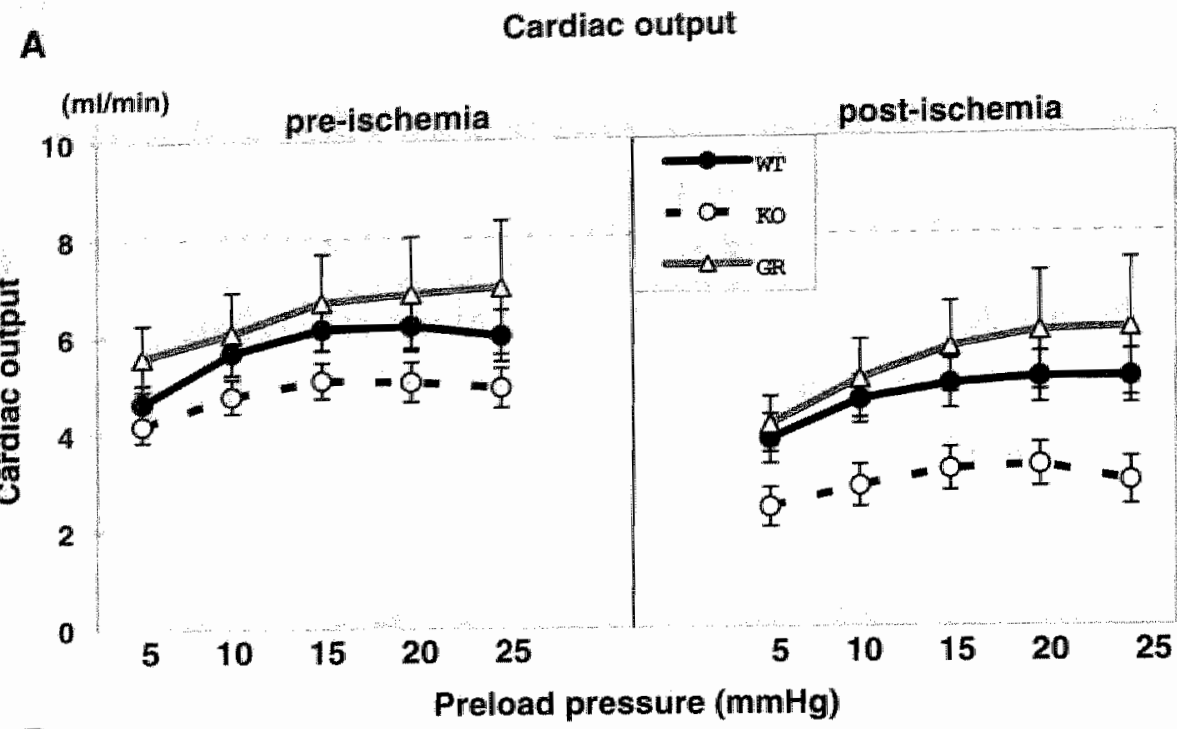

B
( $\mathrm{m} / \mathrm{m} / \mathrm{min})$
Cardiac output at $15 \mathrm{mmHg}$ preload

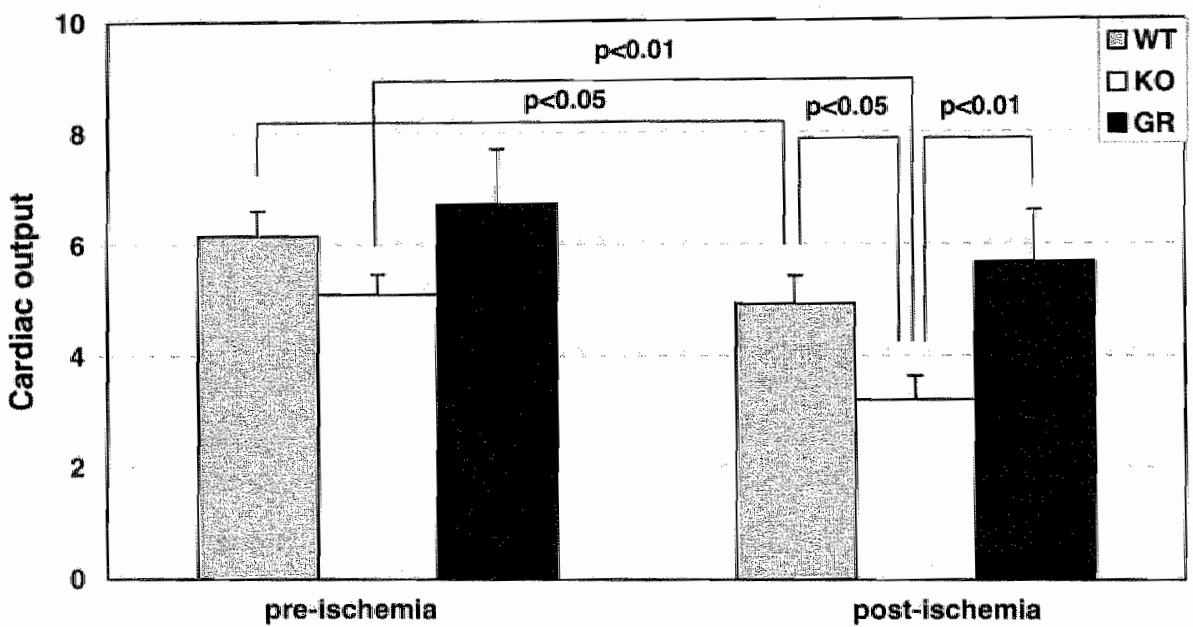

Figure 2: Cardiac ontput of WT, KO, and GR mice. Cardiac output of wild-iype (WT), FAT/CD36 null (KO) and gene-rescued (GR) mice is shown in panel $A$ as a function of increasing preload pressures ( $\mathrm{mm} \mathrm{Hg}$ ). Hearts were compared prior to and afrer 6 minutes of global ischemia and 8 minutes of reperfusion. Panel B compares heart cardiac output across groups at 15 mm $\mathrm{Hg}$ preload pressure prior and post ischemia and reperfusion. 
A

\section{End diastolic pressure}

$(\mathrm{mmHg})$

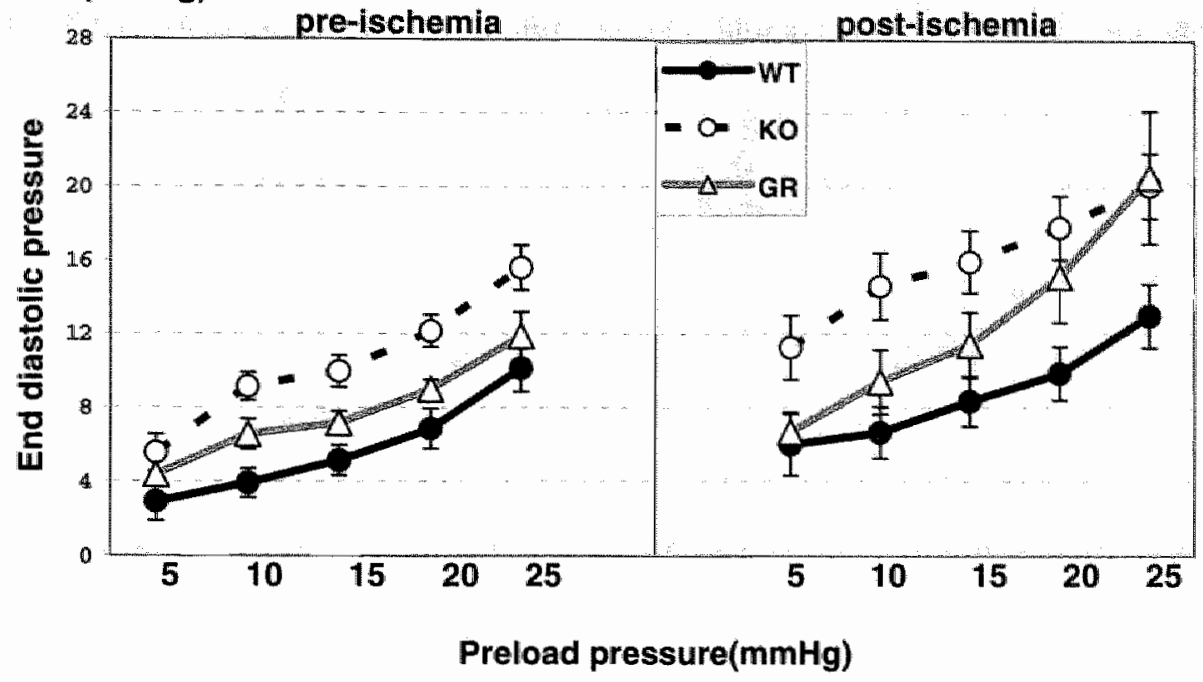

B

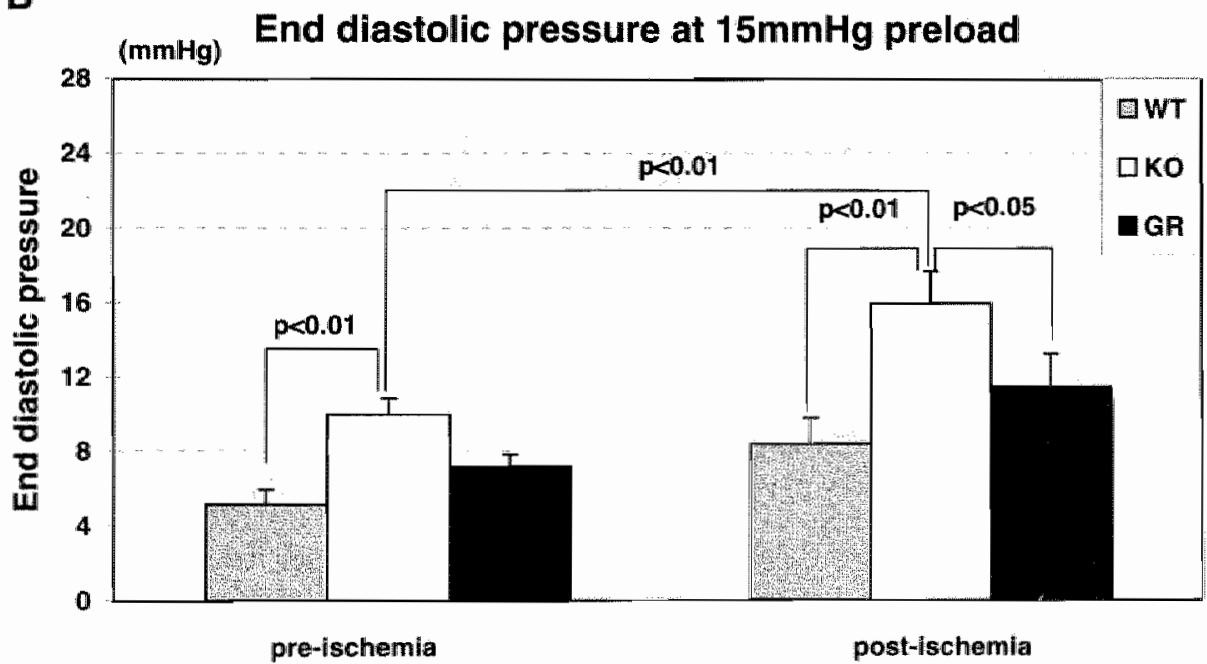

Figure 3: End-diastolic pressure of WT, KO and GR mice. End-diastolic pressure of hearts from wild-type (WT). FAT/CD36 null (KO) and gene-rescued (GR) mice was evaluated at increasing preload pressure (panel A). Hearts were compared prior to and after 6 minutes of global ischemia and 8 mimutes of reperfusion. Panel $\mathrm{B}$ compares across groups, end-diastolic pressure at $15 \mathrm{~mm} \mathrm{Hg}$ of preload pressure prior and post ischemia and reperfusion. 
FAT/CD36 overexpression and ischemic tolerance

To examine whether FAT/CD36 overexpression above wild-type levels could exert a protective effect against ischemia, cardiac function prior to and post-ischemia was analyzed in working hearts isolated from transgenic mice (MCK/CD36, $n=6$ ) with two to four fold myocardial overexpression of FAT/CD36 and compared to that of wild-type controls ( $\mathrm{Cnt}, \mathrm{n}=6$ ). The mice were chosen to have similar body weights and significant differences in heart weight were absent (data not shown). Heart rates were stable throughout the experiments, and MCK/CD36 hearts showed the same heart rate as their controls, both before and after the ischemic period. Data obtained with different preload pressures were consistent, and only the $15 \mathrm{~mm} \mathrm{Hg}$ data are shown in Figure 4 for clarity. Prior to ischemia, significant differences in cardiac output and end-diastolic pressure were absent (Figure 4, left). After ischemia, however, the cardiac output of MCK/CD36 hearts was significantly higher than that of wild-type control hearts $(p<0.05)$, while their end-diastolic pressure was significantly lower $(\mathrm{p}<0.01)$ (Figure 4, right). FAT/CD36 overexpression thus appears to significantly improve myocardial tolerance to ischemia.

\section{The effect of FA utilization during ischemic recovery}

In the set of studies described above, hearts were perfused with bicarbonate buffer (KB) without any FA. FAT/CD36 is well known to bind thrombospondin ${ }^{26}$, an anti-angiogenic factor that might affect the myocardium. In addition, recent work showed that FAT/CD36 mediates the cardiovascular effects of growth hormone releasing peptides ${ }^{27}$. Thus structural effects unrelated to FA uptake could contribute to the functional differences described above. Therefore, we also used a perfusate plus FA, in an effort to dissect out the contribution of defective FA uptake to any of the observed effects on heart function. Hearts from FAT/CD36 null ( $\mathrm{KO}-\mathrm{FA}, \mathrm{n}=5$ ), gene-rescued (GR-FA, $\mathrm{n}=5$ ) and wild-type mice (WT-FA, $\mathrm{n}=$ 6) were perfused with buffer containing $11 \mathrm{mM}$ glucose and $1.2 \mathrm{mM}$ palmitate with 
A

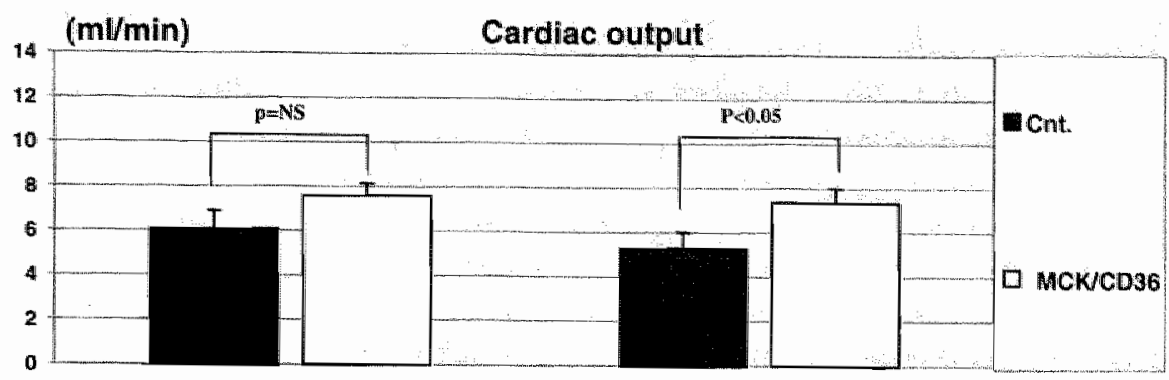

Pre-ischemia

Post-ischemia

$\mathrm{B}$

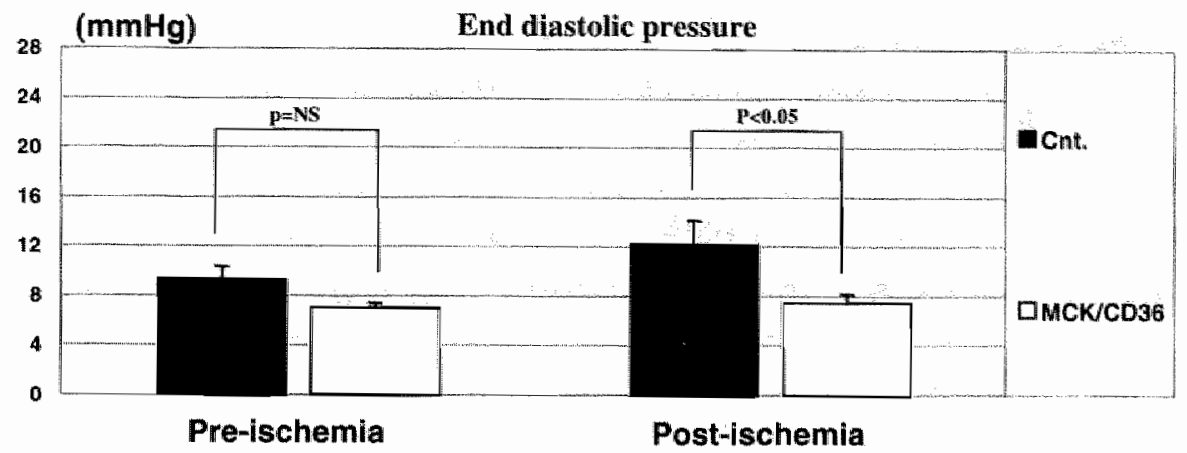

Figure 4: Cardiac performance of $M C K / C D 36$ mice. Cardiac prefornance of wild-type control mice (CMt) and FAT/CD36 overexpressing mice (MCK/CD36) was compared prior to and after 6 minutes of global ischenia and 8 minutes of reperfusion. Panel A shows cardiac output at $15 \mathrm{~mm}$ Hg preload. End-diastolic pressure at $15 \mathrm{~mm}$ Hg preload is shown in panel B.

$3 \% \mathrm{BSA}$, and recovery from ischemia was assessed and compared to that of hearts perfused with glucose but without FA.

Hearts from WT and GR mice perfused in the presence of palmitate showed significantly better recovery of cardiac output after ischemia as compared to that from KO mice (Figure 5, panel A). So the addition of FA to the perfusate did not alter the differences previously noted between the groups. Although palmitate appeared to improve cardiac output for all groups, statistical significance was not reached.

Addition of palmitate to the $\mathrm{KB}$ buffer decreased end-diastolic pressure after ischemia significantly in hearts from wild-type and GR mice (Figure 5, panel B) but no significant effect was observed in hearts from $\mathrm{KO}$ mice. Whereas wild-type 
and GR hearts displayed post-ischemic end-diastolic pressures comparable to the pre-ischemic values, the elevation of the post-ischemic end-diastolic pressure of KO hearts remained comparable to that measured in the absence of palmitate (Figure 5, panel B).

In summary, addition of FA improved heart recovery after ischemia, with the significant effect being on end-diastolic pressure. FAT/CD36 expression appeared necessary for full manifestation of this effect.

\section{ATP content of FAT/CD 36 null and FAT/CD36-rescued hearts}

Glycogen and TAG levels were previously found to be considerably reduced in FAT/CD36 null hearts ${ }^{17}$. As shown in Table 3, also a significantly lower tissue content of adenosine tri-phosphate content (ATP) was measured in FAT/CD36 deficient tissue. Prior to ischemia, ATP levels (Table 3) were significantly lower in KO hearts as compared to those of WT and were restored to normal levels in hearts rescued for FAT/CD36. Ischemia/reperfusion was associated with a decrease of ATP levels in all hearts and normal levels were restored when palmitate was added during the reperfusion (Table 3). However, ATP levels in KO hearts perfused with palmitate remained significantly lower than those in WT and GR hearts.

Table 3: ATP lovels in hearts from wild-type mice (WT), FAT/CD36 null mice (KO) and FAT/CD36 gene-rescued mice (GR)

\begin{tabular}{|c|c|c|c|}
\hline \multirow[t]{2}{*}{ Group (Number) } & \multicolumn{3}{|c|}{ ATP ( $\mu$ mol/g of tissue wet weight) } \\
\hline & Pre-ischemia & $\begin{array}{l}\text { Post-ischemia } \\
\text { (without FA) }\end{array}$ & $\begin{array}{c}\text { Post-ischemia } \\
\text { (with FA) }\end{array}$ \\
\hline$W T(n=4)$ & $7.15 \pm 0.57$ & $3.55 \pm 0.87$ & $8.71 \pm 1.07$ \\
\hline$K O(n=4)$ & $3.15 \pm 0.27 *$ & $2.15 \pm 0.61 *$ & $5.07 \pm 0.57^{*}$ \\
\hline$G R(n=4)$ & $5.45 \pm 0.52$ & $3.32 \pm 0.31$ & $7.12 \pm 0.81$ \\
\hline
\end{tabular}

ATP concentration was derermined by a standard enzymatic assay. Pre-ischemia levels mere obtained from normal hearts before any manipulation. Post-ischemia levels were determined from both hearts perfused with and without the presence of $1.2 \mathrm{mM}$ palmitate complexed to $3 \% \mathrm{BSA}$ in the KB perfusion buffer. Data are mern $( \pm S E M), * p<0.01$. WT and GR versus KO. 


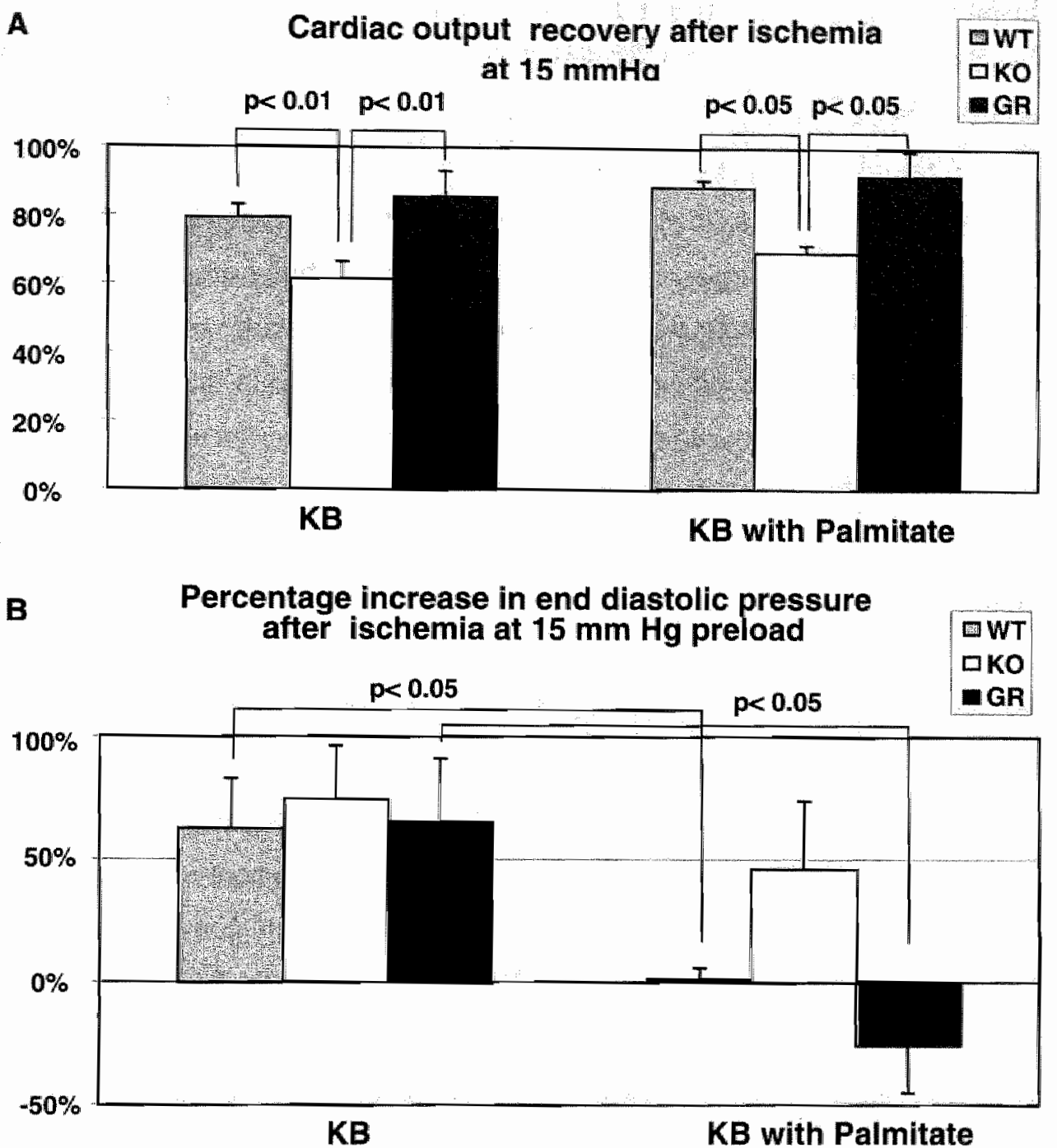

Figure 5: Effect of palmitate in the perfusate on cardiac tolerance to ischemia. Hearts from wildtype (WT), FAT/CD36 null (KO) and FAT/CD36 gene-rescued mice were perfused with KB buffer containing $1.2 \mathrm{mM}$ palmitate bound to $0.44 \mathrm{mM}$ bovine serwm albusnin. Recovery from ischemia was assessed and compared to hearts in figures 3 and 4, which were perfused with bicarbonate buffer without FA. Cardiac autput is shown in panel $A$ as the ratio of post ischemic to the pre-ischemic values. $100 \%$ represent the pre-ischemic cardiac output for each group. The alterations of enddiastolic pressure after ischemia expressed as the \% increase of the end-diastolic pressure postcompared to the values pre-ischemia are shown in panel $B$. 0\% represents the pre-ischenic enddiastolic pressure for each group. 


\section{Discussion}

The data presented in this chapter demonstrate an important role for FAT/CD36facilitated FA transport in cardiac performance and tolerance to ischemia. Hearts from FAT/CD36 null mice showed an impaired tolerance to global ischemia and were more likely to fail following a short ischemic episode. The protective effect of FAT/CD36 expression appears to reflect increased availability of stored energy in the heart prior to ischemia, which would provide for metabolic needs during the ischemic episode and facilitate recovery during reperfusion. In line with this, FA addition generally improved ischemic tolerance. This improvement was displayed in the end-diastolic pressures measured in our working heart preparation and not significant for FAT/CD36 null hearts, which could not utilize FA and which exhibited poor ischemic tolerance whether FA was absent or included in the perfusion buffer. Furthermore, hearts over-expressing FAT/CD36 showed an increased tolerance to ischemia. All our clata are consistent with the concept that cellular energy derived from FAT/CD36 mediated FA uptake is an important determinant of ischemic tolerance of the heart.

The role of FAT/CD36 in muscle FA uptake ${ }^{11}$ and in energy production has been established in vivo ${ }^{9,28,29}$. FAT/CD36 expression levels correlate well with relative rates of FA utilization ${ }^{28,29}$ and a rate-limiting role of $\mathrm{FAT} / \mathrm{CD} 36$-facilitated FA uptake in FA metabolism has been documented both in transgenic mice overexpressing FAT/CD36 ${ }^{\circ}$ and in FAT/CD36 null mice ${ }^{11,26}$. In line with this, muscle contraction (rats and mice) was shown to lead to increased membrane expression of FAT/CD36, which enhances FA transport and consequently FA utilization and ATP production ${ }^{9,28.29}$. The working heart must produce a constant and abundant supply of ATP and under normal conditions this is contributed to a large extent $(50-80 \%)$ by uptake and utilization of $\mathrm{FA}{ }^{30,31}$. The FAT/CD36 null heart, which cannot utilize FA exhibits a large compensatory increase in glucose utilization ${ }^{17}$. However, this increase is apparently not sufficient for maintaining optimal levels of cellular energy stores, which makes the FAT/CD36 null heart vulnerable to insult from ischemic episodes. 
The availability of palmitate during the reperfusion period improved recovery of the heart following ischemia presumably by increasing FA uptake and oxidation thereby accelerating the restoration of normal energy levels which was documented by the measured increases in tissue ATP levels. It has been shown that the extent of mechanical recovery of the injured heart after ischemia is dependent on the amount and availability of substrate metabolized upon reperfusion ${ }^{32}$. In wild-type and GR mice, cardiac output was significantly improved by addition of palmitate and a significantly better diastolic recovery was observed. The slight improvement of ischemic recovery observed in FAT/CD36 deficient hearts in presence of palmitate may reflect the activity of FA transporters other than FAT/CD36 or FA entering myocytes passively. As previously documented, FAT/CD36 mediates $60-80 \%$ of myocardial FA uptake ${ }^{11.33}$.

In contrast to our findings, Lopaschuk et al. showed that high levels of FA delay recovery of cardiac efficiency in post-ischemic hearts by inhibition of glucose oxidation ${ }^{34}$. However, these experiments were done in rat hearts using a long period of reperfusion ( 40 minutes) where FA oxidation may have been impaired. It has been documented that tisste insult from reperfusion is linked to the reperfusion time length ${ }^{35-37}$. So it is possible that in our experiments, since hearts were subjected to a short period of reperfusion ( 8 minutes), the resulting damage was limited. Toxic effect of FA in the perfusion buffer may thus be linked to a declining ability of the myocardium to oxidize them when the reperfusion time is prolonged.

Our data do not rule out contribution of factors independent of FA metabolism to the low ischemic tolerance of FAT/CD36 null hearts. An indirect role of hypertrophic signaling pathways, which lead to transcriptional and morphological changes in the heart may contribute to the altered functional responses of the FAT/CD36-deficient myocardium to ischemia. For example, the c-Jun $\mathrm{N}$-terminal kinases (JNK) pathway ${ }^{38}$, that is activated by thrombospondin, a ligand for FAT/CD36 ${ }^{39}$ may be altered with FAT/CD36 deficiency. In endothelial cells, thrombospondin is a potent inhibitor of angiogenesis and morphogenesis mediated 
by inducing a rapid activation of $\mathrm{JNK}^{39}$ and this activation requires engagement of the FAT/CD36 receptor. More studies are needed to investigate the role of FAT/CD36 expression in this signating pathway and whether it plays a role in ventricle remodeling.

Our findings are likely to be relevant to humans. Several studies report an association between deficiency of FAT/CD36, defective myocardial FA uptake and hypertrophic cardiac myopathy ${ }^{14,16,40,41}$. The FAT/CD36 null mouse heart may be a valuable model for the heart of the FAT/CD36-deficient human since the defect in myocardial FA uptake measured in vivo is similar in both mouse and human ${ }^{1.5}$ and approximates $70 \%$. In addition, hearts from FAT/CD36 null mice exhibit signs of hypertrophy as shown by the significant increase in heart/body weight ratio. Clinically, the incidence of FAT/CD36 deficiency is high in some subpopulations such as Japanese, Africans and African-Americans where it ranges from 3 to $18.5 \%{ }^{42-44}$. The present study suggests that it would be important to determine whether humans with FAT/CD36 deficiency are also more susceptible to heart dysfunction and fatlure from ischemic episodes.

Finally, it has been recently documented that normal FAT/CD36 expression is important for the metabolic adaptation to the diet and FAT/CD36 deficiency increases susceptibility to insulin resistance from diets high in simple sugars ${ }^{17}$. Such high glycemic diets have been shown to contribute to the pathogenesis of the metabolic syndrome in humans ${ }^{12}$. As a result complications from the metabolic consequences of FAT/CD36 deficiency could contribute to undermine myocardial function. Gene therapy with FAT/CD36 may be one approach to improve myocardial recovery from short ischemic episodes and to address other underlying myocardial diseases associated with FAT/CD36 deficiency. 


\section{References}

1. Abumrad N, Harmon C and Ibrahimi A. Mermbrane transport of long-chain fatty acids: evidence for a facilitated process. J Lipid Res 39: 2309-2318, 1998.

2. Harmon CM and Abumrad NA. Binding of sulfosuccinimidyl fatty acids to adipocyte nzembrane proteins: isolation and amino-ferminal sequence of an $88-\mathrm{kD}$ protein implicated in transport of longchain fatty acids. $J$ Membr Biol 133: 43-49, 1993.

3. Abumrad NA, el-Maghrabi MR, Amri EZ, Lopez E and Grimaldi PA. Cloning of a rat adipocyte membrane protein implicated in binding or transport of long-chain fatty acids that is induced during preadipocyte differentiation. Homology with human CD36. J Biol Chem 268: 17665$17668,1993$.

4. Tandon NN, Lipsky RH, Burgess WH and Jamieson GA. Isolation and characterization of platelet glycoprotein IV (CD36). J Biol Chem 264: 7570-7575, 1989.

5. Oquendo P, Hundt $\mathbb{E}$, Lawler J and Seed B. CD36 directly mediates cytoadherence of Plasmodium falciparum parasitized erythrocytes. Cell 58: 95-101, 1989.

6. Van Nieuwenthoven FA, Verstijnen CP, Abumrad NA, Willemsen PH, wan Eys G.ll, van der Yusse GJ and Glatz JF. Putative membrane fatty acid translocase and cytoplasmic fatty acidbinding protein are co-expressed in rat heart and skeletal muscles. Biochem Biophys Res Commun 207: 747-752, 1995 .

7. Poirier H, Degrace P, Niot I, Bernard A and Besnard P. Localization and regulation of the putative membrane fatty-acid transporter (FAT) in the small intestine. Comparison with fatty acidbinding proteins (FABP). Eur J Biochem 238: 368-373, 1996.

8. Chen M, Yang Y, Braunstein E, Georgeson KE and Harmon CM. Gut expression and regulation of FAT/CD36: possible role in fatty acid transport in rat enterocytes. Am I Physiol Endocrinol Metab 281: E916-E923, 2001.

9. Ibrahimi A, Bonen A, Blinn WD, Hajri T, Li X, Zhong $K$, Cameron $R$ and Abumrad NA. Muscle-specific overexpression of FAT/CD36 enhances fatty acid oxidation by contracting muscle, reduces plasma triglycerides and fatty acids, and increases plasma glucose and insulin. $J$ Biol Chem $274: 26761-26766,1999$.

10. Febbraio M, Abumrad NA, Hajjar DP, Sharma K, Cheng W, Pearce SF and Silverstein RL. A null mutation in murine CD36 reveals an important rolle in fatty acid and lipoprotein metabolism. $j$ Biol Chem 274: 19055-19062, 1999.

11. Coburn CT, Knapp FF, Jr., Febbraio M, Beets AL, Silverstein RL and Abumrad NA. Defective uptake and utilization of long chain fattry acids in muscle and adipose tissues of CD36 knockout mice. J Biol Chem 275: 32523-32529, 2000. 
12. Aitman TJ, Cooper LD, Norsworthy PJ, Wahid FN, Gray JK, Curtis BR, McKeigue PM, Kwiatkowski D, Greenwood BM, Snow RW, Hill AV and Scott J. Malaria susceptibility and CD36 mutation. Nature 405: 1015-1016, 2000.

13. Nocaki $\mathbf{S}$, Tanaka T, Yamashita $\mathbf{S}$, Sohmiya $\mathbf{K}$, Yoshizumi $\mathbf{T}$, Okamoto $\mathbf{F}$, Kitaura $\mathbf{Y}$, Kotake C, Nishida H, Nakata A, Nakagawa T, Matsumoto K, Kameda-Takemura K, Tadokoro S, Kurata $Y$, Tomiyama $Y$, Kawamura $K$ and Matsuzawa $Y$. CD36 mediates long-chain fatty acid transport in human myocarditun: complete myocardial accumulation defect of radiolabeled long-chain fatty acid anallog in subjects with CD36 deficiency. Mol Cell Biochem 192: 129-135, 1999.

14. Tanaka T, Nakata T, Oka T, Ogawa T, Okamoto F, Kusaka Y, Sohmiya K, Shimamoto K and Itakura $\mathbf{K}$. Defect in human myocardial long-chain fatty acid uptake is caused by FAT/CD36 mutations. J Lipta Res 42: 751-759, 2001.

15. Fukuchi K, Nozaki S, Yoshizumi T, Hasegawa S, Uehara T, Nakagawa T, Kobayashi T, Tomiyama Y, Yamashita S, Matsuzawa Y and Nishimura T. Enhanced myocardial glucose use in patients with a deficiency in long-chain fatty acid transport (CD36 deficiency). J Nucl Med 40: 239$243,1999$.

16. Tanaka T, Sohmiya $\mathbf{K}$ and Kawamura $\mathbf{K}$. Is CD36 deficiency an etiology of hereditary hypertrophic cardiomyopathy? J Mol Cell Cardiol 29: 121-127, 1997.

17. Hajri T, Han XX, Bonen A and Abumrad NA. Defective fatty acid uptake modulates insulin responsiveness and metabolic responses to diet in CD36-null mice. $J$ Clin Invest 109: 1381-1389, 2002.

18. Myears DW, Sobel BE and Bergmann SR. Substrate use in ischemic and reperfused canine myocardium: quantitative considerations. Am. J Physiol 253: H107-H.114, 1987.

19. Opie LH, Owen P and Riemersma RA. Relative rates of oxidation of glucose and free fatty acids by ischaemic and non-ischaenic myocardiun after coronary artery ligation in the dog. Eur $J$ Clin Invest $3: 419-435,1973$.

20. Van der Vusse GJ, Glatz JFC, Stam HCG and Reneman RS. Fatty acid homeostasis in the normoxic and ischemic heart. Physiol Rev 72: 881-940, 1992.

21. Katz AM and Messine FC. Lipid-membrane interactions and the pathogenesis of ischemic damage in the myocardium. Circ Res 48: 1-16, 1981.

22. Matsuyama N, Leavens JE, McKinnon D, Gaudette GR, Aksehirli TO and Krukenkamp IB. Ischemic but not pharmacological preconditioning requires protein synthesis. Circulation 102: III $312-318,2000$.

23. Babsky A, Hekmatyar $\mathbf{S}$, Wehrli $S$, Doliba $N$, Osbakken $M$ and Bansal $N$. Influence of ischemic preconditioning on intracellular sodium, $\mathrm{pH}$, and cellular energy status in isolated perfused heart. Exp Biol Med (Maywood) 227: 520-528, 2002. 
24. Gustafsson AB, Sayen MR, Williams SD, Crow MT and Gottlieb RA. TAT protein transduction into isolated perfused hearts: TAT-apoptosis repressor with caspase recruitment domain is cardioprotective. Circulation 106: 735-739, 2002.

25. De Windt LJ, Willems J, Roemen TH, Coumans WA, Reneman RS, van der Vusse GJ and wan Bilsen M. Ischemic-reperfused isolated working mouse hearts: membrane damage and type IIA phospholipase A2. Am J Physiol Heart Circ Physiol 280: H2572-H2580, 2001.

26. Febbraio M, Hajjar DP and Silverstein RI. CD36: a class B scavenger receptor inwolved in angiogenesis, atherosclerosis, inflammation, and lipid metabolism. J Clin Imwest 108: 785-791, 2001.

27. Bodart V, Febbraio M, Demers A, MeNicoll N, Pohnankova P, Perreault A, Sejlitz T, Escher E, Silverstein RL, Lamontagne D and Ong H. CD36 mediates the cardiovascular action of growth hormone-releasing peptides in the heart. Circ Res 90: 844-849, 2002.

28. Bonen A, Dyck DJ, Ibrahimi A and Abumrad NA. Muscle contractile activity increases fatty acid metabolism and transport and FAT/CD36. Am J Physiol 276: E642-E649, 1999.

29. Luiken .JJ, Turcotte LP and Bonen A. Protein-mediated palmitate uptake and expression of fatty acid transport proteins in heart giant vesicles. J Lipid Res 40: 1007-1016, 1999.

30. Lopaschuk GD, Belke DD, Gamble J, Itoi T and Schonekess BO. Regulation of fatty acid oxidation in the mammalian heart in health and disease. Biochim Biophys Acta 1213: 263-276, 1994 .

31. Belke DD, Larsen TS, Lopaschuk GD and Severson DL. Glucose and fatty acid metabolism in the isolated working mouse heart. Am J Physiol 277: R1210-R1217, 1999.

32. Saddik M and Lopaschuk GD. Myocardial triglyceride turnover during reperfusion of isolated rat hearts subjected to a transient period of global ischemia. J Biol Chem 267: 3825-3831, 1992.

33. Luiken JJ, van Nieuwenhoven FA, America G, van der Vusse GJ and Glatz JF. Uptake and metabolism of palmitate by isolated cardiac myocytes from adult rats: involvement of sarcolemmal proteins. J Lipid Res 38: 745-758, 1997.

34. Liu Q, Docherty JC, Rendell JC, Clanachan AS and Lopaschuk GD. High levels of fatty acids delay the recovery of intracellular $\mathrm{pH}$ and cardiac efficiency in post-ischemic hearts by inhibiting glucose oxidation. JAm Coll Cardiol 39: 718-725, 2002.

35. Schrijvers AH, de Groot MJ, Heijnen VV, van der Vusse GJ, Frederik PM and Reneman RS. Ischemia and reperfusion induced multilamellar vesicles in isolated rabbit hearts: time correlation between morphometric data and metabolic alterations. J Mol Cell Cardiol 22: 653-665, 1990.

36. Mitchell MB, Winter $\mathbf{C B}$, Banerjee $\mathbf{A}$ and Harken AH. The relationship between ischemia. reperfusion injury, myocardial stunning and cardiac preconditioning. Surg Gynecol Obstet 177; 97$114,1993$.

37. Reffelmann T, Hale SL, Li G and Kloner RA. Relationship between no reflow and infarct size as influenced by the duration of ischemia and reperfusion. Am I Physiol Heart Circ Physiol 282: $\mathrm{H} 766-\mathrm{H} 772,2002$. 
38. Fun SG, Dickens $\mathbf{M}$ and Fuller SJ. c-Jun $\mathbb{N}$-terminal kinase-interacting protein 1 inhibits gene expression in response to hypertrophic agonists in neonatal rat ventricular myocytes. Biochem $I 358$ : $489-495,2001$.

39. Jimenex B, Vollpert $O V$, Reiher $F$, Chang $L$, Munoz A, Karin $M$ and Bouck $N$. c-Jun Nterminal kinase activation is required for the inhibition of neovascularization by thrombospondin- 1 . Oncogene 20: $3443-3448,2001$.

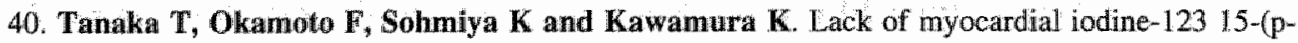
iodiphenyl)-3-R,S-methylpentadecanoic acid (BMIPP) uptake and CD36 abnormality-CD36 deficiency and hypertrophic cardiomyopathy. Jpn Circ J 61: 724-725, 1997.

41. Kashíwagi H, Tomiyama Y, Nozaki S, Kiyoi T, Tadokoro S, Matsumoto K, Honda S, Kosugi S, Kurata $\mathbf{Y}$ and Matsuzawa $\mathbf{Y}$. Analyses of genetic abnormalities in type I CD36 deficiency in Japan: identification and cell biological characterization of two novel mutations that cause $\mathrm{CD} 36$ deficiency in man. Hum Genet 108: 459-466, 2001.

42. Hirooka K, Yasumura Y, Ishida Y, Komamura K, Hanatani A, Nakatani S, Yamagishi M and Miyatake $\mathbf{K}$. Improvement in cardiac function and free fatty acid metabolism in a case of dilated cardiomyopathy with CD36 deficiency. Jpn Circ J 64: 731-735, 2000.

43. Lee K, Godeau B, Fromont P, Plonquet A, Debili N, Bachir D, Reviron D, Gourin J, Fernandez E, Galacteros F and Bierling P. CD36 deficiency is frequent and can cause platelet immunization in Africans. Transfusion 39: 873-879, 1999.

44. Takeishi Y, Chiba J, Abe S, Tonooka I, Komatani A and Tomoike H. Heterogeneous nyocardial distribution of iodine-123 15-(p-iodophenyl)-3-R,S-methylpentadecanoic acid (BMIPP) in patients with hypertrophic cardiomyopathy. Eur J Nucl Med 19: 775-782, 1992. 


\section{Chapter 6}

\section{Targeted disruption of heart-type fatty}

acid binding protein does not influence

\section{ischemic tolerance of the murine heart}

J.F.F. Brinkmann, J. Willems, W.A. Coumans, M. van Bilsen, B. Binas, G.J. van der Vusse and J.F.C. Glatz: submitted for publication 


\section{Abstract}

The accumulation of unesterified FA and FA esters during cardiac ischemia and reperfusion is a well-known phenomenon. Because of their amphipathic character and their ability to form micellar structures, these accumulating FA are likely to exert negative influences on cardiac function. The abundant presence of heart-type fatty acid binding protein (H-FABP) in the cardiac myocyte has been hypothesized to result in protection against accumulating FA. H-FABP expression is essential for the efficient trafficking of PA inside the cardiomyocyte, and based on its highaffinity FA binding characteristics, H-FABP might protect membrane structures and enzymes against high intracellular FA levels. Moreover, in vitro experiments provided evidence that H-FABP might both act as a scavenger for oxygen free radicals, and as a stimulator of phospholipid biosynthesis in ischemic myocardium. By using the recently generated H-FABP null mouse, we directly examined whether H-FABP protects ischemic myocardium through any of these proposed mechanisms.

Hearts from wild-type and hetero- and homozygous H-FABP null mice were analyzed in an isolated left ventricular ejecting mouse heart preparation. Both before and after a period of severe, no-flow, normothermic ischemia followed by reperfusion, significant differences in hemodynamic performance were absent. Hearts of all three groups showed a similar post-ischemic functional recovery. In addition, the energetic status of hearts after reperfusion, measured as the contents of high-energy phosphates and of glycogen, was similar in all three groups. Collectively, these data show that endogenous H-FABP does not exert a cardioprotective function in the heart during ischemia-reperfusion.

\section{Introduction}

Myocardial ischemia, resulting in an inadequate supply of oxygen and substrates to the heart, rapidly leads to a depression of oxidative fatty acid (FA) degradation ${ }^{1,2}$. As a result, FA esters such as acyl-CoA and acylcarnitines have been shown to accumulate in ischemic myocardium (reviewed extensively in: ${ }^{3}$ ). Accumulation of 
unesterified FA during ischemia and especially during reperfusion is also a wellknown phenomenon ${ }^{47}$. The majority of these FA molecules are liberated through the degradation of membrane phospholipids, and this process is relatively slow. FA accumulation in rat and dog hearts could only be demonstrated $20-45$ min after the onset of ischemia ${ }^{8,9}$. During the first minutes of ischemia, however, liberated FA might accumulate in triacylglycerols as a result of an increase in triacylglycerol cycling 3,8 . Reperfusion, the restoration of vascular flow, quickly normalizes cardiac levels of acyl esters. Tissue levels of unesterified FA then remain high or even further increase ${ }^{3,8}$. In ischemic and reperfused rat hearts, FA levels elevated 15-30 fold compared to the pre-ischemic values have been found ${ }^{8-10}$. Due to their amphipathic character and their ability to form micellar structures which may incorporate into cellular membranes, accumulating FA and FA metabolites might negatively influence cardiac function ". High tissue FA levels may specifically affect cardiac function by causing arrhythmias, disturbing mechanical performance and inhibiting a variety of enzymes like mitochondrial carnitine-acylcarnitine translocase, mitochondrial ATP-ADP translocase, plasmalemmal $\mathrm{Na}^{*}-\mathrm{K}^{+}$ATPase and enzymes involved in $\mathrm{Ca}^{2+}$ handling ${ }^{3}$.

Inside the cardiomyocyte, heart-type FA binding protein (H-FABP), an abundantly expressed cytoplasmic protein with a high affinity for FA, is essential for efficient FA trafficking. This was recently demonstrated by generating a $\mathrm{H}-\mathrm{-}$ FABP nullizigous mouse using targeted gene-disruption ${ }^{12}$. The H-FABP deficient mice display elevated plasma FA levels indicative of a hindred FA handling, and heart and skeletal muscle FA uptake were found to be severely decreased in vivo ${ }^{12}$. The role for H-FABP in the cardiomyocyte was directly demonstrated by the findings that both FA uptake and oxidation by isolated H-FABP null cardiomyocytes were markedly reduced, while compensatory cellular adaptations to H-FABP deficiency appeared to be absent ${ }^{13}$. Based on its high-affinity FA binding characteristics it has been postulated that H-FABP could establish an intracellular distribution of FA molecules whereby membrane structures and enzymes are protected against accumulating $\mathrm{FA}^{14,15}$. Such protection might be 
feasible because under normal conditions only a minor part, approximately $2 \%$, of the cardiomyocyte H-FABP content is theoretically complexed with FA, and thus a large over-capacity for FA binding is present inside the cardiomyocyte ${ }^{16}$. Also relevant to ischemia is the in vitro observation that H-FABP may act as a scavenger for free radicalls, such as the superoxide anion $\left(\mathrm{O}_{2}^{-}\right)$, the hydroxyl radical $\left(\mathrm{OH}^{*}\right)$ and the hydrochloride radical $\left(\mathrm{OCl}^{\circ}\right)$. This led to the hypothesis that H-FABP might protect ischemic myocardium against the action of these compounds which are formed during reperfusion ${ }^{17,18}$. Finally, notable is also is the observation that purified H-FABP was able to stimulate key enzymes in phospholipid biosynthesis in vitro, and H-FABP might thus also limit the loss of membrane phospholipids, and consequently the liberation of FA during ischemia ${ }^{19}$.

Circumstantial evidence for a potential protective role of H-FABP during ischemia and reperfusion was obtained in Langendorff (retrograde) perfused rat hearts ${ }^{20}$. In these experiments, hearts were perfused with liposome-incorporated HFABP, which protected them from tissue injury, improved the recovery of coronary flow during reperfusion, better preserved myocardial high-energy phosphate compounds and enhanced the reacylation of arachidonic acid into phospholipids ${ }^{20}$. As outlined previously in detail by Glatz et. $a l^{21}$, the experimental design raised questions whether the observed protection was a direct effect of increased tissue $\mathrm{H}$ FABP contents. The question whether H-FABP limits cellular damage under pathophysiological conditions by sequestrating accumulating FA, by preserving membrane phospholipids or by scavenging free radicals is thus unresolved to date.

The aim of the present study was to directly analyze whether H-FABP expression influences heart tolerance to ischemia followed by reperfusion by the use of the recently generated mouse null in H-FABP ${ }^{12}$. Wild-type, H-FABP homoand $\mathrm{H}-\mathrm{FABP}$ heterozygous gene-disrupted hearts were therefore analyzed in a working mouse heart preparation and cardiac function of the different groups was compared both before and after a period of severe global ischemia. In addition, cardiac energy status after reperfusion was analyzed in the form of high energy phosphate and glycogen contents. 
In this paper, we report that the expression of H-FABP in the heart does not influence cardiac tolerance to ischemia followed by reperfusion.

\section{Materials and Methods}

\section{Aninals}

The H-FABP null mice were generated by Binas et al. using targeted genedisruption and they were identified by PCR as previously described ${ }^{12}$. Homo- and heterozygous gene-disrupted mice had been backcrossed four times onto the C57Bl/6 background, and their wild-type littermates were used as controls. Mice used in experiments were 3-6 months of age and were weight, age and sex matched. They were housed under standard conditions in a facility equipped with a 12-h light-dark cycle, had unlimited access to water and were fed a standard pelleted diet (Hope Farms, Woerden, the Netherlands) ad libitum. All experimental protocols were approved by the Institutional Animal Care and Use Committee of Maastricht University.

\section{Isolated working mouse heart preparation}

The ejecting isolated mouse heart preparation was previously described in detail ${ }^{22}$. Briefly, hearts of anaesthetized mice $(50 \mathrm{mg} / \mathrm{kg}$ sodium pentobarbital i.p.) were quickly excised and mounted on a perfusion system. Retrograde perfusion at a perfusion pressure of $50 \mathrm{~mm} \mathrm{Hg}$ was started immediately, after which the hearts started to beat spontaneously. The left atria were cannulated with an atrial cannula through one of the lung veins. Left ventricular pressure was measured with a PE-50 catheter, inserted through the apex into the left ventricular cavity, connected to a Baxter pressure transducer (Baxter Healthcare Corp., Irvine, CA, USA). Aortic pressure was measured through a side branch located $3 \mathrm{~mm}$ above the entrance of the aortic cannula by means of a pressure transducer (Baxter Healthcare Corp.). The Krebs-Henseleit perfusion buffer consisted of $118 \mathrm{mM} \mathrm{NaCl}, 4.7 \mathrm{mM} \mathrm{KCl}, 3.0$ $\mathrm{mM} \mathrm{CaCl}, 1.2 \mathrm{mM} \mathrm{MgSO}$, $1.2 \mathrm{mM} \mathrm{KH_{2 }} \mathrm{PO}_{4}, 25 \mathrm{mM} \mathrm{NaHCO}, 0.5 \mathrm{mM}$ EDTA, 
$10 \mathrm{mM}$ D-glucose, $1.5 \mathrm{mM}$ Na-pyruvate and $100 \mathrm{mU} / \mathrm{l}$ insulin (Novo Nordisk A/S, Bagsvaerd, Denmark) and was gassed continuously with $95 \% \mathrm{O}_{2} / 5 \% \mathrm{CO}_{2}$. Care was taken to maintain the temperature of the perfusate and heart at $38.5^{\circ} \mathrm{C}$.

\section{Hemodynamic data}

All hemodynamic variables were continuously recorded using specialized software (Hemodynamic Data Acquisition System, Technical Department, Maastricht University), allowing the on-line acquisition, presentation and calculation of left atrial filling flow, aortic flow (AOF), left ventricular systolic pressure (LVSP), left ventricular end-diastolic pressure (LVEDP), diastolic aortic pressure (AODP) and the first maximal and minimal derivatives of left ventricular pressure ( $\mathrm{LV} \mathrm{dP} / \mathrm{dt}_{\max }$ and $L V d P / d t_{\min }$ ). Left ventricular developed pressure (LVDP) was defined as the difference between LVSP and LVEDP. Cardiac output (CO) was defined as the sum of AOF and coronary flow (CF). CF was determined from the difference between $A O F$, measured by a $1 \mathrm{~N}$ inline aortic flow probe and left atrial filling flow, measured by a $2 \mathrm{~N}$ inline flow probe placed in the left atrial inflow tract ${ }^{22}$. These CF data were periodically verified by timed collection of the coronary effluent.

\section{Experimental protocol}

After mounting the hearts on the perfusion system, they were allowed to stabilize during an initial 10 min retrograde perfusion period at $50 \mathrm{~mm} \mathrm{Hg}$. Antegrade perfusion was started by opening the left atrial conduit. Left atrial filling pressure was set at $10 \mathrm{~mm} \mathrm{Hg}$ and the diastolic aortic pressure was kept at $50 \mathrm{~mm} \mathrm{Hg}$. Hearts were normoxically perfused in the antegrade mode for $20 \mathrm{~min}$, after which they were exposed to normothermic $\left(38.5^{\circ} \mathrm{C}\right)$, no-flow global ischemia for $15 \mathrm{~min}$. Normorthermia was maintained by filling the water-jacketed chamber surrounding the cannulated hearts with perfusate, until the hearts were completely submersed. Following the ischemic period, the hearts were first reperfused retrogradely (50 $\mathrm{mm} \mathrm{Hg}$ perfusion pressure) and after $10 \mathrm{~min}$ the left atrial conduit was re-opened 
for an additional 50 min perfusion in the antegrade mode $(10 \mathrm{~mm} \mathrm{Hg}$ preload and $50 \mathrm{~mm} \mathrm{Hg}$ afterload). All hearts used in the experiments showed electromechanical recovery. The hearts were paced at 450 beats/min throughout the experiments, except for the ischemic period and during the first $5 \mathrm{~min}$ of reperfusion. After completion of the experimental protocol, hearts were immediately frozen between aluminium clamps previously cooled in liquid nitrogen, and stored at $-80^{\circ} \mathrm{C}$ for further analysis.

\section{Analysis of heart energy content and stores}

Cardiac contents of glycogen and high-energy phosphates were determined in freeze-dried $\left(-30^{\circ} \mathrm{C}\right)$ tissue. High energy phosphates and related compounds were analyzed by reversed phase HPLC (Varian Vista 5500) on a LiChrosorb RP-18 column (Merck, Germany) as described previously in detail ${ }^{23,24}$. Glycogen contents were determined fluorimetrically in HCL tissue extracts ${ }^{25}$ and expressed as $\mu$ mole glycosyl units per gram dry weight.

\section{Statistical analysis}

Data are expressed as mean values \pm SEM. The significance of differences in mean values was evaluated using the two-tailed, unpaired Student's $t$ test. Data from homo- and heterozygous gene-disrupted hearts were separately compared to the wild-type values. The level of significance was taken as $p<0.05$.

\section{Results}

\section{Cardiac performance}

Baseline hemodynamic performance of isolated will-type (WT), heterozygous HFABP (H-FABP+/-) and homozygous H-FABP gene-disrupted hearts (H-FABP null), as measured during the pre-ischemic phase of the experiments, is shown in Table 1. 
Table 1: Pre-ischemic functional paraneters of isolated, left wentricular ejecting hearts from wildtope, H-FABP+/- and H-FABP rull mice

\begin{tabular}{|c|c|c|c|}
\hline & WT & $\mathrm{H}-\mathrm{FABP}+\mathrm{l}$ & H-FABP-/- \\
\hline $\mathrm{CO}\left(\mathrm{ml} \mathrm{min} \mathrm{m}^{-1}\right)$ & $12.5 \pm 1.0$ & $11.1 \pm 1.0$ & $10.6 \pm 0.8$ \\
\hline $\mathrm{CF}\left(\mathrm{m} / \mathrm{min}^{-1}\right)$ & $3.4 \pm 0.5$ & $3.7 \pm 0.4$ & $4.1 \pm 0.7$ \\
\hline $\mathrm{AOF}\left(\mathrm{ml} \mathrm{min} \mathrm{m}^{-1}\right)$ & $9.1 \pm 0.7$ & $7.3 \pm 0.8$ & $6.5 \pm 0.6$ \\
\hline LVEDP (mm Hg) & $14 \pm 1$ & $16 \pm 1$ & $15 \pm 1$ \\
\hline LVSP (mm Hg) & $94 \pm 2$ & $97 \pm 3$ & $88 \pm 4$ \\
\hline LVDP (mm Hg) & $80 \pm 1$ & $81 \pm 3$ & $74 \pm 4$ \\
\hline 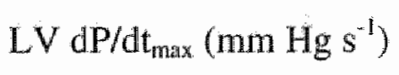 & $6,457 \pm 392$ & $6,560 \pm 446$ & $5,285 \pm 253$ \\
\hline $\mathrm{LV} \mathrm{dP} / \mathrm{dt}_{\min }\left(\mathrm{mm} \mathrm{Hg} \mathrm{s^{-1 } )}\right.$ & $3,327 \pm 143$ & $3,325 \pm 173$ & $3,004 \pm 186$ \\
\hline
\end{tabular}

Data are means $\pm S E M(n=8$ per group). Lsolated hearts were perfused in the antegrade mode for 20 min, at a pre- and afterload of 10 and $50 \mathrm{~mm} \mathrm{Hg}$, respectively, and a pacing frequency of 450 beats/min. $C O$, cardiac outpu; $C F$, coronary flow; $A O F$, aortic flow; $L V E D P$, left ventricular enddiastolic pressure; LVSP, left ventricular systolic pressure; LVDP, left ventricular developed pressure; $L V$ dP/dt $t_{\text {max }}$ first maximal derivative of left ventricular pressure; $L V d P / d t_{\text {min }}$ first minimal derivative of left ventricular pressure.

Significant differences between WT and H-FABP manipulated hearts were absent, and CO, CF, AOF, LVEDP, LVSP, LVDP, LV dP/dt $\mathrm{t}_{\max }$ and LV dP/dt $\mathrm{din}_{\min }$ of $\mathrm{WT}, \mathrm{H}-$ FABP+/- and H-FABP null hearts were similar. Though the AOF of H-FABP null hearts was approximately $30 \%$ lower and the CF approximately $20 \%$ higher than those of the WT, the differences did not reach statistical significance.

\section{Cardiac tolerance to ischemia/reperfusion}

To examine the ischemic tolerance of isolated H-FABP deficient hearts, WT, HFABP+l- and H-FABP null hearts were forced to undergo a $15 \mathrm{~min}$ period of 
normothermic, no-flow global ischemia. Following this ischemic period and 50 min of reperfusion in the antegrade mode, $C O$ recovered to approx, $40 \%$ of the pre-ischemic value in the hearts of all three groups, while LVDP recovered to 55 $70 \%$ (Table 2, Fig. 1). Significant differences between WT and H-FABP manipulated hearts were absent, and CO, CF, AOF, LVEDP, LVSP, LVDP, LV $\mathrm{dP} / \mathrm{dt}_{\max }$ and $L V \mathrm{dP} / \mathrm{dt}_{\min }$ of WT, H-FABP+/- and H-FABP null hearts were similar during the entire reperfusion phase (Table 2).

Table 2: Functional parameters of reperfused wild-type, H-FABP+/- and H-FABP null hearts after 15 min of global ischemia followed by 60 min of reperfusion

\begin{tabular}{lccc}
\hline & WT & H-FABP+/ & H-FABP-/- \\
\hline $\mathrm{CO}\left(\mathrm{ml} \mathrm{min}^{-1}\right)$ & $5.9 \pm 1.8$ & $5.3 \pm 0.9$ & $4.7 \pm 1.1$ \\
$\mathrm{CF}\left(\mathrm{ml} \mathrm{min}^{-1}\right)$ & $3.0 \pm 0.9$ & $4.1 \pm 0.7$ & $4.4 \pm 1.0$ \\
$\mathrm{AOF}\left(\mathrm{ml} \mathrm{min}^{-1}\right)$ & $2.9 \pm 1.4$ & $0.8 \pm 0.4$ & $0.3 \pm 0.4$ \\
& & & \\
LVEDP $(\mathrm{mm} \mathrm{Hg})$ & $19 \pm 5$ & $15 \pm 1$ & $17 \pm 2$ \\
LVSP $(\mathrm{mm} \mathrm{Hg})$ & $62 \pm 7$ & $70 \pm 3$ & $58 \pm 6$ \\
LVDP $(\mathrm{mm} \mathrm{Hg})$ & $44 \pm 9$ & $55 \pm 3$ & $42 \pm 7$ \\
& & & \\
LV dP/dt & & $3,855 \pm 238$ & $2,866 \pm 506$ \\
LV dP/dt & & & \\
\end{tabular}

Data are means $\pm S E M$ ( $n=8$ per group). Following 15 min of norntothernic, no-flow global ischemia, isolated hearts were reperfused in the antegrade mode for 50 min, at a pre- and afferload of 10 and $50 \mathrm{~mm} \mathrm{Hg}$, respectively, and a pacing frequency of 450 beats/min. $C O$, cardiac outpu, $C F$, coronary flow: AOF, aortic flow; LVEDP. left ventricular end-diastolic pressure; LVSP, left yentricular systolic pressure; $L V D P$, left ventricular developed pressure; $L V$ dP/dt man $_{\text {first maximal }}$ derivative of left ventricular pressure; $L V$ dP/dt mus first minimal derivative of left ventricalar pressure. 
Post-ischemic recovery of these parameters, expressed as percentage of the pt ischemic value, was similar in all three groups and significant differences we absent (Fig. 1). The only difference that we could detect in this study was a no significant trend between a decrease in H-FABP content and a decrease in $\mathrm{AC}$ and an increase in $\mathrm{CF}$, as these parameters changed consistently from WT to FABP+/- and H-FABP null hearts (Table 1 and 2). Though this trend mig indicate a small difference in baseline cardiac performance, implications ischemic tolerance seem to be absent, because the trend was present a comparable both before and after ischemia and reperfusion.

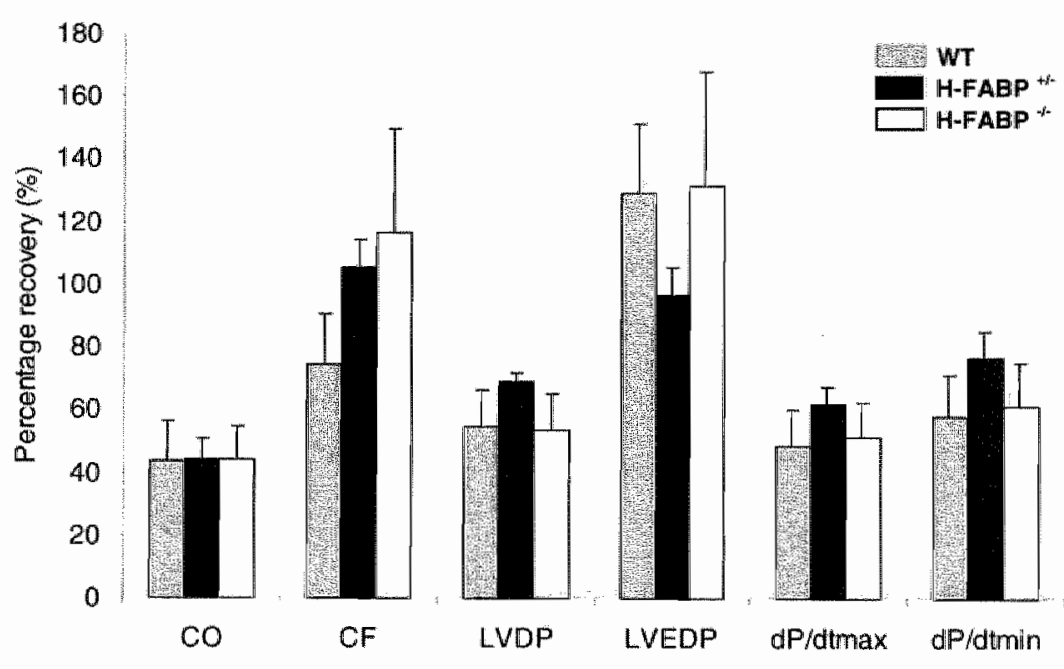

Figure 1: Post ischemic percentage recovery of functional parameters in isolated wild-type, $\mathrm{H}$ FABP+/-and H-FABP null hearts following 15 min of global ischemia and 60 min of reperfusio Data are means $\pm S E M(n=8$ per group). CO, cardiac output; $C F$, coronary flow; $L V D P$, left ventricular developed pressure: $L V E D P$, left ventricular end-diastolic pressure; $d P / d t_{\max }$ first maximal derivative of left ventricular pressure; $d P / d t_{m a n}$. first minimal derivative of left ventricular pressure. 


\section{Cardiac energy content}

To analyze the energetic status of the isolated WT, H-FABP+/- and H-FABP null hearts after the period of reperfusion, phosphocreatine, creatine, ATP, ADP AMP and glycogen levels were determined in heart tissue immediately frozen after the experiments (Table 3). Significant differences in ATP, phosphocreatine and glycogen levels (respectively $9.2 \pm 1.2,35.8 \pm 2.4$ and $306 \pm 68 \mu \mathrm{mol} / \mathrm{g}$ dry weight for WT hearts), were absent. Moreover, also the other parameters measured, as well as the calculated tissue energy charges, did not differ among the three groups (Table 3).

Table 3: High-energy phosphate and glycogen contents of ischemic-reperfused wild-type, H-FABP+/- and H-FABP null heart tissue

\begin{tabular}{lccc}
\hline & WT & H-FABP+/- & H-FABP-1- \\
\hline PCr & $35.8 \pm 2.4$ & $34.9 \pm 4.3$ & $35.7 \pm 3.8$ \\
$\mathrm{Cr}$ & $57.7 \pm 3.0$ & $57.7 \pm 4.9$ & $60.4 \pm 3.4$ \\
& & & \\
ATP & $9.2 \pm 1.2$ & $10.7 \pm 1.3$ & $9.8 \pm 0.9$ \\
ADP & $2.1 \pm 0.2$ & $2.4 \pm 0.1$ & $2.5 \pm 0.1$ \\
AMP & $0.30 \pm 0.04$ & $0.37 \pm 0.06$ & $0.48 \pm 0.09$ \\
EC & $0.88 \pm 0.02$ & $0.87 \pm 0.02$ & $0.84 \pm 0.03$ \\
& & & \\
glycogen & $1,934 \pm 417$ & $2,511 \pm 176$ & $1,949 \pm 347$ \\
\hline
\end{tabular}

Data are means \pm SEM ( $n=8$ per group) and expressed as $\mu$ mol/g dry weight of venvicular kissue. frozen following $15 \mathrm{~min}$ of global ischemia and 50 min of reperfusion in the antegrade mode. $P C r$, phosphocreatine; $C r$, creatine; $E C$, energy charge, defined as $(A T P+0.5 A D P M / A T P+A D P+$ $A M P$ ). 


\section{Discussion}

The major finding of the current study is that the tolerance to ischemia followed by reperfusion is not affected in H-FABP null hearts. Hemodynamic parameters of $\mathrm{H}-$ $\mathrm{FABP}+\%$ and H-FABP null hearts were similar to those obtained with their WT counterparts, both before and after a period of severe ischemia followed by reperfusion in our working heart system. Moreover; cardiac phosphocreatine, creatine, ATP, ADP, AMP and glycogen levels in H-FABP+/- and null hearts after ischemia and reperfusion each were comparable to the WT levels, indicating that the energetic impact exerted by our protocol was also comparable.

The present study challenges the findings reported by Srimani and coworkers $^{20}$, who documented that rat hearts perfused in situ with liposome incorporated H-FABP were protected against tissue injury compared to hearts perfused with liposomes only. The latter study contained, nevertheless, several shortcomings in the experimental design, and, among other remarks, it has been doubted whether the observed effects are directly attributable to raised tissue $\mathrm{H}$ FABP contents, and even whether tissue H-FABP contents were raised at all with the approach applied ${ }^{21}$. By using the H-FABP null mouse, here we directly addressed the question whether the intracellular presence of H-FABP limits cellular damage in hearts undergoing ischemia and reperfusion, and did not find a role for H-FABP under these conditions. The H-FABP null mouse appears to represent a well suitable model for this analysis, because H-FABP null hearts and their cardiomyocytes have been extensively characterized, did not show any structural abnormalities, nor expression of other types of FABPs that could compensate for the H-FABP deficiency ${ }^{13}$.

The hypothesis that led us to carry out the current experiments was that HFABP might protect ischemic myocardium against accumulating FA by binding them with high-affinity. Additionally, H-FABP might limit the loss of membrane phospholipids, and thus the formation of FA during ischemia. The latter hypothesis is based on in vitro experiments only, wherein H-FABP was shown to be able to stimulate key enzymes in phospholipid biosynthesis, notably glycerophosphate 
acyl transferase and acyl CoA monoacylglycerophosphorylcholine acyl transferase more potently than bovine serum albumin ${ }^{19}$. Studies initially carried out to characterize our working mouse heart preparation showed that cardiac FA accumulation already occurs in reperfused hearts subjected to a $10 \mathrm{~min}$ ischemic period. Prolonging ischemia to a $15 \mathrm{~min}$ period, the same period as was used in the current study, did not significantly raise the amount of FA accumulated and FA levels were at least 2 fold higher in reperfused hearts compared to the pre-ischemic levels (De Windt, unpublished results and ${ }^{26}$ ). Though we thus can assume that significant amounts of FA were accumulating during our protocol, we did not find any differences between the post-ischemic functional recovery of WT, H-FABP+/ and H-FABP null hearts, thereby rendering a cardioprotective role for FABP during severe ischemia, either by the binding of FA or by limiting phospholipid breakdown in vivo, highly unlikely. The absence of this cardioprotective role is in accordance with several other findings and considerations. First, detailed studies with isolated rat hearts that were subjected to successively ischemia, reperfusion and the calcium paradox showed that FA and H-FABP were initially released from the heart in a $0.9: 1$ molar ratio, as might be expected if both compounds had been complexed in the cardiomyocyte ${ }^{27}$. After the initial 3 min period, however, FA release continued where the rate of H-FABP release decreased. Second, the fact that H-FABP is released from damaged tissue obviously limirs its ability to act as a protective agent for severe ischemic cells. In the detailed studies mentioned, the tissue accumulation of FA continued when most of the cellular H-FABP had been released from the hearts ${ }^{27}$. Both observations suggest that H-FABP might, at best, limit tissue injury during the initial phase of ischemia and might not protect severely ischemic cells from damage ${ }^{27}$. In the current study mouse hearts were subjected to severe ischemia only, and it is therefore possible that shortening the ischemic period might result in differences between the three groups of hearts tested. Third, and most important, calculations based on data obtained with labeled (anthroloxy) FA and artificial phospolipid bilayers, together with data on the binding characteristics and myocardial content of H-FABP estimated that normally 
only $10-15 \%$ of the cellular FA are complexed to $\mathrm{H}-\mathrm{FABP}$, where the remaining $85-90 \%$ were estimated to be associated with membrane structures ${ }^{16}$. Given the fact that increasing the amount of FA in tissue will not only raise the percentage of FA complexed to H-FABP but also the amount of FA associated with membranes, a process that is governed by the partition behaviour between the phases ${ }^{28}$, the majority of accumulating FA might incorporate into membranes, and thus might not bind to H-FABP.

An additional mechanism by which H-FABP could exert a protective function in the ischemic heart has been put forward by Samanta and coworkers ${ }^{17}$ who reported that the protein might act as a scavenger for free radicals. Three major lines of evidence implicate oxygen free radicals (reactive oxygen species) in the pathogenesis of reperfusion injury ${ }^{29}$. First, an increase in reactive oxygen species (ROS) can be detected in postischemic myocardium ${ }^{30-33}$, and the maximum oxidant production in isolated, perfused canine hearts occurred 10 to 30 seconds after the start of reperfusion ${ }^{32}$. Second, exposing myocardium to exogenous ROS results in myocyte and myocardial tissue disfunction that is comparable to that elicited by ischemia-reperfusion, notably the persistent loss of $\mathrm{K}^{+}$, depletion of high-energy phosphates, elevation of intracellular calcium concentrations, loss of systolic force development, progressive increase in diastolic tension, depression of metabolic function and the development of arrhythmias ${ }^{34-36}$. Third, pre-treating animals with anti-oxidant enzymes (e.g. superoxide dismutase and catalase) ${ }^{37-44}$ or genetic over-expressing these enzymes ${ }^{45.47}$ yields protection against reperfusion injury, and oppositely, gene-disruption results in a phenotype more susceptible to myocardial reperfusion injury ${ }^{48}$. Mainly based on its abundant expression in the cardiomyocyte, Samanta et al. ${ }^{17}$ compared the reactivity of H-FABP towards several different free radicals with the reactivity of bovine serum albumin. These experiments showed that H-FABP was a more potent ROS scavenger than serum albumin in vitro. As our direct study showed that the susceptibility of WT, HFABP+1- and H-FABP null hearts towards cardiac ischemic and reperfusion 
damage is comparable, a crucial role for endogenous H-FABP as ROS scavenger $h$ vivo is highly unlikely.

Though we can conclude that the absence of H-FABP does not influence mouse heart tolerance to ischemia and reperfusion, our results do not totally rule out that the binding of accumulating FA to proteins ameliorates cellular ischemic damage. It has been well established that H-FABP gene-disruption does not result in a compensatory expression of other FABPs. However, analysis of cytosolic preparations indicated that the capacity to bind oleate in H-FABP null hearts is

reduced by $55 \%$ only ${ }^{13}$. Therefore we cannot rule out that the capacity for binding FA in the H-FABP null cytoplasm by the presence of proteins and/or membrane structures other than FABP is sufficient to trap harmful accumulating FA, thereby preventing cellular damage.

In conclusion, we tested whether the absence of H-FABP influences ischemic tolerance of the murine heart, and did not find any differences between the ischemic recovery of wild-type, heterozygous and homozygous H-FABP genedisrupted hearts.

\section{References}

1. Myears DW, Sobel BE and Bergmann SR. Substrate use in ischemic and reperfused canine myocardium: quantitative considerations. Am J Physiol 253: H107-H114, 7987.

2. Opie LH, Owen P and Riemersma RA. Relative rates of oxidation of glucose and free fatty acids by ischaemic and non-ischaemic myocardium after coronary artery ligation in the dog. Eur $J$ Clin Invest 3: 419-435, 1973.

3. Van der Vusse GJ, Glatz JFC, Stam HCG and Reneman RS. Fatty acid homeostasis in the normoxic and ischemic hear. Physiol Rew 72:881-940, 1992.

4. Chien KR, Han A, Sen A, Buga LM and Willerson JT. Accumulation of unesterified arachidonic acid in ischemic canine myocardium. Relationship to a phosphatidylcholine deacylation-reacylation cycle and the depletion of membrane phospholipids. Circ Res 54: 313-322, 1984.

5. Van Bilsen $M$ and van der Vusse GJ. Phospholipase-A2-dependent signalling in the heart. Cardiovasc Res 30: 518-529, 1995. 
6. Van der Vusse GJ, Roemen TH, Prinzen FW, Coumans WA and Reneman RS. Uptake and tissue content of fatty acids in dog inyocardium under nomoxic and ischemic conditions. Circ Res $50: 538-546,1982$

7. Cornelussen RN, van der Vusse GJ, Roemen TH and Snoeckx LH. Heat pretreatment differentially affects cardiac fatty acid accumulation during ischemia and postischemic reperfusion. Am J Physiol Heant Circ Physiol 280: H1736-H1743, 2001.

8. Van Bilsen M, wain der Vusse GJ, Willemsen PH, Coumans WA, Roemen TH and Reneman RS. Lipid alterations in isolated, working rat hearts during ischemia and reperfusion: its relation to myocardial damage. Circ Res 64: 304-314, 1989.

9. de Groot MJ, Coumans WA, Willemsen PH and van der Vusse GJ. Substrate-induced changes in the lipid content of ischemic and reperfused myocardium. Its relation to hemodynamic recovery. Circ Res 72: 176-186, 1993.

10. Burton KP, Buja LM, Sen A, Willerson JT and Chien KR. Accumulation of arachidonate in triacylglycerols and unesterified fatty acids during ischemia and reflow in the isolated rat heart. Correlation with the loss of contractile function and the development of calcium overload. Am $J$ Pathol 124: 238-245, 1986.

11. Katz AM and Messineo FC. Lipid-membrane interactions and the pathogenesis of ischemic damage in the myocardium. Circ Res 48: 1-16, 1981.

12. Binas B, Danneberg $\mathbf{H}$, McWhir J, Mullins $\mathbf{L}$ and Clark AJ. Requirement for the heart-type fatty acid binding protein in cardiac fatty acid utilization. Faseb J 13: 805-812, 1999.

13. Schaap FG, Binas B, Danneberg H, van der Vusse GJ and Glatz JF. Impaired long-chain fatty acid utilization by cardiac myocytes isolated from mice lacking the heart-type fatty acid binding protein gene. Circ Res 85: 329-337, 1999.

14. Glatz JF, Paulussen RJ and Veerkamp JH. Fatty acid binding proteins from heart. Chem Phys Lipids $38: 115-129,1985$.

15. Glatz JF, Vork MM and van der Vusse GJ. Significance of cytoplasmic fatty acid-binding protein for the ischemic heart. Mol Cell Biochem 123: 167-173, 1993.

16. Vork MM, Glatz JF and van der Vusse GJ. On the mechanism of long chain fatty acid transport in cardiomyocytes as facilitated by cytoplasmic fatty acid-binding protein. J Theor Btol 160 : $207-222,1993$.

17. Samanta A, Das DK, Jones R, George A and Prasad MR. Free radical scavenging by myocardial fatty acid binding protein. Free Radic Res Commun 7: 73-82, 1989.

18. Ferrari $\mathrm{R}$, Curello $\mathrm{S}$, Cargnoni A, Condorelli $\mathrm{E}$, Comini L, Ghielmi S and Ceconi $\mathrm{C}$, Importance of free radicals generated by endothelial and myocardial cells in ischemia and reperfusion. In: Parhophysiology of Severe Ischemic Myocardial Injury. edited by Piper HM. Dordrecht, Boston, London: Kluwer Academic Publishers, 1990, p. 221-238. 
19. Samanta A, Prasad MR, Engelman RM and Das DK Possible physiological role of myocardial fatty acid binding protein in phospholipid biosynthesis. LLipld Mediat 1: 243-255, 1989.

20. Srimani BN, Engelman RM, Jones $\mathbf{R}$ and Das DK. Protective role of intracoronary fatty acid binding protein in ischemic and reperfused myocardium. Circ Res 66: 1535-1543; 1990.

21. Glatz JF, van der Vusse GJ and Reneman RS. Protective role of fatty acid-binding protein in ischemic and reperfused heart. Circ Res 68: 1490-1491, 1991.

22. De Windt LJ, Willems J, Reneman RS, van der Vusse GJ, Arts $T$ and Van Billsen M. An improved isolated, left ventricular ejecting; murine heart model. Functional and metabolic evaluation. Pflugers Arch 437: 182-190, 1999.

23. Wynants $\mathbb{J}$ and Van Belle H. Single-run high-performance liquid chromatography of nucleotides, nucleosides, and major purine bases and its application to different tissue extracts. Anal Biochem 144: 258-266, 1985.

24. Van der Vusse GJ, Coumans WA, van der Veen FH, Drake A, Flameng $\mathbf{W}$ and Suy $R$. ATP, creatine phosphate and glycogen content in human myocardial biopsies: markers for the efficacy of cardioprotection. Vase Surg 8: 127-134, 1984.

25. Lowry OH and Pasonneau JV. A Fleible System of Enzymatic Analysis. New York: Acadewic, 1972.

26. De Windt LJ, Willems J, Roemen TH, Coumans WA, Reneman RS, van der Vusse G.J and van Bilsen M. Ischemic-reperfused isolated working mouse hearts: membrane damage and type IIA phospholipase A2. AmJ Physiol Heart Circ Physiol 280; H2572-H2580, 2001.

27. Vork MM, Glatz JF and van der Vusse GJ. Release of fatty acid-binding protein and long chain fatty acids from isolated rat heart after ischemia and subsequent calcium paradox. Mol Cell Biochem 123: 175-184, 1993.

28. Storch J. Diversity of farty acid-binding protein structure and function: studjes with fluorescent ligands. Mol Cell Biochem: 123: 45-53, 1993.

29. Lefer DJ and Granger DN. Oxidative stress and cardiac disease. Am I Med 109: 315-323, 2000.

30. Kramer JH, Arroyo CM, Dickens BF and Weglicki WB. Spin-trapping evidence that graded myocardial ischemia alters post-ischemic superoxide production. Free Radic Biol Med 3: 153-159, 1987.

31. Zweier JL, Flaherty $\boldsymbol{J T}$ and Weisfeldt ML. Direct measurement of tree radical generation following reperfusion of ischemic myocardium. Proc Natl Acad Sci U S A 84: 1404-1407, 1987.

32. Zweier JL, Kuppusamy P, Williams R, Rayburn BK, Smith D, Weisfeldt ML and Flaherty JT. Measurement and characterization of postischemic free radical generation in the isolated perfused heart. J Biol Chem 264: 18890-18895, 1989.

33. Garlick PB, Davies MJ, Hearse DJ and Slater TF. Direct detection of free radicals in the reperfused rat heart using electron spin resonance spectroscopy. Circ Res 61: 757-760., 1987. 
34. Wetss IN, Goldhaber II and Sen J. Oxygen free radicals in the pathophysiology of myocardial ischemia/reperfusion. In: Oxygen Free Radicals in Tissue Damage, edited by Samson F. Boston: Brinkhauser, 1993, p. 250-266.

35. Tarr M and Valenzeno DP. Reactive oxygen-induced modification of cardiac electrophysiology: a comparison of the effects of Rose Bengal and other reactive oxygen generators. In: Oxygen Free Radicals in Tissue Damage, edited by Samison F. Boston: Brinkhauser, 1993, p. 267-284.

36. Bolli R. Mechanismi of myocardial stunning. Circulation 82: 723-738, 1990.

37. Jolly SR, Kane WJ, Bailie MB, Abrams GD and Lucehesi BR. Canine myocardial reperfusion injury. Its reduction by the combined administration of superoxide dismutase and catalase. Circ Res $54.277-285,1984$.

38. Ambrosio G, Becker LC, Hutchins GM, Weisman HF and Weisfeldt ML. Reduction in experimental infarct size by recombinant human superoxide dismutase: insights into the pathophysiology of reperfusion injury. Circulation 74: 1424-1433, 1986.

39. Chambers DE, Parks DA, Patterson G, Roy R, McCord JM, Yoshida S, Parmley LF and Downey JM. Xanthine oxidase as a source of free radical damage in myocardial ischemia. $J$ Mol Cell Cardiol 17: 145-152, 1985.

40. Werns SW, Simpson PJ, Mickelson JK, Shea MJ, Pitt B and Lucchesi BR. Sustained limitation by superoxide dismutase of canine myocardial injury due to regional ischemia followed by reperfusion. J Cardiovasc Pharmacol 11: 36-44, 1988.

41. Werns SW, Shea MJ, Driscoll EM, Cohen C, Abrams GD, Pitt B and Lucchesi BR. The independent effects of oxygen radical scavengers on canine infarct size. Reduction by superoxide dismutase but not catalase. Circ Res 56: 895-898, 1985.

42. Naslund U, Haggmark S, Johansson G, Marklund SL, Reiz S and Oberg A. Superoxide dismutase and catalase reduce infarct size in a porcine nyocardial occlusion-reperfusion model. $J \mathrm{Mol}$ Cell Cardiol 18: 1077-1084, 1986.

43. Ma XI, Johnson G, 3rd and Lefer AM. Low doses of superoxide dismutase and a stable prostacyclin analogue protect in myocardial ischemia and reperfusion. $J$ Am Coll Cardiol 19: 197$204,1992$.

44. Mehta JL, Nichots WW, Donnelly WH, Law son DL, Thompson L, ter Riet M and Saldeen TG. Protection by superoxide dismutase from myocardial dysfunction and attenuation of vasodilator reserve after coronary occlusion and reperfusion in dog. Circ Res 65: 1283-1295, 1989.

45. Chen EP, Bittner HB, Davis RD, Folz RJ and wan Trigt P. Extracellular superoxide dismutase transgene overexpression preserves postischemic myocardial function in isolated murine hearts. Circulation 94: II 412-417, 1996. 
46. Chen Z, Siu B, Ho YS, Vincent R, Chua CC, Hamdy RC and Chua BH. Overexpression of MnSOD protects against myocardial ischemia/reperfusion injury in transgenic mice. $J \mathrm{Mol} \mathrm{Cell}$ Cardiol 30: 2281-2289, 1998.

47. Yoshida T, Watanabe M, Engelman DT, Engelman RM, Schley JA, Maulik N, Ho YS, Oberley TD and Das DK. Transgenic mice overexpressing glutathione peroxidase are resistant to myocardial ischemia reperfusion injury. J Mol Cell Cardiol 28: 1759-1767, 1996.

48. Yoshida T, Maulik N, Engelman RM, Ho YS, Magnenat JL, Rousou JA, Flack JE, 3rd, Deaton D and Das DK. Glutathione peroxidase knockout mice are susceptible to myocardial ischemia reperfusion injury. Circulation 96: II 216-220, 1997. 
\begin{tabular}{cc}
4 \\
$\cdots$ \\
\hdashline
\end{tabular} 


\section{Chapter 7}

\section{General discussion}




\section{Background of the studies}

Though the heart is essentially omnivorous as each fatty acids, ketone bodies, carbohydrates and amino acids can be used for energy production, normally longchain fatty acids (FA) are the major source for ATP generation in the cardiac myocyte. Cardiomyocytes are capable of storing substrates as triacylglycerols and glycogen in limited amounts only, and a continuous supply of substrates by the circulation is required to preserve proper cardiac function '. The extraction of FA from the blood is remarkably efficient ', and the net flux of FA from the sarcolemma (plasma membrane) to the mitochondria in cardiomyocytes (60-80 $\mathrm{nmol} / \mathrm{min}$ per $\mathrm{g}$ tissue wet weight in the rat heart) is among the highest FA fluxes found in organs ${ }^{2}$. The expression of heart-type fatty acid binding protein (H-FABP) is essential to maintain this high FA flux, as was recently demonstrated by generating and studying a mouse null in the corresponding gene ${ }^{3}$. H-FABP null mice show a marked defect in periferal FA consumption, their cardiac myocytes show drastically decreased FA uptake and utilization rates, and the effects become apparent especially at increased demands of ATP production ${ }^{3,4}$.

The mechanism by which FA pass the sarcolemma was thought to occur by spontaneous diffusion for a long period of time. However, the presence of a saturable component in FA uptake by several cell-types, including cardiomyocytes, led to the search for membrane FA transporters. This high-affinity component showed the characteristics of facilitated diffusion and could be inhibited by general inhibitors of anion transport processes ${ }^{5-9}$. Distinct approaches led to the identification of three major potential FA transporters. Plasma membrane fatty acid binding protein (FABP PM ) was identified as potential FA transporter by its properties to bind radiolabelled oleate, the protein was purified from hepatocyte membranes using oleate affinity-chromatography, and it was later shown to be the membrane bound form of the aspartate aminotransferase mitochondrial isoform 8.10,11. Fatty acid translocase (FAT), a protein that later turned out to be the rat homologue of human platelet CD36, was identified by its binding of both radiolabeled DIDS (4,4'-diisothiocyanostilbene-2,2'-sulfonate) and reactive sulfo- 
$\mathrm{N}$-succinimidyl FA esters ${ }^{12,13}$. These compounds were both inhibitors of FA uptake by isolated adipocytes. The novel protein named "fatty acid transport protein" (FATP) was identified as third candidate FA transporter by an expression-cloning strategy, and the initial identification of FATP led to the subsequent discovery of an evolutionary conserved FATP family ${ }^{14,15}$. Though all three candidate FA transporters are linked to influences on FA uptake, e.g. expression each of each of the three candidates was shown to increase FA uptake rates in cell models ${ }^{14-18}$, its expression profile and the ability to inhibit FA uptake FAT/CD36 specifically resulted in a focus on FAT/CD36. A wealth of biochemical evidence implicating a function for FAT/CD36 as FA transporter has now accumulated ${ }^{19}$. FAT/CD36 is abundantly expressed in heart and skeletal muscle, adipose tissue and intestine, which all are tissues active in FA metabolism ${ }^{20-22}$. Its expression profile in different muscle types coincides with a role in FA transport and parallels the expression of H-FABP ${ }^{20,21,23}$. In addition, FAT/CD36 expression is modulated by conditions that alter lipid metabolism such as diabetes mellitus and high fat feeding ${ }^{24}$. More directly, FA uptake by isolated cardiomyocytes, adipocytes and skeletal muscle preparations each is inhibited by non-metabolized reactive sulfo- $N$ succinimidyl FA esters ${ }^{9,12,25}$, and FAT/CD36 was also shown to reversibly bind $\mathrm{FA}^{26}$.

However, the observation that FA quickly pass model and adipocyte membranes by a flip-flop mechanism without the help of proteins ${ }^{27-30}$ renewed the discussion whether the candidate FA transporters might have a true function in FA transport, or whether they might indirectly influence FA uptake. Here, it has to be noted that for each FAT/CD36, FABP $\mathrm{PM}$, and FATP other functions than FA transporter have been documented, and that all biochemical evidence for the existence of FA transporters was either indirect or might be explained by indirect influences of FAT/CD36 on FA metabolism ${ }^{29}$. The first studies described in this thesis were therefore aimed at determining the quantitative significance of FAT/CD36 for FA transport in muscle tissues. Thereafter, we analyzed whether the disturbance of FA transport in the heart, more specifically FAT/CD36 and H-FABP 
deficiency, influences heart tolerance to ischemia and reperfusion, which are pathophysiologic conditions in which $\mathrm{FA}$ are thought to play and important role.

\section{The function of FAT/CD36 as FA transporter in cardiac and skeletal muscle}

In the heart, both capillary endothelial cells and cardiomyocytes express FAT/CD36. Because both the capillary endothelial cell layer and the sarcolemma of cardiomyocytes form significant barriers for FA on their way from the bloodstream to the mitochondria of the cardiomyocyte ${ }^{1}$, FAT/CD36 might have a function in FA uptake in either of the two cell-types. Therefore, we decided to further quantify FAT/CD36 protein levels in rat heart by using the native protein purified from rat hearts. This study confirmed that FAT/CD36 is abundantly expressed in the heart. Its level found in the rat heart was remarkably high, $14 \pm 4$ $\mathrm{mg} / \mathrm{g}$ of total protein, and comparable to the amount of H-FABP, which is reported to amount to $5.7 \pm 1.1 \mathrm{mg} / \mathrm{g}$ of protein ${ }^{20}$. H-FABP is known to be an abundantly expressed protein in the cardiomyocyte, and its expression level corresponds to circa $1.4 \%$ of the total cellular protein pool in the mouse heart ${ }^{31}$. The finding that the high FAT/CD36 levels present in the rat cardiomyocyte are comparable to the level in the total rat heart, in which endothelial cells and cardiomyocytes are presumably the major cell-types expressing FAT/CD36, supports an important physiological function for FAT/CD36 in FA transport also in the cardiomyocyte.

At the time of writing this thesis, an overwhelming amount of evidence confirming a function of FAT/CD36 in FA transport in heart and skeletal muscle has accumulated, and the accordance between in vivo and in vitro data is notable. For studies on isolated cells, the reactive FA analog sulfo- $N$-succinimidyloleate (SSO) has proven to be a valuable tool. This compound is considered to specifically inhibit FAT/CD36 mediated FA uptake, and the binding of SSO to FAT/CD36 in fact formed the rationale to isolate the protein as potential FA transporter ${ }^{12}$. Considering the heart to exemplify the evidence, pre-treating freshly isolated rat cardiomyocytes with SSO results in about 50\% inhibition of FA uptake $^{9}$. This inhibition was also found by analyzing rat heart giant sarcolemmal 
vesicles and these vesicles provided a model to study FA uptake in the absence of subsequent metabolism ${ }^{23}$. To more directly investigate the function of FAT/CD36, a mouse null in the corresponding gene was generated by targeted genedisruption ${ }^{32}$. The analysis of FA uptake in FAT/CD36 null mice in vivo by the use of the non-metabolized FA tracer [ ${ }^{125}$ I]BMIPP (15-( $p$-iodophenyl)-3( $\left.R, S\right)$-methyl pentadecanoic acid) showed a prominent $50-80 \%$ reduction in cardiac FA uptake. Other FAT/CD36 null tissues showing significant $40-75 \%$ reductions were skeletal muscle and adipose tissue, and applying the readily oxidized FA analog IPPA ((15-p-iodophenyl)-pentadecanoic acid) confirmed these results ${ }^{33}$. Interestingly, the defect in FA transport present in the FAT/CD36 null heart is fully comparable to the defect in myocardial FA uptake that has been found in FAT/CD36 deficient humans by using BMIPP ${ }^{34}$.

As a next step in investigating the significance of FAT/CD36 for muscle metabolism, we characterized a new transgenic mouse model that had been generated using a genetic rescue approach. In this model, raised on the FAT/CD36 null background, FAT/CD36 expression was restricted to heart and skeletal muscle by using the same approach that previously had been used for generating a muscletargeted FAT/CD36 overexpressing mouse ${ }^{35}$. This approach was successful, and FAT/CD36 gene-rescued (GR) mice indeed showed the re-appearance of FAT/CD36 on the sarcolemma of cardiac and skeletal muscle myocytes. With the GR mice, we first examined to which extend the metabolic phenotypes that previously had been reported for FAT/CD36 null and muscle specific FAT/CD36 overexpressing mice could be reversed and thereby marked as direct and genespecific. First, GR mice displayed fasted plasma FA and triacylglycerol (TAG) levels that were comparable to the wild-type levels, whereas these levels are increased in FAT/CD36 null and decreased in FAT/CD36 overexpressing mice. Plasma glucose levels, which are decreased in FAT/CD36 null and increased in FAT/CD36 overexpressing mice, also normalized in the GR, to reach a level comparable to the wild-type. Second, we analyzed FA oxidation by isolated soleus muscles, a thin muscle rich in red oxidative fibers and highly dependent on FA 
derived energy. This parameter was previously found to be increased in FAT/CD36 overexpressing soleus muscles under electrically stimulated conditions ${ }^{35}$. Soleus palmitate oxidation rates were reduced by approximately 50\% in the FAT/CD 36 null muscles, where the GR muscles showed normalized FA oxidation rates, somewhat, but insignificantly lower compared to their wild-type counterparts under non-stimulated conditions. Adding dipyridamole to the muscle incubations as a tool to mimic electrical stimulation did not show an effect on the FAT/CD36 null muscle, but enlarged the difference between the FAT/CD36 null and wild-type, respectively, GR muscles. FA oxidation rates of wild-type and GR muscles were indistinguishable and approximately three times higher than those of the FAT/CD36 null. Dipyridamole presumably exerts its action by inducing FAT/CD36 protein translocation from an intracellular compartment to the plasma membrane. This mechanism is also underlying the increased FA transport rates observed upon electrical stimulation ${ }^{36}$. The combined findings show that alterations in FAT/CD36 facilitated FA transport, and subsequently in FA utilization, in muscles are directly reflected in plasma substrate levels. In other words, skeletal muscle, in view of its large total mass being a key FA oxidizer, is the principal site for the removal of FA from the circulation, and this removal is mediated by FAT/CD36. Interestingly, these findings might also imply that, at least in skeletal muscle, the expression of FAT/CD36 by the structural muscle cells only is sufficient for maintaining normal FA uptake rates. Because the GR mice were raised using the muscle-specific regulatory sequences of the mouse muscle creatine kinase gene ${ }^{37}$ to control the re-expression FAT/CD36, it is likely that endothelial cells remain FAT/CD36 deficient in these mice. Nevertheless, plasma substrate levels in GR mice were almost completely normalized.

Since muscle, especially that rich in red oxidative fibers, has a high dependence on energy from FA oxidation, we next examined whether FAT/CD36 expression impacts the ability to undergo exercise. Wild-type, FAT/CD36 null and GR gene-rescued mice were forced to undergo a swimming test, which resulted in a clear discrimination between the endurance of FAT/CD36 null mice and the two 
other mouse groups. Where the GR mice endured the swimming procedure to an extend comparable to their wild-type controls, FAT/CD36 null mice clearly showed a drastically reduced ability to undergo forced swimming. This effect is essentially due to a decrease in muscle energy stores, as both the muscle TAG and glycogen contents are decreased in FAT/CD36 null mice already under normal housing conditions. The limitation of generating energy in FAT/CD36 null muscle is additionally demonstrated by the finding that muscle ATP levels are significantly lowered compared to the wild-type levels. The direct and FAT/CD36 specific link between muscle glycogen and TAG stores, ATP content and the ability to undergo forced exercise is further substantiated by the finding that these parameters are normalized and fully comparable to the wild-type levels in GR muscles.

Unexpectedly, we could not directly demonstrate a normalization of FA oxidation rates in the GR heart. First, immunolabeling of cardiac tissue slices showed the re-appearance of the FAT/CD36 protein on the sarcolemma of the GR cardiomyocyte. However, where both the measurements of palmitate oxidation by isolated perfused FAT/CD36 null hearts and isolated FATCD36 null cardiomyocytes confirmed the presence of a prominent reduction in FA utilization in the FAT/CD36 null heart, no sign of normalization could be observed in the GR heart. These findings appear to directly contradict the findings described in the next section, notably the normalization of both cardiac ischemic tolerance and cardiac ATP levels by FAT/CD36 re-expression in the GR heart. Especially the latter normalization of cardiac ATP levels is indicative of a rescued. FAT/CD36 function. Possibly, the absence of forced (electro-)stimulation in the experiments with isolated hearts and cardiomyocytes, which generally increases their metabolic demands, might underlie the absence of normalization. However, this explanation appears unlikely, as stimulation was not required to demonstrate the difference between FAT/CD36 null and wild-type cardiac FA utilization. Further addressing this question awaits the comparison of cardiac FAT/CD36 null and GR FA transport in vivo by assaying BMIPP uptake. 
The role of the FA transporters FAT/CD36 and H-FABP during ischemia and reperfusion

Myocardial ischemia, resulting in the inadequate supply of oxygen and substrates to the heart, is a pathophysiological condition clearly linked to FA metabolism. For instance, ischemia rapidly results in a depression of $\mathrm{FA}$ oxidation ${ }^{38,39}$, and as a result FA and FA esters accumulate in ischemic myocardium ". Reperfusion, the restoration of vascular flow, quickly normalizes cardiac levels of acyl-esters, whereas tissue unesterified FA levels remain high, or even further increase. FA levells elevated $15-30$ fold compared to the pre-ischemic values have been found 1,40-42. These high FA levels are likely to negatively influence cardiac function and the recovery from ischemia ${ }^{43}$, which implicates that hearts null in FA transporters, more specifically FAT/CD36 null and H-FABP null hearts, might show altered tolerances to ischemia and reperfusion. By enhancing FA transport across the sarcolemma, FAT/CD36 was initially hypothesized to increase cellular FA concentrations, thereby reducing ischemic tolerance. Alternatively, in the presence of high intracellular FA concentration FAT/CD36 might also act as a FA exporter, thereby possibly reducing cellular FA contents and the damage exerted during ischemia. Notably, the mechanism by which FAT/CD36 mediates FA transport and the possible reversibility thereof are remaining to be fully explored. H-FABP, the protein that intracellularly binds FA with high-affinities, was hypothesized to bind accumulating FA, thereby protecting membrane structures and proteins from cellular damage. Alternative mechanisms by which H-FABP could exert cardioprotection were based on in vitro experiments, wherein H-FABP was shown to be both a more potent scavenger for oxygen free radicals and a more potent stimulator of phospholipid biosynthesis than bovine serum albumin ${ }^{44,45}$. Interestingly, the latter observation might reduce the liberation of FA from phospholipids, as the degradation of membranes was reported to be the predominant source for the FA accumulated during ischemia and reperfusion ${ }^{40,42}$. To determine the cardiac tolerance to ischemia and reperfusion, both FAT/CD36 null and gene-rescued GR hearts, and H-FABP homo- and heterozygous null hearts 
were compared to their corresponding wild-types by using two different isolated working mouse heart preparations at two different laboratories. Cardiac function of the different mouse groups was compared both before and after a period of global no-flow ischemia followed by reperfusion.

H-FABP homo- and heterozygous null hearts did not show any difference in hemodynamic performance compared to the corresponding wild-type hearts, both before and after undergoing a period of severe ischemia subsequently followed by reperfusion. Moreover, the cardiac energy status of both homo-and heterozygous H-FABP null hearts after reperfusion, more specifically phosphocreatine, ATP and glycogen levels, were fully comparable to the energetic status of wild-type hearts. The collected findings indicate that an influence of H-FABP expression on heart tolerance to ischemia, either by binding unesterified $\mathbb{F A}$, protecting membranes from degradation, scavenging oxygen free radicals, or by other unidentified mechanisms is highly unlikely.

A similar approach for analyzing the FAT/CD36 manipulated hearts also did not provide evidence for a link between FA transporters and FA accumulation, but highlighted the importance of FA, and thus FAT/CD36 derived energy for cardiac ischemic tolerance. Under baseline conditions, FAT/CD36 null hearts showed alterations in cardiac performance in the form of an elevated end-diastolic pressure. Their cardiac output was comparable to the wild-type. After ischemia, however, the cardiac output of FAT/CD36 null hearts was significantly lower than the wild-type, whereas the difference of the end-diastolic pressure was maintained. The lowered ischemic tolerance of the FAT/CD36 null heart was directly attributable to the FAT/CD36 gene, as was demonstrated by the finding that both the decreases in cardiac output and the increase in end-diastolic pressure observed in the FAT/CD36 null hearts following ischemia were corrected in the gene-rescued GR hearts. Taken together with the finding that cardiac tissue ATP levels are severely reduced in FAT/CD36 null hearts compared to both the wild-type and the GR, and that this reduction is present both pre- and post ischemia, the combined data demonstrate that the cellular energy derived from FAT/CD36 mediated FA 
transport is an important modulator of heart ischemic tolerance. The FAT/CD36 null heart exhibits a large increase in glucose usage, to compensate for the defect in FA transport ${ }^{47}$. However, this increase is apparently not sufficient for maintaining optimal levels of cellular energy stores, and our experiments show that that this makes the CD36 null heart more vulnerable to the insult from ischemic episodes. Furthermore, the studies mentioned above were carried out using perfusates in which glucose was the only available metabolic substrate. Adding physiologically relevant concentrations of FA-albumin complex accelerated the restoration of cellular ATP levels during reperfusion in the wild-type and GR, as well as in the FAT/CD36 null heart. The ATP levels in the FAT/CD36 null, however, remained significantly lowered compared to the wild-type and the GR. Cardiac functional ischemic recovery was significantly improved in wild-type and GR hearts only. These observations are in line with the idea that hemodynamic recovery of the ischemic heart is dependent on the amount and availability of substrate metabolized upon reperfusion, a finding that has been also documented by Saddik and coworkers ${ }^{46}$. The latter data thus suggest that FAT/CD36 expression also accelerates ischemic recovery by facilitating FA uptake and utilization during reperfusion.

\section{The difference between the FAT/CD36 null and the H-FABP null metabolic phenotype}

Though the FAT/CD36 null and the H-FABP null phenotypes display a remarkable resemblance, notably a similar metabolic shift that is reflected in plasma metabolite levels and a similar severe defect in FA uptake and utilization, the H-FABP null phenotype appears to be milder than that of the FAT/CD36 null. Where FAT/CD36 null mice clearly showed a reduced tolerance to undergo forced swimming, this reduction is less obvious in H-FABP null mice ${ }^{3}$. Furthermore, FAT/CD36 null hearts display a severely decreased ischemic tolerance, whereas H-FABP null hearts do not show alterations from their wild-types during ischemia-reperfusion experiments. Cardiac FA uptake is, however, severely reduced by at least $50 \%$ in 
both models, and in both models the defects are compensated by a large shift towards glucose usage ${ }^{3,4,47}$. Strikingly, H-FABP null hearts were found to contain unaltered TAG and elevated glycogen levels ${ }^{4}$, whereas both TAG and glycogen levels are severely reduced in the FAT/CD36 null hearts. This decrease in cardiac energy stores is accompanied by decreased tissue ATP levels, and both the results from experiments on forced exercise and cardiac ischemic tolerance are fully in line with the concept that the absence of FAT/CD36 mediated FA transport in muscle tissues severely impacts muscle energy production, of which the effects become apparent during heightened cellular demands. Likely, the absence of decreases in H-FABP null cardiac TAG and glycogen contents, which are indicative of a less severe disturbance in muscle ATP production, might explain the milder phenotype of the H-FABP null mouse. The increased usage of glucose thus may be sufficient to maintain cellular energy production and metabolite storage in the H-FABP null mouse, whereas the FAT/CD36 null mouse may be unable to further increase the usage of glucose, resulting in a more severe disturbance of metabolism.

\section{The possible roles of AABP $_{P M}$ and FATP in FA transport}

Though FAT/CD36 clearly has a crucial function as mediator of FA transport in the heart, skeletal muscle and adipose tissue, the absent or very low FAT/CD36 expression in the liver ${ }^{21}$, an organ which is highly active in FA metabolism, demonstrates the putative existence of alternative mechanisms. In line with this absent or very low expression level, the FAT/CD36 null liver did not show alterations in FA transport by assaying BMIPP uptake in vivo ${ }^{33}$, though cellular measurements demonstrated the presence of a saturable and inhibitable component in the FA uptake by isolated hepatocytes ${ }^{7,48}$. To avoid misunderstandings, it has to be noted that hepatic FA uptake, FA incorporotion in TAG and cholesteryl esters, and the production of very low-density lipoprotein were reported to be indirectly increased in the FAT/CD36 null mouse, as an effect secondary to an increased. circulating FA load reaching the liver ${ }^{47}$. 
Several lines of evidence show that FATP1 has the activity of a very long-chain FA-acyl-COA synthetase (VLACS), and it is presently unclear whether FATP1's enhancement of FA uptake is mediated by this activity, or by an additional FA transport activity ${ }^{49}$. VLACS intracellularly activates FA before their subsequent utilization, and might thus be rate limiting for FA uptake. Interestingly, the findings documented in a recent report imply that Fat1p, the FATP1 homolog in the yeast Saccharomyces cerevisiae, possesses separate long-chain FA import and very long-chain FA esterification activities ${ }^{50}$. It is thus tempting to speculate that the mammalian FATP1 may also have these separate activities, thereby yielding an alternative FA transporter.

Also attractive is a hypothetical model in which FABP $\mathrm{PM}_{\mathrm{PM}}$ FAT/CD36 and FATP may act synergistically in the uptake of $\mathrm{FA}^{51}$. After the dissociation from albumin or the liberation from lipoproteins by the action of lipoprotein lipase, FA could either partition directly into the phospholipid bilayer, or they could bind to proteins. The membrane-bound protein $\mathrm{FABP}_{\mathrm{PM}}$ may trap extracellular $\mathrm{FA}$ to concentrate the amount present in the vicinity of the membrane, and channel them towards FAT/CD36 and/or FATP. Most tempting is the concept that FATP might be involved in the model by functioning as VLACS. This function would imply that very long-chain fatty acids could be directly activated after their transport step, thereby being trapped inside the cell. Alternatively, FATP might also function as a FA transporter. Though it is presently clear that the majority of FA is taken up through a FAT/CD36 mediated mechanism in the heart, skeletal muscle and adipose tissue, the question whether this also holds true for very long-chain fatty acids is remaining to be investigated. Additionally, the molecular mechanism by which FAT/CD36 exerts its function is remaining to be fully explored. Though facilitating the movement of the polar FA carboxyl group through the phospholipid bilayer appears to be an attractive mode of action ${ }^{19}$, it has to be mentioned that the flip-flop of FA through phospholipid billayers is reported to be fast enough for enabling physiologic FA uptake rates ${ }^{27.30}$. Also other mechanisms, i.e. trapping FA in the vicinity of the membrane, could possibly underlie FAT/CD36 mediated FA 
uptake. Anyhow; the observation that FA uptake by muscle giant sarcolemmal vesicles was inhibited by both SSO and an anti-FABP $P_{P M}$ antiserum, but that applying both agents together did not result in a further reduction of FA uptake supports the idea that $\mathrm{FABP}_{\mathrm{PM}}$ and FAT/CD36 might function in a concerted mode of action ${ }^{23}$.

\section{Directions for future research}

Because several experimental models to study the influence of FAT/CD36 expression on FA homeostasis have been developed, a crucial role for FAT/CD36 in FA transport has finally been established. Elucidating the molecular mechanism by which FAT/CD36 exerts this role can follow several approaches. Most direct, the FAT/CD36 protein has been demonstrated to reversibly bind FA ${ }^{26}$, and obtaining a (partial) X-ray crystal structure of FAT/CD36 in the FA bound form would be of great value. Alternatively, exploring the possible protein-protein

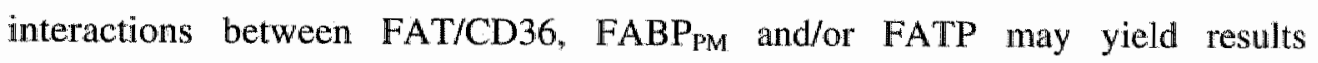
answering the question whether FAT/CD36 is part of a protein cluster active in FA uptake. Generating transgenic and gene-disrupted models for FABPPM and FATP is likely to unravel the function of the two alternative candidate FA transporters, which, in turn, appears useful for understanding the FA transporting mechanism of FAT/CD36. Finally, site-directed mutagenesis identified separate FA transport and VLACS activities of the yeast FATP1 homolog Fat $1 p{ }^{50}$. Because FATP1 is also functional in yeast ${ }^{52}$, applying a similar approach to analyze the activity of FATPI is an attractive alternative for the generation of gene-manipulated mouse models.

Alternative protein-protein interactions can be envisioned between FAT/CD36 and the cytoplasmic FA transporter H-FABP, by which membrane and intracellular transport could be tuned. Though such interactions appear to be unlikely due to the presence of only two rather short (approx. 10 amino acid) cytoplasmic domains in the predicted FAT/CD36 structure ${ }^{53}$, the resemblance of the FAT/CD36 and HFABP null mouse metabolic phenotypes indicates that FAT/CD36 and H-FABP might operate in concerted action. In addition, FAT/CD36 was indeed found to 
associate with cytoplasmic fatty acid-binding protein in bovine mammary gland ${ }^{54}$.Crossing the wo null mice, to result in a mouse both null in FAT/CD36 and H-FABP may yield valuable information about the way by which membrane and intracellular transport may be tuned.

By restricting FAT/CD36 expression to muscles, we were able to further specify the main metabolic abnormalities in FAT/CD36 null mice and the influences of FAT/CD36 mediated FA transport in muscles on total body FA homeostasis. Applying a comparable genetic rescue approach for restricting FAT/CD36 expression to adipose tissue, a tissue that is highly active in both the import and export of FA, is expected to yield valuable information on the important physiological role of this tissue type. The genetic rescue of FAT/CD36 expression in the FAT/CD36 null intestine, the intestine being an organ in which FAT/CD36 is thought to be active in the absorption of dietary-fat ${ }^{55}$, also seems attractive. The finding that FAT/CD36 expression levels significantly impact muscle function and performance implicates that it would be informative to determine whether FAT/CD36 levels determine muscular performance and athletic ability in humans.

Altering FAT/CD36 levels in rodents models results in defective FA transport in cardiac and skeletal muscle, and this defect is compensated by a large shift towards glucose usage ${ }^{47.56}$. Interestingly, FAT/CD36 deficiency is directly linked to the development of insulin resistance in the FAT/CD36 deficient spontaneous hypertensive rat (SHR) ${ }^{57}$, while FAT/CD36 null mice normally display an enhanced insulin sensitivity ${ }^{47}$. These findings implicate that the mere presence of high FA levels in the blood is not sufficient to induce periferal insulin resistance. Several differences between SHR and FAT/CD36 null muscle FA metabolism have been observed, and these differences indicate that the uptake of FA by the SHR muscle may still exceed the oxidative capacity. Because FA uptake in the FAT/CD36 null mouse is decreased below the muscle's capacity to both oxidize and esterify FA, the concept was developed that muscle insulin responsiveness is most likely linked to the balance between FA uptake and FA oxidation, with resistance reflecting conditions were uptake exceeds oxidative capacity ${ }^{47}$. These 
findings directly exemplify the value of the different rodent models that became available for FAT/CD36. FAT/CD36 deficiency is also directly linked to the development of cardiac hypertrophy in the SHR ${ }^{56}$, whereas FAT/CD36 null mice display dilated hearts and may represent a good model of dilated cardiomyopathy ${ }^{58}$. Remarkably, a mild form of cardiac hypertrophy is also developed by the H-FABP null mouse ${ }^{3}$. Where the H-FABP null may be able to compensate the defect in FA utilization more complete than the FAT/CD36 null mouse, the SHR displays a less severe disturbance of FA metabolism. For unraveling the mechanisms underlying the development of cardiac hypertrophy and the more severe appearing dilatation, further analysis of the different models thus appears worthwhile. The clinical relevance of these experiments is underscored by the observation that FAT/CD36 deficiency also leads to a severe defect in FA transport in the human heart, and might be linked to a heightened susceptibility towards cardiac diseases ${ }^{34,59}$. Further characterization of the different genetic rodent models for FAT/CD36 is expected to yield valuable information about the interaction between FA metabolism and the metabolism of other major substrates. This, in turn, should contribute to a better understanding of the mechanisms underlying the etiology of many life-threatening pathologies like cardiac hypertrophy, heart failure and diabetes.

\section{References}

1. Van der Vusse GJ, Glatz JFC, Stam HCG and Reneman RS. Fatty acid homeostasis in the normoxic and ischemic heart. Physiol Rev 72: 881-940, 1992.

2. Lopaschuk GD, Spafford MA, Davies NI and Wall SR. Glucose and palmitate oxidation in isolated working rat hearts reperfused after a period of transient global ischemia. Circ Res 66: 546 $553,1990$.

3. Binas B, Danneberg H, McWhir J, Mullins $\mathbf{L}$ and Clark AJ. Requirement for the heart-type fatty acid binding protein in cardiac fatty acid utilization. Faseb J 13: 805-812, 1999. 


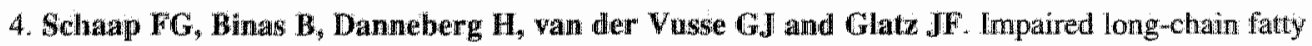
acid utilization by cardiac myocytess isolated from mice lacking the heart-type fatty acid binding protein gene. Circ Res $85: 329-337,1999$.

5. Abumrad NA, Park $\mathbf{J H}$ and Park CR. Perneation of long-chain fatty acid into adipocytes. Kinetics, specificity, and evidence for involvement of a membrane protein. I Biol Chem 259: 8945$8953,1984$.

6. Abumrad NA, Perkins RC, Park JH and Park CR. Mechanism of long chain fatty acid permeation in the isolated adipocyte. J Biol Chem 256: 9183-9191, 1981.

7. Sorrentino D, Robínson RB, Kiang CL and Berk PD. At physiologic albumin/oleate concentrations oleate uptake by isolated hepatocytes, cardiac myocytes, and adipocytes is a saturable function of the unbound oleate concentration. Uptake kinetics are consistent with the conventional theory. J Clin Invest 84: 1325 1333, 1989.

8. Stump DD, Zhou SL and Berk PD. Comparison of plasma membrane FABP and mitochondrial isoform of aspartate aminotransferase from rat liver. Am J Physiol 265: G894-902, 1993.

9. Luiken JJ, van Nieuwenhoven FA, America G, van der Vusse GJ and Glatz JF. Uptake and metabolism of palmitate by isolated cardiac myocytes from adult tats: involvement of sarcolemmal proteins. J Lipid Res 38: 745-758, 1997.

10. Berk PD, Wada H, Horio Y, Potter BJ, Sorrentino D, Zhou SL, Isola LM, Stump D, Kiang CL and Thung S. Plasma membrane fatty acid-binding protein and mitochondrial glutamicoxaloacetic transaminase of rat liver are related. Proc Natl Acad Sci U S A 87: 3484-3488, 1990.

11. Stremmel W, Strohmeyer G, Borchard F, Kochwa S and Berk PD. Isolation and partial characterization of a fatty acid binding protein in rat liver plasma membranes. Proc Natl Acad Sci U S A 82: 4-8, 1985.

12. Harmon CM and Abumrad NA. Binding of sulfosuccinimidyl fatty acids to adipocyte membrane proteins: isolation and amino-terminal sequence of an 88 -kD protein implicated in transport of long-chain fatty acids. J Membr Biol 133:43-49, 1993.

13. Abumrad N, Harmon $\mathbf{C}$ and Ibrahimi A. Membrane transport of long-chain fatty acids: evidence for a facilitated process. J Lipid Res 39:2309-2318, 1998.

14. Schaffer JE and Lodish HF. Expression cloning and characterization of a novel adipocyte long chain fatty acid transport protein. Cell 79: 427-436, 1994.

15. Hirsch D, Stahl A and Lodish HF. A family of fatty acid transporters conserved from mycobacterium to man. Proc Nat Acad Sci U S A 95: 8625-8629, 1998.

16. Zhou SL, Stump D, Sorrentino D, Potter BJ and Berk PD. Adipocyte differentiation of 3T3LI cells involves augmented expression of a $43-\mathrm{kD}$ a plasma membrane fatty acid-binding protein. $J$ Biol Chem 267: 14456-14461, 1992. 
17. Zhou SL, Stump D, Isola $L$ and Berk PD. Constituke expression of a saturable transport system for non-esterifred fatty acids in Xenopus laevis oocytes. Blochen J297:315-319, 1994.

18. Ibrahimi A, Sfeir Z, Magharaie H, Amri EZ, Grimaldi $P$ and Abumrad NA. Expression of the CD36 homolog (FAT) in fibroblast cells: effects on fatty acid transport. Proc Narl Acad So U SA 93: 2646-2651, 1996.

19. Abumrad N, Coburn $C$ and Ibrahimi A. Membrane proteins implicated in long-chain fatty acid uptake by mammalian cells: CD36. FATP and FABPn. Biachim Biophys Acta 1441: 4-13, 1999.

20. Pelsers MMAL, Lutgerink JT, Nieuwenhoven FA, Tandon NN, van der Vusse G.J, Arends JW, Hoogenboom HR and Glatz JFC. A sensitive immunoassay for rat fatty acid translocase (CD36) using phage antibodies selected on cell transfectants: abundant presence of fatty acid translocase/CD36 in cardiac and red skeletal muscle and up regulation in diabetes. Biochem 733 : 407-414, 1999.

21. Van Nieuwenhoven FA, Verstijnen CP, Abumrad NA, Willemsen PH, van Eys G.I, van der Vusse GJ and Glatz JF. Putative membrane fatty acid translocase and cytoplasinic fatty acidbinding protein are co-expressed in rat heart and skeletal muscles. Biochem Biophys Res Commun 207: 747-752, 1995.

22. Abumrad NA, el-Maghrabi MR, Amri EZ, Lopez E and Grimaldi PA. Cloning of a rat adipocyte membrane protein implicated in binding or transport of long-chain fatty acids that is induced during preadipocyte differentiation. Homology with human CD36. J Biol Chem 268: 17665$17668,1993$.

23. Luiken JJ, Turcotte LP and Bonen A. Protein-mediated palnitate uptake and expression of fatty acid transport proteins in heart giant vesicles. $J$ Lipid Rex 40: 1007-1016, 1999.

24. Greenwalt DE, Scheck SH and Rhinehart-Jones T. Heart CD36 expression is increased in murine models of diabetes and in mice fed a high fat diet. J Clin Invest 96: 1382-1388, 1995.

25. Bonen A, Luiken JJ, Liu S, Dyck DJ, Kiens B, Kristiansen S, Turcotte LP, wan der Vusse GJ and Glatz. JF. Palmitate transport and fatty acid transporters in ted and white muscles. Am $J$ Physiol. 275: E471-E478, 1998.

26. Baillie AG, Coburn CT, and Abumrad NA. Reversible binding of long-chain fatty acids to purified FAT, the adipose CD36 homolog. J Membr Biol 153: 75-81, 1996.

27. Civellek VN, Hamilton JA, Tornheim K, Kelly KL, and Corkey BE. Intracellular pH in adipocytes: effects of free fatty acid diffusion across the plasma membrane, lipolytic agonists, and insulin. Proc Nat Acad Sci U S A 93: 10139-10144, 1996.

28. Kamp F, Hamilton JA and Westerhoff HV. Movement of fatty acids, fatty acid analogues, and bile acids across phospholipid bilayers. Biochemistry 32: 11074-11086, 1993.

29. Hamilton JA and Kamp F. How are free fatty acids transported in membranes? Is it by proteins or by free diffusion through the lipids? Diaberes $48: 2255-2269,1999$. 
30. Hamilton JA. Fatty acid transport: difficult or easy? J Lipid Res 39:467 481, 11998 .

31. Glate IF and van der Vusse GJ. Cellular fatty acid-binding proteins: their function and physiólogical significance. Prog Lipid Ress 35: 243-282, 1996.

32. Febbraio M, Abumrad NA, Hajjar DP, Sharma K, Cheng W, Pearce SF and Silverstein RL. A null mutation in murine CD36 reveals an important role in fatty acid and lipoprotein metabolism. $J$ Biol Chem 274: 19055-19062, 1999.

33. Coburn CT, Knapp FF, Jr, Febbraio M, Beets AL, Silverstein RL and Abumrad NA. Defective uptake and wtilization of long chain fatty acids in muscle and adipose tissues of CD36 knockout mice. I Biol Chem 275: 32523-32529, 2000.

34. Tanaka T, Sohmiya $\mathbf{K}$ and Kawamura K. Is CD36 deficiency an etiology of hereditary hypentrophic cardiomyopathy? J Mol Cell Cardiol 29: 121-127, 1997.

35. Ibrahimi A, Bonen A, Blinn WD, Hajri T, Li X, Zhong K, Cameron R and Abumrad NA. Muscle-specific overexpression of FAT/CD36 enhances fatty acid oxidation by contracting muscle, reduces plasma triglycerides and fatty acids, and increases plasma glucose and insulin. $J$ Biol Chem 274: $26761-26766,1999$.

36. Luiken JJ, Willems J, Coort SL, Coumans WA, Bonen A, van der Vusse GJ and Glatz JF. Effects of CAMP modulators on long-chain fatty acid uptake and utilization by electrically stimulated rat cardiac myocytes. Biochem J: (epub ahead of print), 2002.

37. Levak-Frank S, Radner H, Walsh A, Stollberger R, Knipping G, Hoefler G, Sattler W, Weinstock PH, Breslow JL and Zechner R. Muscle-specific overexpression of lipoprotein lipase causes a severe myopathy characterized by proliferation of mitochondria and peroxisomes in transgenic mice.PG - 976-86. J Clin lvwest 96, 1995.

38. Myears DW, Sobel BE and Bergmann SR. Substrate use in ischemic and reperfused canine myocardium: quantitative considerations. Am J Physiol 253: H107-H114, 1987.

39. Oplie LH, Owen P and Riemersma RA. Relative rates of oxidation of glucose and free fatty acids by ischaemic and non-ischaemic myocardium after coronary artery ligation in the dog. Eur $J$ Clin lnvest 3: 419-435, 1973 .

40. van Bilsen M, van der Vusse GJ, Willemsen PH, Coumans WA, Roemen TH and Reneman RS. Lipid alterations in isolated, working rat hearts during ischemia and reperfusion: its relation to myocardial damage. Circ Res 64: 304-314, 1989.

41. Burton KP, Buja LM, Sen A, Willerson JT and Chien KR. Accurnulation of arachidonate in triacylglycerols and unesterified fatty acids during ischemia and reflow in the isolated rat heart. Correlation with the loss of contractile function and the development of calcium overload. Am J Pathol 124: 238-245, 1986. 
42. de Groot MJ, Coumans WA, Willemsen PH and van der Vusse GJ. Substrate-induced changes in the lipid content of ischemic and reperfused myocardium. Its retation to hemodynamio recovery. Cinc Res 72: $176-186,1993$.

43. Katz AM and Messineo FC. Lipid-membrane interactions and the pathogenesis of ischemic damage in the myocardium. Circ Res 48: 1-16, 1981.

44. Samanta A, Das DK, Jones R, George A and Prasad MR. Free radical scavenging by myocardial fatty acid binding protein. Free Radic Res Commun 7: 73-82, 1989.

45. Samanta A, Prasad MR, Engelman RM and Das DK. Possible physiological role of myocardial fatty acid binding protein in phospholipid biosynthesis. J Lipid Mediat 1: 243-255, 1989.

46. Saddik M and Lopaschuk GD. Myocardial triglyceride turnover during reperfusion of isolated rat hearts subjected to a transient period of global ischemia. J Biol Chem 267:3825-3831, 1992.

47. Hajri T, Han XX, Bonen A and Abumrad NA: Defective fatty acid uptake modulates insulin responsiveness and metabolic responses to diet in CD36-null mice.

$J$ Clin Inwest 109: 1381-1389, 2002.

48. Stremmel W, Strohmeyer G and Berk PD. Hepatocellular uptake of oleate is energy dependent, sodium linked, and inhibited by an antibody to a hepatocyte plasma membrane fatty acid binding protein. Proc Natl Acad Sci U S A 83: 3584-3588, 1986.

49. Schaffer JE. Fatty acid transport: the roads taken. Am I Physiol Endocrinol Metab 282: E239E246, 2002.

50. Zou Z, DiRusso CC, Ctrnacta $V$ and Black PN. Fatty acid transport in Saccharonyces cerevisiae. Directed mutagenesis of FAT1 distinguishes the biochemical activities associated with Fatlp. I Biol Chem 277: 31062-31071, 2002.

51. Glatz. JF, van Nieuwenhoven FA, Luiken JJ, Schaap FG and van der Vusse GJ. Role of membrane-associated and cytoplasmic fatty acid-binding proteins in cellular fatty acid metabolism. Prostaglandins Leukot Essent Fatty Acids 57: 373-378, 1997.

52. Dirusso CC, Connell EJ, Faergeman NJ, Knudsen J, Hansen JK and Black PN. Murine FATP alleviates growth and biochemical deficiencies of yeast fat Delta strains. Eur $J$ Biachem 267: $4422-4433,2000$.

53. Greenwalt DE, Lipsky RH, Ockenhouse CF, Ikeda H, Tandon NN and Jamieson GA. Membrane glycoprotein CD36: a review of its roles in adherence, signal transduction, and transfusion medicine. Blood 80: 1105-1115, 1992.

54. Spitsberg VL, Matitashvili $\mathbf{E}$ and Gorewit RC. Association and coexpression of fatty-acidbinding protein and glycoprotein $\mathrm{CD} 36$ in the bovine mammary gland. Eur $J$ Biochem 230: 872-878, 1995. 
55. Poirier H, Degrace P, Nutot, Bernard A and Besnard P. Localization and regulation of the putative membrane ratty-acid transporter (FAT) in the small intestine. Comparison with fatty acidbinding proteins (FABP). Fur J Biochem 238: 368-373, 1996.

56. Majri T, Ibrahimi A, Coburn CT, Knapp FF, Jr., Kurtz T, Pravenee M and Abumrad NA. Defective fatty acid uptake in the spontaneously hypertensive rat is a primary determinant of altered glucose metabolism, hyperinsulinemia, and myocardial hypertrophy. $J$ Biol Chem 276: 23661-23666, 2001 .

57. Pravenec M, Landla V, Zidek V, Musilova A, Kren V, Kazdova L, Aitman TJ, Glazier AM, Ibrahimii A, Abumrad NA, QI N, Wang JM, St Lezin EM and Kurtz TW. Transgenic rescue of defective $\mathrm{Cd} 36$ ameliorates insulin resistance in spontaneously hypertensive rats. Nat Genet 27: 156158,2001 .

58. Hahn RT, Febbraio M, Bella JN and Silverstein RL. The role of CD36 in cardiac size and function: a possible murine modlel of dilated cardiomyopathy. Circulation 98: 1-236, Supplement I, 1998.

59. Tanaka T, Nakata T, Oka T, Ogawa T, Okamoto F, Kusaka Y, Sohmiya K, Shimamoto K and Itakura $\mathbf{K}$. Defect in human myocardial long-chain fatty acid uptake is caused by FAT/CD36 mutations. J Lipid Res 42: 751-759, 2001. 


\section{Summary}

The flow of blood through the vasculature is essential for supplying organs with oxygen and metabolic substrates and for removing waste products and heat. By providing the force for this flow, contraction of the heart is essential for maintaining normal cellular and organ function. Cardiac myocytes generate the mechanical force for contraction of the heart, and these cells preferentially use long-chain fatty acids (FA) as substrate for energy production.

Although FA are poorly soluble in aqueous environments their binding to proteins allows that physiologically significant concentrations can be reached. In the blood, FA travel bound to plasma albumin or they are complexed into the lipid core of circulating lipoproteins. Prior to their oxidation in the mitochondria of the cardiac myocytes, FA have to cross several barriers. FA first travel through the endothelium by a yet unidentified mechanism, they reach the interstitial space in which albumin is the FA carrier, and then cross the sarcolemma (plasma membrane) of the cardiomyocyte. In the cytoplasm of the cardiac myocyte FA associate with the low molecular mass heart-type FA binding protein (H-FABP) by which they are further transported to their site(s) of conversion or action. Initial studies indicated that the majority of the FA oxidized in the cardiomyocyte is translocated across the sarcolemma by a mechanism mediated by the integral membrane protein fatty acid translocase (FAT/CD36). The studies described in this thesis sought to determine the significance of FAT/CD36 in myocardial FA transport under both normal and pathophysiological circumstances.

A brief introduction to cardiac FA uptake and utilization and an outline of the thesis are presented in Chapter 1. For a long period of time FA were thought to pass plasma membranes by a spontaneous diffusional process. Though it thas been clearly demonstrated that uncharged FA move rapidly across phospholipid bilayers, the presence of an additional protein-facilitated component in the transport of FA across adipocyte, hepatocyte and cardiac and skeletal muscle myocyte membranes led to the identification of three major candidate FA transport proteins named 
plasma membrane fatty acid binding protein (FABPPM), fatty acid translocase (FAT), a protein more widely known as CD36, and fatty acid transport protein (FATP). Evidence for the involvement of FAT/CD36 as a membrane FA transporter in several tissues is quickly evolving due to the availability of several genetic models. These models, the current knowledge of the candidate FA transporters and the recently identified regulational mechanisms for FAT/CD36 are reviewed in Chapter 2.

The native FAT/CD36 protein was purified from total rat heart homogenates using a newly developed purification procedure to enable further investigation of the FAT/CD36 content that is present in cardiac myocytes (Chapter 3). This procedure was subsequently applied to purify a significant amount of FAT/CD36 from total rat heart tissue and isolated rat cardiomyocytes. These FAT/CD36 preparations showed identical molecular masses on SDS-PAGE gels, and western analysis did not reveal any differences in antigenicity. The FAT/CD36 contents of isolated rat cardiomyocyte and heart homogenate samples were found to be of comparable order of magnitude, which further demonstrated that FAT/CD36 is an abundantly expressed protein in the cardiomyocyte. Immunofluorescence labeling confirmed that at least part of the FAT/CD36 present is associated with the sarcolemma.

A new transgenic mouse model was characterized to further specify the function of FAT/CD36 in muscle FA transport. This gene-rescue model was raised on the FAT/CD36 null background. Gene-rescued (GR) mice re-expressed FAT/CD36 in heart and skeletal muscle under control of the mouse muscle creatine kinase promoter. Both western analysis and immunofluorescence labeling confirmed the muscle specific expression of FAT/CD36 in GR mice. Whereas FAT/CD36 null mice display fasting hypoglycemia and increased plasma triacylglycerol and FA concentrations, GR mice showed fasting plasma glucose, $\mathrm{FA}$, and triacylglycerol levels that were restored to the respective levels found in wild-type animals. The FA oxidation rate of soleus muscle isolated from GR mice was significantly higher than the rate of soleus muscle from FAT/CD36 null mice and comparable to that found in muscle from-wild type mice. Stimulation by 
dipyridamole increased oxidation rates in wild type and GR muscles but did not affect oxidation in FAT/CD36 null muscle. Glycogen, triacylglycerol and ATP levels were significantly decreased in FAT/CD36 null muscles and fully normalized to WT levels in GR muscles. In contrast to the rescue of FA utilization in skeletal muscle, a normalization of FA oxidation was not observed in isolated GR hearts and GR cardiomyocytes. Both isolated FAT/CD36 null and GR hearts and their isolated cardiomyocytes showed drastically reduced FA oxidation rates compared to the wild-type. To examine the effect of FAT/CD36 on in vivo muscle function, the mice were subjected to forced swimming tests. FAT/CD36 null mice had a drastically reduced ability to endure exercise in comparison to both wild type and GR mice. The absence of FAT/CD36 im muscles thus directly and genespecifically results in decreased FA utilization rates and a decreased ability to exercise (Chapter 4).

The role of FAT/CD36 in post ischemic functional recovery of the heart was examined in an isolated working mouse heart preparation (Chapter 5). The function of FAT/CD36 null and GR hearts was compared to wild-type hearts both before and after a period of global no-flow ischemia followed by reperfusion. FAT/CD36 null hearts had a similar cardiac output and a higher end-diastolic pressure than wild-type hearts. After ischemia, cardiac output was significantly lower and end-diastolic pressure significantly higher in FAT/CD36 null compared to wild-type hearts. Both defects were corrected in GR hearts. Moreover, hearts over-expressing FAT/CD36 displayed an increased tolerance to ischemiareperfusion compared to their wild-type controls. To dissect out the role of FA uptake during the perfusions, experiments were also done in the presence of FA. The addition of palmitate to the perfusate improved heart functional recovery from ischemia in wild-type and GR, as well as in FAT/CD36 null hearts, but more dramatically in wild-type and FAT/CD36-rescued hearts as compared with the FAT/CD36 null hearts. FAT/CD36-mediated FA uptake thus is important for optimal myocardial recovery from ischemia and FAT/CD36 deficient hearts are more likely to fail following short ischemic episodes. This may reflect the 
decreased ATP and glycogen levels of FAT/CD36 deficient hearts and their impaired ability to oxidize palmitate during recovery.

Hearts from wild-type and hetero- and homozygous H-FABP null mice were atso analyzed in an isolated left ventricular ejecting mouse heart preparation (Chapter 6). Both before and after a period of severe, no-flow, normothermic ischemia followed by reperfusion, significant differences in hemodynamic performance were absent and the hearts of all three groups showed a similar pastischemic functional recovery. In addition, measuring the contents of high-energy phosphates and glycogen did not reveal any difference in cardiac energetic status among the groups. These data demonstrate that endogenous H-FABP does not exert a cardioprotective function in the heart during ischemia-reperfusion.

The main results and conclusions of the studies described in this thesis are further discussed in Chapter 7. FAT/CD36 plays a key role in cardiac and skeletal muscle metabolism as a mediator of transmembrane FA transport. The effects of FAT/CD36 deficiency become apparent under heightened metabolic demands such as occurring during ischemia and appear more severe than the effects of H-FABP deficiency. The differences of metabolic phenotypes, the possible roles for FATP and FABPPM are discussed and this chapter concludes with some directions for future results. 


\section{Samenvatting}

Organen worden voorzien van zuurstof en voedingsstoffen door middel van een continue bloedstroom door het bloedvatenstelsel. Daarnaast worden de door weefsels gevormde afvalproducten en warmte via de bloedstroom afgevoerd. Door de contractie van het hart wordt het bloed rondgepompt en dit is essentieel voor het functioneren van weefsels en organen. Het samentrekken van hartspiercellen (cardiomyocyten) ligt ten grondslag aan de contractie van het hart en dit is een energievergend proces. Hoewel cardiomyocyten ook andere chemische stoffen zoals glucose verbruiken, maken deze cellen bij voorkeur energie vrij door de verbranding van langketenige vetzuren, een proces dat plaatsvindt in de mitochondria van de cel.

Voordat vetzuren verbrand kunnen worden in de cardiomyocyten moeten deze verbindingen eerst een aantal barrières passeren. Langketenige vetzuren, verder vetzuren genoemd, zijn slecht oplosbaar in een waterige omgeving. De concentraties die normaal in het lichaam aanwezig zijn worden mogelijk gemaakt doordat vetzuren binden aan specifieke eiwitten. Vetzuren in het bloed worden gebonden door albumine of ze bevinden zich in een complex met circulerende lipoproteïnes. Vanuit het bloed bereiken ze eerst de endotheelcellaag van de haarvaten. Nadat ze deze laag gepasseerd zijn via een tot nu toe onopgehelderd mechanisme bereiken ze de interstitiële ruimte. Deze ruimte overbruggen ze gebonden aan albumine, waarna de vetzuren het sarcolemma (de plasmamembraan) van de cardiomyocyten bereiken en passeren. In het cytoplasma van de cardiomyocyt binden vetzuren aan het hart-type vetzuurbindend eiwit (H-FABP voor "heart-type fatty acid-binding protein") en in deze vorm worden ze verder getransporteerd binnen de cel. Recentelijk zijn aanwijzingen verkregen dat vetzuren het sarcolemma van de cardiomyocyt passeren met belzulp van een eiwit genaamd "fatty acid translocase", dat aanwezig is in de fosfolipide dubbellaag van het sarcolemma. De studies die in dit proefschrift beschreven worden, onderzoeken de betekenis van dit eiwit voor het functioneren van het hart onder zowel normale als pathosfysiologische omstandigheden. 
Een korte introductie over de opname en verbranding van vetzuren in het hart, alsmede en beschrijving van de opzet van dit proefschrift zijn gegeven in Hoofdstuk 1 . Lange tijd werd gedacht dat vetzuren de plasmamembraan passeren via een spontaan optredend diffusieproces en het is inderdaad overtuigend aangetoond dat ongeladen vetzuren zich snel door fosfolipide dubbellagen kunnen verplaatsen. De aanwezigheid van een additionele, eiwit-gefaciliteerde component in het vetzuurtransport over de celmembraan van vetcellen, levercellen en hart- en skeletspiercellen heeft geleid tot de identificatie van drie kandidaat vetzuurtransporteiwitten genaamd "plasma membraan fatty acid binding protein" (FABP PM), "fatty acid translocase" (FAT), een eiwit dat ook bekend is als CD36, en "fatty acid transport protein" (FATP). Het bewijs dat FAT/CD36 in verschillende weefsels betrokken is bij het transport van vetzuren over de plasmamembraan groeit snel doordat een aantal genetische modellen beschikbaar is gekomen. Deze modellen, de huidige kennis van de drie kandidaat vetzuurtransporters en het moleculaire mechanisme van de regulatie van FAT/CD36 worden beschreven in Hoofdstuk 2.

Om het gehalte aan FAT/CD36 dat aanwezig is in de cardiomyocyt nader te kunnen onderzoeken, is een nieuwe procedure ontwikkeld om het natieve FAT/CD36 te zuiveren uit gehomogeniseerde rattenharten (Hoofdstuk 3). Deze methode is vervolgens gebruikt om een significante hoeveelheid FAT/CD36 te zuiveren uit geissoleerde ratten-cardiomyocyten. De eiwitten gezuiverd uit harten en cardiomyocyten hadden identieke schijmbare moleculaire massa's op SDS-PAGE gels en beide eiwitten vertoonden dezelfde antigeniciteit bij western analyse. Geisoleerde ratten cardiomyocyten en hart-homogenaten bleken vergelijkbare hoeveelheden FAT/CD36 te bevatten, hetgeen aantoont dat FAT/CD36 hoog tot expressie komt in de hartspiercel. Het immunufluorescente labelen van hartweefsel secties bevestigde dat op zijn minst een deel van het FAT/CD36 geassocieerd is met het sarcolemma. De relatief hoge gehaltes aan en de sub-cellulaire lokalisatie van FAT/CD36 in de cardiomyocyt zijn in overeenstemming met de verwachte rol bij het transsarcolemmale transport van vetzuren. 
Een nieuw muismodel is gekarakteriseerd on de bijdrage van FAT/CD36 aan het transport van vetzuren in spierweefsel nader te specificeren. Dit transgene model (GR genoemd, voor gene-rescued) is gegenereerd op de genetische achtergrond van de FAT/CD36 deficiënte muis en bracht FAT/CD36 tot reexpressie in hart en skeletspier onder controle van de spier-specifieke kreatine kinase promoter. Zowel western analyse als immunufluorescentie studies toonden aan dat FAT/CD36 spier-specifiek tot expressie kwam in de GR muis. FAT/CD36 deficiënte muizen hebben een verlaagde plasma glucose concentratie en verhoogde plasma triacylglycerol- en vetzuurconcentraties na overnacht vasten. Deze parameters bleken genormaliseerd in de GR muis, dat wil zeggen dat de GR muizen gevaste plasma glucose-, triacylglycerol- en vetzuurconcentraties hadden die vergelijkbaar waren met de concentraties in wild-type muizen. De vetzuuroxidatiesnelheid van een skeletspierspier, de soleus, geïsoleerd uit de poot van GR muizen, was significant hoger dan de oxidatiesnelheid van de soleus uit FAT/CD36 deficiënte muizen, en vergelijkbaar met de oxidatiesnelheid van spieren uit de wild-type muizen. De vetzuuroxidatiesnelheid door wild-type en GR spieren was hoger na de toevoeging van dipyridamole, terwijl dit effect niet aanwezig was in FAT/CD36 deficiënte soleus spieren. Dipyridamole is een verbinding die de translocatie van FAT/CD36 vanuit intracellulaire opslagplaatsen naar de celmembraan stimuleert. Glycogeen, triacylglycerol en ATP concentraties waren significant verlaagd in de FAT/CD36 deficiënte skeletspier en volledig genormaliseerd tot wild-type niveaus in GR skeletspieren. Het effect van FAT/CD36 deficiëntie op de in vivo functie van de skeletspier is onderzocht door middel van een gedwongen zwemtest. Vergeleken met zowel wild-type ais GR muizen hadden FAT/CD36 deficiënte muizen een drastisch verlaagd uithoudingsvermogen tijdens deze test. De afwezigheid van FAT/CD36 in de skeletspier leidt dus direct en gen-specifiek tot verlaagde vetzuuroxidatiesnelheden en een verlaagd uithoudingsvermogen gedurende zware inspanning. Een verassende bevinding was dat GR harten en cardiomyocyten, in tegenstelling tot de GR skeletspieren, geen normalisatie van de vetzuuroxidatie vertoonden. Zowel geïsoleerde FAT/CD36 deficiënte als GR harten en de hieruit geisoleerde 
cardiomyocyten oxideerden veturen met een significant verlaagde snelheid ten opzichte van wild-type harten en cardiomyocyten. Een verklaring voor de verschillen tussen hart- en skeletspier is op dit moment nog niet voorhanden (Hoofdstuk 4).

De rol van FAT/CD36 in het post-ischemische functionele herstel van het hart is onderzocht met behulp van geisoleerde, met buffer geperfundeerde muizenharten (Hoofdstuk 5): Het hemodynamisch functioneren van FAT/CD36 deficiënte en GR harten is hierbij zowel voor als na een periode van globale ischemie, opgelegd door het stoppen van de toevoer van buffer, gevolgd door reperfusie vergeleken met de functie van wild-type harten. Het pompvermogen van FAT/CD36 deficiënte harten was vergelijkbaar met die van wild-type harten, terwijl de eind-diastole druk van het FAT/CD36 deficiënte hart verhoogd bleek. Na een periode van ischemie bleek thet pompvermogen van FAT/CD36 deficiënte harten significant verlaagd en de eind-diastole druk significant verhoogd ten opzichte van wild-type harten. Beide defecten waren gecorrigeerd in GR harten. Ook bleken harten afkomstig uit muizen die FAT/CD36 tot over-expressie brengen beter bestand tegen ischemie dan wildtype controle harten. Om de rol van het vetzuurmetabolisme gedurende reperfusie nader te analyseren zijn ook vergelijkbare experimenten uitgevoerd met de aanwezigheid van vetzuren in de gebruikte buffer. De toevoeging van palmitaat aan de perfusie-buffer had een positief effect op het functionele herstel van zowel FAT/CD36 deficiènte, als van GR en wild-type harten. Dit effect was echter aanmerkelijk meer uitgesproken voor wild-type en GR harten. Gezamenlijk tonen deze resultaten aan dat de door FAT/CD36 gemedieerde opname en de daarop volgende oxidatie van vetzuren belangrijk is voor een optimaal herstel van het hart na ischemie. Het FAT/CD36 deficiènte hart is daardoor waarschijnlijk minder goed bestand tegen korte periodes van verminderde bloedtoevoer. Het verminderde vermogen om palmitaat te oxideren gedurende de herstelperiode en de gevonden verlaging van ATP en glycogeen concentraties in het FAT/CD36 deficiënte muizenhart lijken hieraan ten grondslag te liggen.

Ook harten van wild-type, hetero- en homozygote H-FABP deficiënte muizen zijn geanalyseerd in een geïsoleerd werkend muizenhart model (Hoofdstuk 6). 
Significante verschillen in het hemodynamisch functioneren waren afwezig zowel vóor als na een periode van zware, normothermische ischemie gevolgd door reperfusie. Harten uit de drie verschillende muis-typen vertoonden een vergelijkbaar vermogen om te herstellen van de opgelegde ischemische periode. De energetische status van de H-FABP gemanipuleerde harten na reperfusie was vergelijkbaar met de status van wild-type harten, hetgeen gedemonstreerd werd door gemeten gehaltes aan hoog-energetische fosfaten en glycogeen. In tegenstelling tot verschillende gepostuleerde hypothesen tonen deze data op een elegante manier aan dat H-FABP geen beschermende rol speelt in het hart tijdens ischemie-reperfusie.

De belangrijkste resultaten en conclusies van de in dit proefschrift beschreven studies worden verder bediscussieerd in Hoofdstuk 7. Als mediator van het vetzuurtransport over het sarcolemma speelt FAT/CD36 een belangrijke rol in het metabolisme van hart- en skeletspiercellen. De effecten van FAT/CD36 deficiëntie worden duidelijk waarneembaar onder metabool veeleisende omstandigheden als ischemie-reperfusie en lijken ernstiger dan de effecten van H-FABP deficiëntie. De verschillen in metabole fenotypes en de mogelijke rol van FATP en FABPPM bij de vetzuuropname worden bediscussieerd en dit hoofdstuk eindigt met enige suggesties voor toekomstig onderzoek. De beschikbaarheid van verschillende genetische modellen voor FAT/CD36 heeft zijn waarde bewezen. Verdere karakterisering van deze modellen zal waardevolle informatie opleveren over de interactie tussen het metabolisme van vetzuren en het metabolisme van andere belangrijke substraten. Samen met de opheldering van het moleculaire mechanisme waarmee FAT/CD36 de vetzuuropname beinvloed zal deze kennis bijdragen aan het begrip van de ontwikkeling van ernstige pathologieën als hypertrofie, hartfalen en diabetes. 
8

a.

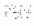




\section{Curriculum vitae}

The author of this thesis was born on the $17^{\text {th }}$ of April, 1970, in Haarlem, The Netherlands. He graduated in 1990 from the Adebert College in Wassenaar, after which he started his study in Bioprocesstechnology at the Agricultural University in Wageningen (1990-1996). The studies described in this thesis were started in February 1998 at the Department of Physiology at Maastricht University, and involved the analysis of the physiological role of fatty acid translocase (FAT/CD36) in heart muscle. During his thesis work, a visit was paid to the laboratory of Dr. N.A. Abumrad, SUNY at Stony Brook, USA, to study a new transgenic mouse model. Presently, the author is working as a post-doc at the Department of Opthalmogenetics of the Netherlands Ophthalmic Research Institute, where he is involved in studying the genetic background underlying the development of primary open-angle glaucoma.

\section{List of Publications and Abstracts}

N.N.M.E. van Peij, J.F.F. Brinkmann, M. Vršanská, J. Visser and L.H. de Graaff. B-Xylosidase activity, encoded by $x \ln \mathrm{D}$, is essential for complete hydrolysis of xylan by Aspergillus niger but not for induction of the xylanolytic enzyme spectrum. Eur. J. Biochem. 245:164-173, 1997

J.F.F. Brinkmann, M.M.A.L. Pelsers, G.J. van der Vusse and J.F.C. Glatz. Purification and quantification of fatty acid translocase (FAT/CD36) from rat heart. J. Mol. Cell. Cardiol. 31:A90, 1999

J.F.F. Brinkmann, M.M.A.L. Pelsers, G.J. van der Vusse and J.F.C. Glatz. Fatty acid translocase (CD36) is a relatively abundant protein in the cardiomyocyte. Chem. Phys. Lipids 101:188-189, 1999

J.F.F. Brinkmann, J.J.F.P. Luiken, W.A. Coumans, A. Bonen, G.J. van der Vusse and J.F.C. Glatz. Fatty acid uptake by giant sarcolemmal vesicles from mouse skeletal muscle and liver. FASEB J. 14(4):A209, 2000 
J.F.F. Brinkmann, N.A. Abumrad, A. Ibrahimi, G. J. van der Vusse and J.F.C. Glatz. New insights into long-chain fatty acid uptake by heart muscle: a crucial role for FAT/CD36. Biochem J 367(Pt 3):561-70, 2002

H. Irie, G.R. Gaudette, A.E. Saltman, J.F.F. Brinkmann, N.A. Abumrad, I.B. Krukenkamp and A. Ibrahimi. The FAT/CD36 protein is a modulator of ischemic tolerance in the murine heart: accepted for publication by Proc Natl Acad Sci U SA

J.F.F. Brinkmann, N.A. Abumrad, W. Jou, J.A. Johnson, G.J. van der Vusse, J.F.C. Glatz and A. Ibrahimi. Metabolic abnormalities of FAT/CD36 null mice are normalized by restoring FAT/CD36 expression in heart and skeletal muscle: submitted for publication

J.F.F. Brinkmann, M.M.A.L. Pelsers, F.A. van Nieuwenhoven, G.J. van der Vusse and J.F.C. Glatz. Purification, immunochemical quantification and localization of fatty acid translocase (FAT)/CD36 from rat heart: submitted for publication

J.F.F. Brinkmann, J. Willems, W.A. Coumans, M. van Bilsen, B. Binas, G.J. van der Vusse and J.F.C. Glatz. Targeted disruption of heart-type fatty acid binding protein does not influence ischemic tolerance of the murine heart: submitted for publication 


\section{Dankwoord}

Graag wil ik iedereen bedanken die heeft bijgedragen aan de totstandkoming wan dit proefschrift.

Een bijzonder woord van dank gaat uit naar:

De Begeleiders:

Jan Glatz en Ger van der Vusse

Stony Brook (thank you very much for a great time):

Dr. Abumrad, Azeddine, Tahar, Chris, Dr. Ajmal en William

De collega's, kamergenoten en overige gënteresseerden:

Danny, Jodil, Debby, Ferdi, Roy, Frans, Richard, Frank, Andries, Maurice, Susan,

Daniëlle, Kristel, Hera, Joost, Paul, Freek, Vic en Josephine 